\title{
Neck muscle function in individuals with persistent pain and disability after whiplash injury
}

\author{
Gunnel Peterson
}

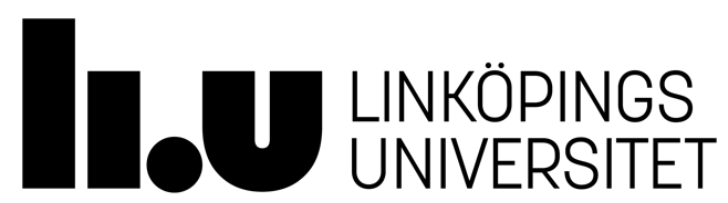

Department of Medical and Health Sciences

Linköping University, Sweden

Linköping 2016 
(c)Gunnel Peterson, 2016

Cover illustration: Emilia Norström

Illustration in the thesis: Emilia Norström

Published articles have been reprinted with the permission of the copyright holder.

Printed in Sweden by LiU-Tryck, Linköping, Sweden, 2016

ISBN 978-91-7685-747-2

ISSN $0345^{-0082}$ 
To my family

Att vara smart är att göra något bra. Och är man inte så smart så är det bra att fråga. Albin 4 år 



\section{CONTENTS}

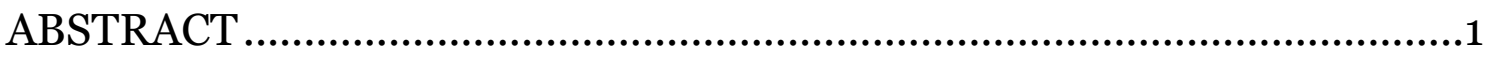

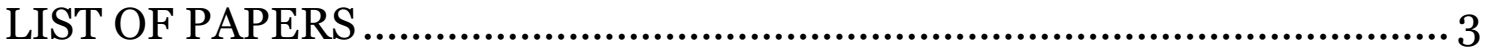

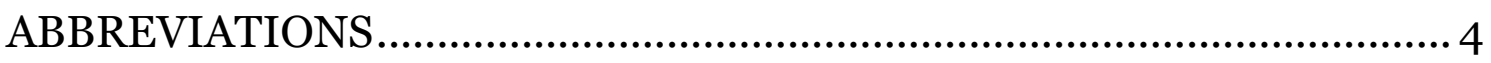

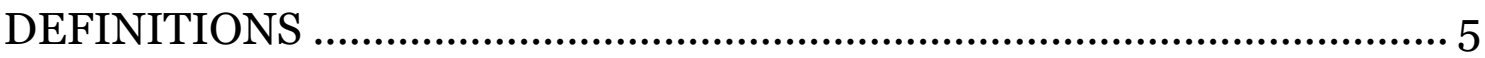

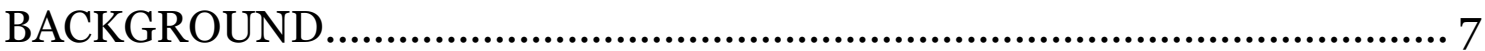

Biomechanics of the cervical spine in whiplash-associated disorders . 7

Diagnosis in WAD ............................................................................. 8

Ultrasound measurement of skeletal muscle …………........................... 9

Motor control and muscle function .................................................... 10

Neck muscle function .............................................................................. 11

Muscle adaption to pain ..........................................................................13

The biopsychosocial model of pain ...................................................... 13

Treatment of persistent whiplash-associated disorders ...................... 14

Exercises and behavioral approaches in WAD ...................................... 14

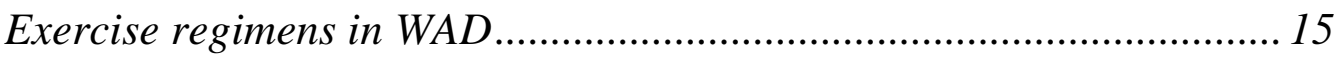

The individual perspective on treatment ................................................ 15

Rationale of the thesis ............................................................................17

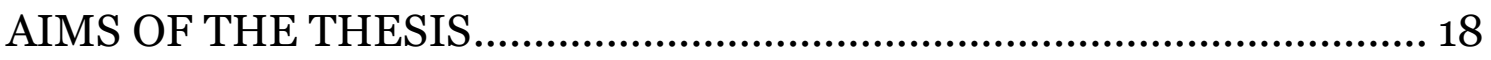

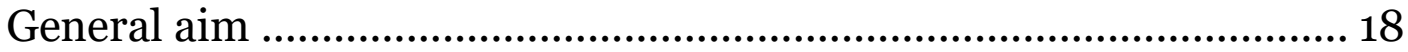

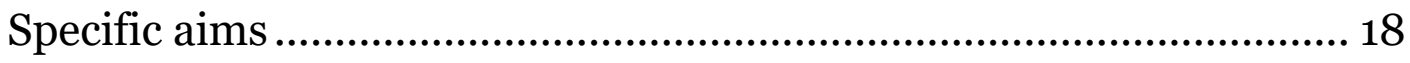

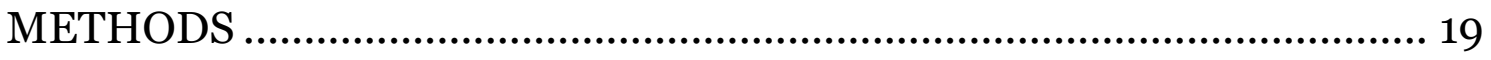

Study design ............................................................................................ 19

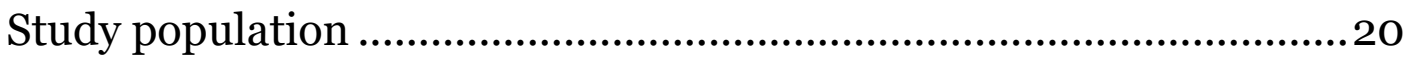

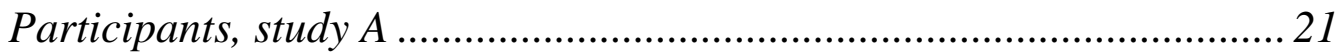

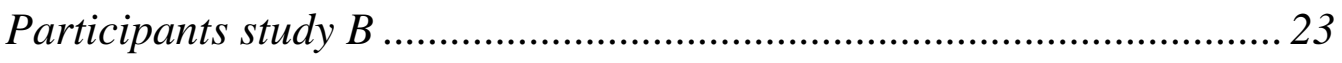

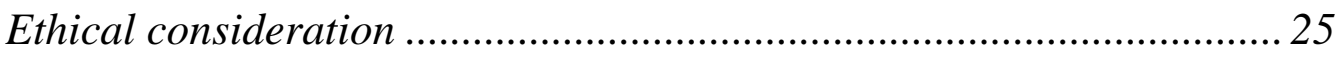

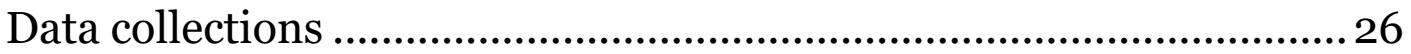




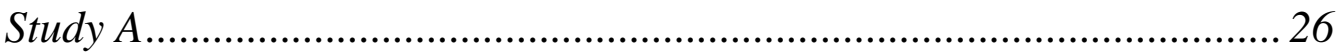

Study B

Interventions study A ..........................................................................

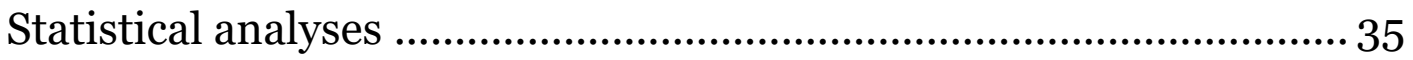

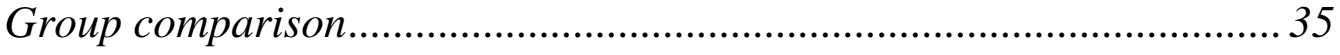

Correlation and linear regression of deformation and deformation

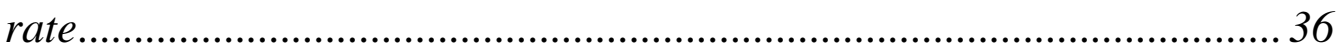

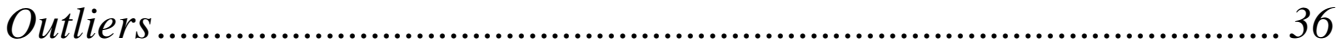

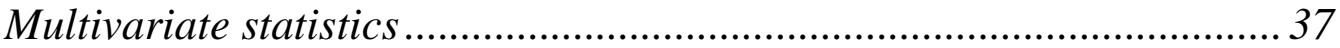

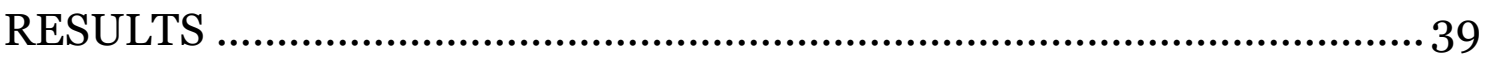

The effect of three different exercise interventions on neck muscle endurance test, pain intensity, kinesiophobia, exercise compliance and patient satisfaction (Paper I) ..................................................... 39

Dorsal Neck Muscle Endurance ................................................................ 39

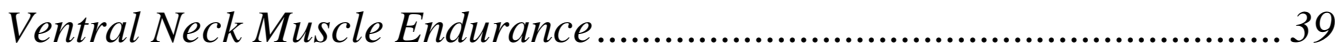

Neck pain intensity ................................................................................... 39

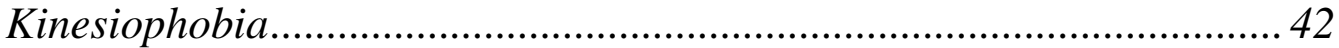

Patient satisfaction and exercise compliance ......................................... 42

Mechanical neck muscle function, deformation and deformation rate

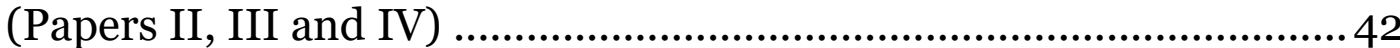

Comparisons between the WAD and control group in deformation ........ 42

Comparison between the WAD and control groups in deformation rate.

Neck muscle interactions in individuals with persistent WAD and healthy

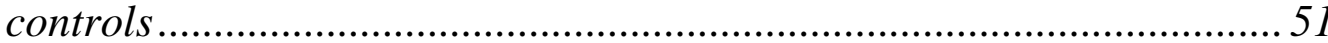

Differences in ventral neck muscle function after three months neckspecific exercises compared to waiting-list .......................................... 57

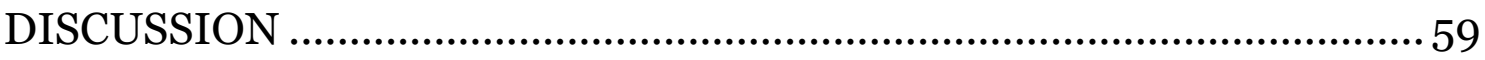

Main findings.................................................................................... 59

Discussion of the results ...................................................................... 59

The effect of three different exercise interventions on neck muscle endurance and pain intensity.....

The effect of three exercise interventions on kinesiophobia, exercise compliance and patient satisfaction.

Mechanical neck muscle function, deformation and deformation rate... 62 
Neck muscle interactions in individuals with persistent WAD and healthy

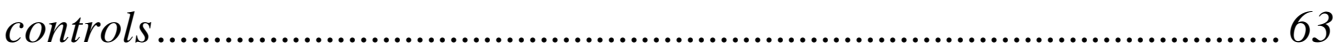

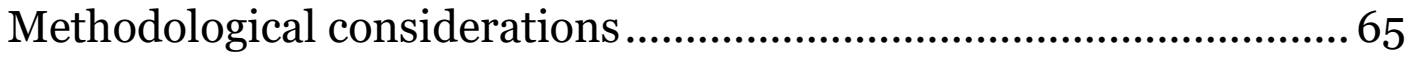

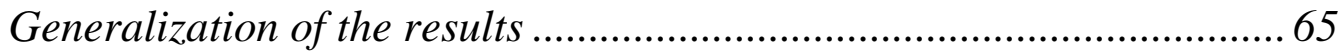

The effect of three exercise interventions on neck muscle endurance and

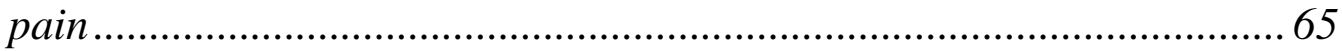

Validity and limitations of ultrasound ..................................................... 67

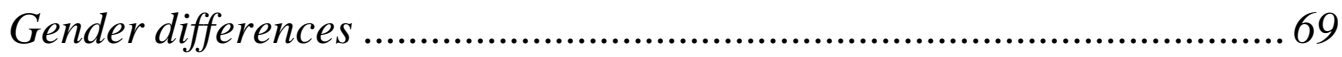

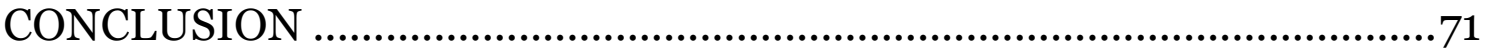

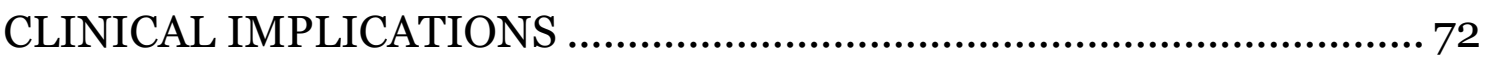

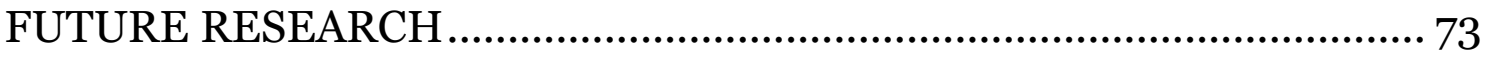

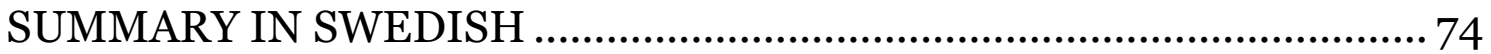

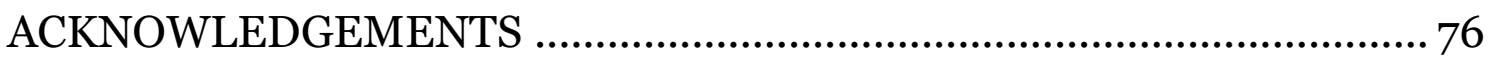

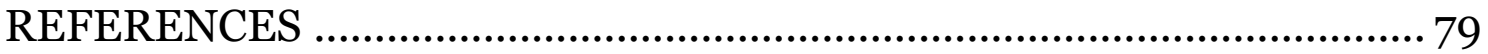





\section{ABSTRACT}

Background: Neck pain and disability are common after whiplash injury. One year after the accident up to $50 \%$ still have symptoms called whiplash associated disorders (WAD). Despite decades of research the cause of persistent pain and disability are largely unknown and effective treatment and diagnostic tools are lacking. Altered neck muscle function may cause pain and disability, and real-time non-invasive methods that investigate both superficial and deep neck muscle function need to be evaluated.

Aim: The general aim of the work presented in this thesis was to investigate mechanical neck muscle function and evaluate effects of three different exercise interventions related to neck muscle function in individuals with persistent pain and disability after whiplash injury.

Method: The thesis comprised two studies, reported in four papers. Study A was a prospective randomized controlled trial with 216 participants. The effects of three exercise interventions; neck-specific exercises, neckspecific exercises with behavioral approach and prescription of physical activity were evaluated. Neck muscle endurance, perceived pain following testing, kinesiophobia and satisfaction with treatment were compared between the three groups (paper I). Study B was an experimental casecontrol study with participants consecutively recruited from the randomized controlled trial. Deformation and deformation rates in the neck muscles were investigated with real-time ultrasound imaging during ten repetitive arm elevations (paper II-IV). To investigate ventral neck muscles, 26 individuals with WAD were compared with 26 healthy controls (paper II). The dorsal neck muscles were investigated in paper III, including 40 individuals with WAD and 40 controls. In total 46 individuals, 23 with WAD and 23 healthy controls were included in paper IV to develop ventral neck muscle interaction models.

Results: Paper I: Participants in the two neck-specific exercise groups (with and without behavioral approach) showed increased dorsal neck muscle endurance $(\mathrm{p}=0.003)$, decreased pain intensity following testing $(\mathrm{p}=0.04)$ and were more satisfied with treatment $(\mathrm{p}<0.001)$ than participants in the prescribed physical activity group. Kinesiophobia did not significantly differ between groups $(p>0.12)$.

Paper II: Deformation and deformation rate showed linear positive relationship between ventral muscle pairs in healthy controls, especially between superficial and deep neck muscles. This relationship was weaker or absent in the WAD group. 
Paper III: The WAD group had higher deformation rates in the deepest dorsal neck muscles during the first and tenth (only women) arm elevations compared to the control group ( $<<0.04)$. Women in the WAD group showed a weaker linear relationship between the two deepest dorsal neck muscles compared to women in the control group.

Paper IV: The results revealed two different ventral neck muscle models in individuals with $\mathrm{WAD}$ and healthy controls $\left(\mathrm{R}^{2} \mathrm{Y}=0.72, \mathrm{Q}^{2} \mathrm{Y}=0.59\right)$. The models were capable to detect different neck muscle interplay in people with WAD.

Conclusion: Neck-specific exercise intervention with or without a behavioral approach appears to improve neck muscle endurance in individuals with persistent WAD. Decreased pain after the neck muscle endurance test also suggests improved tolerance of load in these two groups. Altered mechanical neck muscle function was revealed in individuals with WAD indicating decreased muscular support for maintain a stable cervical spine during repetitive arm elevations. The results show great promise for improved diagnosis of neck muscle function in WAD. 


\section{LIST OF PAPERS}

I. Gunnel Peterson, Maria Landén Ludvigsson, Shaun O'Leary, Åsa Dedering, Thorne Wallman, Margaretha Jönsson, Anneli Peolsson. The Effect of 3 Different Exercise Approaches on Neck Muscle Endurance, Kinesiophobia, Exercise Compliance, and Patient Satisfaction in Chronic Whiplash. J Manipulative Physiol Ther. 2015;38(7):465-76 e4.

II. Gunnel Peterson, Åsa Dedering, Erika Andersson, David Nilsson, Johan Trygg, Michael Peolsson, Thorne Wallman, Anneli Peolsson. Altered ventral neck muscle deformation for individuals with whiplash associated disorder compared to healthy controls - A casecontrol ultrasound study. Man Ther. 2015;20(2):319-27.

III. Gunnel Peterson, David Nilsson, Simon Peterson, Åsa Dedering, Johan Trygg, Thorne Wallman, Anneli Peolsson. Changes in dorsal neck muscle function in individuals with chronic whiplashassociated disorders: a real-time ultrasound case-control study. Ultrasound Med Biol. 2016;42(5):1090-102

IV. Gunnel Peterson, David Nilsson, Johan Trygg, Deborah Falla, Åsa Dedering, Thorne Wallman, Anneli Peolsson. Novel insights into the interplay between ventral neck muscles in individuals with whiplash-associated disorders. Sci Rep. 2015;5:15289 


\section{ABBREVIATIONS}

CSA Cross-sectional area

fMRI Functional magnetic resonance imaging

Lcap Longus capitis muscle

Lco Longus colli muscle

MRI Magnetic resonance imaging

MF Multifidus muscle

NDI Neck Disability Index

NME Neck Muscle Endurance test

NSE Neck-specific exercise group

NSEB Neck-specific exercise with a behavioral approach group

OPLS-DA Orthogonal partial least square discriminant analysis

PCA Principal component analysis

PLS Projection to latent structures

PLS-DA Partial least square discriminant analysis

PPA Prescription of physical activity group

QTF Quebeck Task Force

Scap Semispinalis capitis muscle

Scerv Semispinalis cervices muscle

SCM Sternocleidomastoid muscle

SP Splenius capitis muscle

TSK-11 Tampa Scale of Kinesiophobia, short version

TR Trapezius muscle

VAS Visual Analogue Scale

VIP Variable influence of projection

WAD Whiplash-associated disorders 


\section{DEFINITIONS}

Acoustic impedance The resistance an ultrasound beam meets as it passes through tissue. Dependent on tissue density and the speed of sound.

Muscle deformation

The change in the longitudinal direction of the muscle (elongation or shortening) calculated as the percentage change of the muscles' length (\% deformation).

Muscle deformation rate

The rate of the change in deformation, expressed as the amount of deformation per time unit (\% deformation/s).

Mechanical neck muscle function

In this thesis, the mechanical function of the muscle including the neck muscles passive or active elongation or shortening.

Motor control

Neuromuscular motor function

Speckle tracking

The ability to regulate or direct the mechanisms essential to movement.

Interaction between nerves and muscles, signals from the nervous system to the muscles.

Ultrasound imaging technique that analyses the deformation and deformation rate in muscles, i.e. quantification of mechanical muscles function.

Two-way interaction The simultaneous influence of two variables ( $\mathbf{x}$ variables; the neck muscles in this thesis) on a third variable (the explained $\mathbf{y}$ variable; WAD/healthy controls). Also called interaction terms.

Variable influence of projection

The most important variables in a complex PLS model can be detected using variable influence of projection (VIP). The higher VIP value (cut-off value often 1.0 or higher), the more influence the variable has on the explained $\mathbf{y}$ variable. 


\section{BACKGROUND}

Whiplash injuries have a reported annual incidence of 200-300/100 ooo $(1,2)$. Up to $50 \%$ will suffer from persistent symptoms called whiplashassociated disorders (WAD), more than one year post injury $(3,4)$ resulting in both personal burden and societal costs $(1,5)$. Most of the individuals return to work (6), but half of those with persistent WAD have longstanding reduced earnings after the injury (5). Common symptoms in WAD are neck pain, headache, arm pain, dizziness, visual disturbance, and psychological distress $(3,7)$. Risk factors for persistent disability following acute whiplash injury are for example high neck pain intensity and disability on inception, high catastrophizing and female sex (8). Despite many years of research, the underlying mechanism and cause to persistent problems are largely unknown and WAD is associated with biopsychosocial factors (9) that can contribute to prolonged disability. Diagnostic tools for investigating neck muscle function are meager and there is today no clear evidence on which to base the management of persistent WAD (10). Moreover, earlier randomized controlled studies have often excluded those with more severe symptoms, i.e. neurological signs, after the whiplash injury.

\section{Biomechanics of the cervical spine in whiplash- associated disorders}

Whiplash injury is defined as "an acceleration-deceleration mechanism of energy transfers to the neck. It may result from rear-end or side-impact motor vehicle collisions but can also occur during driving or other mishaps. The impact may result in bony or soft-tissues injuries (whiplash injury) which in turn may lead to a variety of clinical manifestations (whiplashassociated disorders)" (11). The injury causes strains on the bones, facet joints and soft tissue structures in the neck and may lead to the variety of symptoms reported. The cervical facet joints and capsule have been proposed to cause pain due to pinching of the synovial fold and/or strain of the capsule (12). Increased segmental $\mathrm{C}_{3}-\mathrm{C}_{4}$ and $\mathrm{C}_{5}$ - $\mathrm{C} 6$ motion was also reported in women with chronic WAD (13). Strains above physiological levels in the ligaments and increased joint laxity have been observed in simulated frontal and rear impact (12), also including disc injuries (14). The ligaments, facet joints and vertebrae do not actively stabilize the spine (15), but give neurological feedback signals that activate muscles, important for joint positioning. The relevant muscles and tendons produce adequate stability in the spine by muscle recruitment and reflex response from the neural system. These three subsystem: bone and ligaments, muscles with 
tendons, and nerves, provides neuromuscular control of spine stability and are functionally interdependent (15).

Whiplash injury may decrease spinal stability due to damage in facet joints, ligaments and/or muscles. This can lead to compensatory reorganization in muscle activation to increase spinal stability. Persistent compensatory changes in muscles and tendons may be one reason for persistent pain and disability even though the acute injury after whiplash accident has healed. However, our ability to detect altered muscle function has to date been insufficient.

\section{Diagnosis in WAD}

In 1995, the Quebec Task Force (QTF) presented a classification of whiplash injury in five grades, 0 to 4 , that corresponded to the severity of the injury (11). The Task Force proposed a clinical classification of WAD in three grades related to soft tissue injury (Table 1), as also suggested by Jansen et al. (16). In addition, the QTF classification included related symptoms, for example tinnitus, headache and memory loss that could be manifest in all three grades. Individuals with no pain or physical signs, i.e. no manifest disorder (grade o) or bony injury such as fracture or dislocation (grade 4) were excluded from the WAD classification $(11,16)$. Other classifications have been proposed including psychological factors that can be related to persistent symptoms in WAD (17-19); but these classifications are rarely used.

Table 1. The Quebec Task Force classification of whiplash-associated disorders.

\section{Clinical classification of whiplash-associated disorders}

Grade I Neck pain, stiffness or tenderness only. No physical signs.

Grade II Neck pain, stiffness, tenderness. Clinical musculoskeletal signs including decreased range of motion and point tenderness.

Grade III Neck pain, stiffness, tenderness. Clinical musculoskeletal signs include decreased range of motion and point tenderness. Neurological signs including decreased or absent deep tendon reflexes, weakness and sensory deficits.

Although the QTF scientific monograph on WAD (11) was presented two decades ago, highlighting the knowledge gap in diagnosis and treatment after whiplash injury, the ability to identify the symptoms and clinical findings are still very limited. Assessment with X-ray can detect fracture or dislocation in the cervical spine but are not sufficient to find soft tissue injuries. 
Magnetic resonance imaging (MRI), functional MRI (fMRI) or still-image ultrasonography can investigate morphological change and soft tissue alterations, but not during real-time activity. MRI can detect fatty infiltration and measure cross-sectional area (CSA) in the neck muscles in WAD $(20,21)$, and increased CSA was related to the higher amount of fat in the neck muscles that can represent pseudo-hypertrophy (22). No changes in CSA were seen in individuals with WAD three and six months after the accident (23), but Elliott et al. reported that fatty infiltration was higher in the deep multifidus muscle in those with more severe symptoms three months post-injury (24). Investigations with fMRI, based on an increase in T2 relaxation time of muscle water after exercise, revealed a tendency to less activity in the deep neck flexor muscles in individuals with persistent WAD (25). Still-image ultrasonography showed decreased size of the deep multifidus muscle, indicating muscle atrophy in chronic WAD (26). However, none of these methods can detect muscle function in real time during an activity.

Electromyography (EMG) measures neuromuscular motor function, i.e. the interaction between nerves and muscles, and can be used in real-time investigations. However, it has limits in assessing the deep neck muscles. Surface EMG, with electrodes applied on the skin, has revealed increased activity in superficial neck muscles in chronic $\operatorname{WAD}(27,28)$. To investigate the deep neck muscles, invasive EMG methods are required. Fine-wire EMG was used to assess the dorsal semispinalis cervices muscle (29) and an altered muscle activation pattern was reported in individuals with chronic trauma-induced neck pain including WAD. A nasopharyngeal electrode was inserted to examine the deep ventral longus capitis and longus colli muscles $(30,31)$. It showed alteration in the deep ventral neck muscle in patients with chronic neck pain $(30,31)$; but no studies have included individuals with WAD. These invasive methods cause pain and discomfort to the patients and cannot be used in clinical practice or in larger research studies. Also, these invasive methods per se may cause alterations in the muscle behavior.

\section{Ultrasound measurement of skeletal muscle}

Ultrasound produces sound waves, and echoes returning off the tissues can be recorded to visualize grey-scale images from different depths in the body. Tissues have differing acoustic impedance, depending on their density and stiffness, and the returning echoes indicate reflection of sound waves at tissue boundaries and from small irregularities in the tissues. Different grades of white and black images are produced, called B-mode (brightness mode) ultrasound (32). The echoes from the small irregularities in the muscles serve as acoustic markers because they form a 
unique speckle pattern. This speckle pattern can be followed frame-byframe through the ultrasound images. It provides measurements of muscle deformation (elongation or shortening) and deformation rate (the rate at which the deformation occurs) with post-process speckle tracking analysis. The method was developed to measure myocardial contraction and relaxation, and is sensitive to detect impairment in longitudinal contraction early in cardiomyopathy and infarcted segments in coronary artery disease (33). The method has been tested in musculoskeletal muscles and detected real-time changes in the muscles $(34,35)$. The advantage of ultrasound investigation is that the method is pain-free, non-invasive and relatively inexpensive. Real-time ultrasound images can also provide measurements during activity and thereby improve knowledge of mechanical muscle function. Ultrasound can detect muscle deformation in deep muscles close to the spine and at the same time, deformation in more superficial muscle layers.

\section{Motor control and muscle function}

Motor control is inherently variable and humans never seem to replicate a movement exactly (36). The degrees of freedom in joints and the redundancy in the motor control system have interested researchers for decades. How can the brain and body control so many degrees of freedom and how do muscles coordinate to achieve movement? Lower movement variability can be seen as an indicator of skilled performance but can also be a sign of a stereotyped movement pattern due to pain or disease (37). On the other hand, high variability seems to be necessary for flexibility. Bernstein's famous study of a skilled smith showed that although the hammer exactly hit the target every time during repeated hammering, there was clear variability between the repetitions (Fig. 1). Also, large variability within and between individuals in motor control strategies were reported during repeated work tasks (38). The redundancy of neck muscles allows variation in neck movement. These variations between repeated movements may protect joints and muscles from overuse that can lead to pain and disability. The variability in movement "shares" the load around joints and muscles so that tissues or structures is not repeatedly loaded but some individuals seems to perform a task in a more stereotyped manner than others (39). Those individuals, with less variability, may be those more likely to develop pain as they overuse the same muscles. 


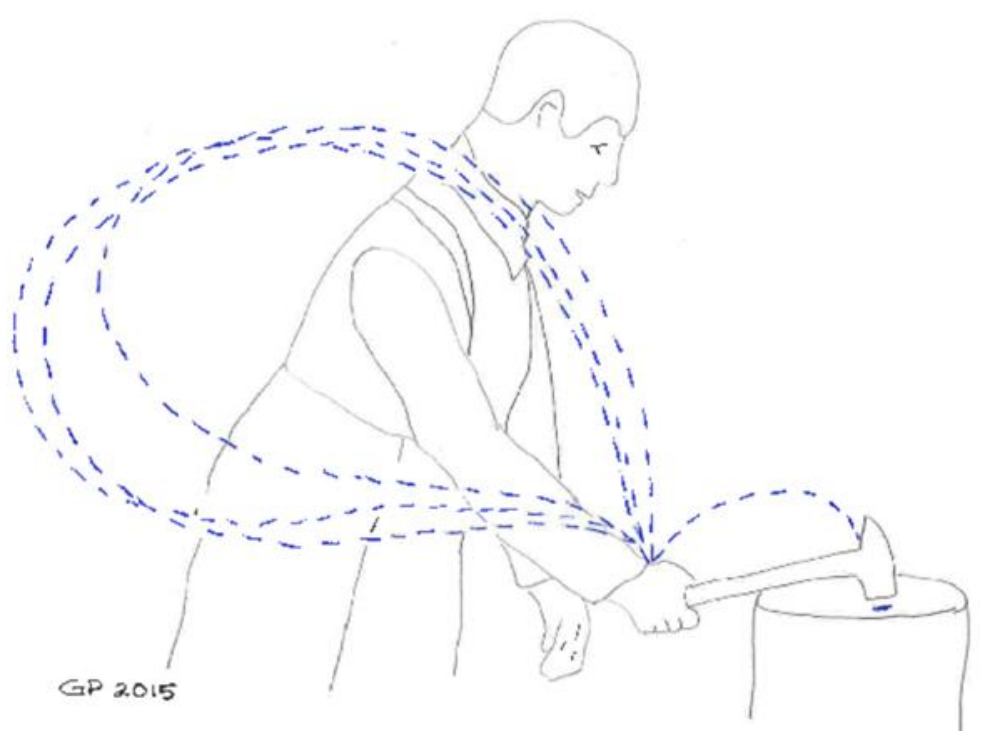

Figure 1. An infinite number of muscle activation patterns can be used to reach the goal of a movement task.

\section{Neck muscle function}

The neck- and head movement control system is complex. Neck muscles maintain postural control of the cervical spine, move the head, and interact with vestibular-, eye- and arm movement control systems (40). The redundancy of neck muscles allows different solutions to perform a particular movement. The deep ventral longus capitis and longus colli and dorsal semispinalis cervicis, rotatores and multifidus muscles are assumed to maintain the postural control and stability of the cervical spine due to their close attachment to the vertebrae and their small movement arms (15, 41). The superficial muscles; sternocleidomastoid, trapezius, splenius capitis and semispinalis capitis, are attached to the trunk and head and have long movement arms. The dominant neck extension muscles are splenius capitis and semispinalis capitis, the dominant flexion muscle is sternocleidomastoid whereas rotation movement capacity is greatest for trapezius (42), see figure 2 for schematic illustration of these neck muscles. However, the some twenty-five pairs of neck muscles have many different solutions to produce a specific movement (40) and the muscles can be activated in different ways. In one study, the splenius capitis muscle was activated during neck flexion in half of the individuals tested and during neck extension in the other half (43). Siegmund et al. reported that the dorsal neck muscles were activated in an individual specific manner during reflexive contraction (44). 


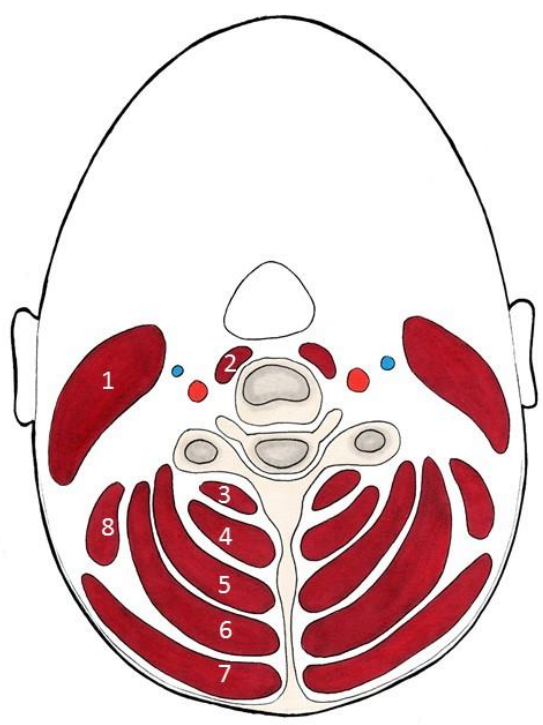

Figure 2. Schematic illustration of neck muscles at the $\mathrm{C}_{4}$ level of the cervical spine. Numbers 1 and 2 shows ventral neck muscles, and 3 to 8 dorsal neck muscles; 1) sternocleidomastoid, 2) longus colli and longus capitis, 3) rotatores and multifidus, 4) semispinalis cervicis, 5) semispinalis capitis, 6) splenius capitis, 7) trapezius, 8) levator scapulae.

Studies using MRI, fMRI or EMG have reported altered neck muscle function in persistent WAD. Impaired ventral neck muscle function with increased activity in the superficial SCM muscle and delayed activity in the deep muscles in neck pain $(25,27)$ have been shown in WAD. Also in the dorsal neck muscles, increased activity in superficial neck extensors in WAD has been seen $(28,45)$, but a study controlling for differences in movement velocity reported no differences between WAD and healthy controls (46). Two small studies have reported altered deep dorsal neck muscle function in WAD. A less defined and decreased activation in the semispinalis cervices muscle was reported (29) and the multifidus muscle was affected by eye movements (45).

Skeletal muscles can activate in different ways. During concentric contraction the muscle is actively shortening, while eccentric contraction means elongation during contraction (i.e. the muscle lengthens as it contracts) and isometric contraction is when the muscle actively holds a fixed length. The muscle can also passively elongate (stretch) or be shortened by pressure from surrounding tissues. In this thesis, mechanical neck muscle function implies the active or passive elongation or shortening of the muscle. 


\section{Muscle adaption to pain}

Movement and motor control patterns change in pain. The vicious model proposed that pain increases muscle activity leading to muscle spasm and more pain (47). In contrast, the pain adaption model suggested that pain reduces contraction in agonist muscles but increases activity in antagonist muscles, a strategy to protect the spine from further injury and pain (48). Recent, research has shown a more individual response to pain (49-51). Experimentally induced low-back pain in healthy individuals' increases spinal stability with increased activity in the six muscles investigated but the response was not stereotypical, the pattern of muscle activity was individual-specific (49). In the calf muscle, a large variation between the study participants was seen, with no systematic muscle activation pattern after induced pain (50). A painful stimulus in the left splenius capitis muscle in the neck caused an individual response in twelve investigated superficial neck muscles (51), and no two of the eight participants showed the same muscle adaption pattern.

\section{The biopsychosocial model of pain}

The biopsychosocial model of pain has been widely accepted during the past few decades. To better understand a person's experience of pain, both the biological- and the psychosocial factors, including emotion and cognition, need to be investigated (52). Biological factors in WAD are the damage to the soft-tissue structures in the neck caused by the accident. Emotion is the direct reaction to the pain after injury while cognition gives meaning to the emotional experience. Avoiding a pain-related movement can be an adaptive behavior in the acute stage but can worsen the problem in persistent pain (53). Psychosocial factors have conflicting and little evidence of being prognostic factors in the development of persistent WAD $(1,54)$, although catastrophizing, fear-avoidance beliefs, distress and low self-efficacy are related to persistent disability and pain in $\operatorname{WAD}(8,17)$. The fear-avoidance model has been suggested for understanding the development from acute whiplash injury to persistent disability in WAD (55). If pain is associated with harm and risk of aggravating pain or (re)injury, an individual's behavior will change, resulting in decrease, or complete avoidance, of the painful movement, called kinesiophobia. Also, fear-avoidance beliefs may affect neck-related exercise performance and compliance with exercise programs if neck movement is associated with pain and fear of increasing the damage. Thus, a behavioral approach in the management of persistent WAD has been proposed $(7,9,56)$. Behavioral approaches often include progressive goal attainment strategies, pain physiology education and graded activity to modify fear of pain and (re)injury related to physical activity $(9,57)$.

Clinically, increased neck pain is commonly described in patients with WAD after work with repeated arm elevation. Activity-related increased 
pain after arm lift has been reported in WAD (58) and may indicate that the deep neck muscles do not maintain a stable cervical spine during arm lifting tasks and/or that the superficial neck muscles are overused. Delayed or decreased activation in the deepest muscles, believed to stabilize the cervical spine, may lead to increased activation in superficial muscles. The superficial muscles with long movement arms may then produce negative forces and stress on the cervical spine, hence continuing neck pain.

\section{Treatment of persistent whiplash-associated disorders}

To date, there is no clear evidence in the management of persistent WAD. Current evidence neither supports nor refutes the effectiveness of conservative treatment such as manual therapies, patient education, exercises and multimodal rehabilitation in WAD grades I and II (10). This because the poor methodological quality and conflicting results in current literature (10). However, active interventions seems to be more effective than passive interventions in chronic $\operatorname{WAD}(10,59)$. Moderate evidence supports radiofrequency neurotomy, i.e. heat lesion in nerves from facet joints, as an effective treatment (6o) although the relief from pain is not permanent. The pain returns, the median time to the return to $50 \%$ preoperative level of pain was 8 to 14 months, but it seems that the procedure can be repeated with similar probability of effect (61-63). However, methodological considerations indicate that the highly invasive procedure needs further research to determine what patients are likely to obtain significant decreases in pain (64). There is no evidence for other surgical or injection-based interventions in WAD (60).

\section{Exercises and behavioral approaches in WAD}

There is moderate quality evidence that strengthening and endurance exercises for cervical- and shoulder muscles are of value to reduce pain and disability in idiopathic neck pain (65). Despite reported altered neck muscle pattern and muscle morphology changes in persistent WAD (20, 21, 29, 66, 67) and the advantage of biopsychosocial approaches in the management of persistent pain (52), randomized controlled trails (RCT) examining exercise or behavioral approaches have reported no or only modest improvement. Stewart et al. (68) reported that general exercise including cognitive behavioral therapy principles was slightly effective compared to advice in the short-time. Two different neck exercise programs, stabilizing neck exercises using a ceiling-mounted sling compared to usual exercises led by a physiotherapist showed no differences between groups and very small improvements after 12 months (69). No differences was seen between a cognitive behavioral approach including neck- and general exercises compared to common used physiotherapy 
management (70), but the study was limited by methodological factors, including small sample size and poorly standardized treatment. Recently reported (71), a comprehensive physiotherapy exercise program was equally effective as advice for chronic WAD grades I and II. Only one study included individuals with WAD grade III (68), but they were excluded if they still had neurological signs when entering the study three-to-twelve months after the injury. Thus, individuals with more severe symptoms, i.e. neurological signs, have been excluded in previous studies.

\section{Exercise regimens in WAD}

If a reorganization in the active stabilizing muscular system persists, with reduced activity in the deep neck muscles $(27,29,66)$, appropriate exercises may be designed for this in the first stage. Most studies have investigated exercises mainly targeting the deep flexor muscles (72-74). Endurance exercises for the deep extensor or rotatores muscles are rarely incorporated in exercise regimens although reduced activity has been reported (75). In persistent WAD, the sling-exercise treatment (69) was intended to improve neuromuscular control in the deep neck muscles. However, only small improvement in ventral neck muscle endurance was reported. In a comprehensive exercise program (71), the specific exercise program (76) focused on isometric endurance training of the deep ventral neck muscles. For extensor muscles, training was performed during active cervical flexion and extension where the load of the head may provoke pain from facet joints. Current evidence for idiopathic mechanical neck pain indicates strengthening and endurance neck exercises (65). An exercise regimen including endurance exercise for deep flexor and dorsal rotatores muscles was effective to reduce the prevalence of neck pain in air force helicopter pilots (77). In chronic musculoskeletal pain, regular physical activity exercise has shown positive effects in modulating (78) and preventing $(79,80)$ chronic pain but has not been specifically studied in persistent WAD.

\section{The individual perspective on treatment}

Measurement of patient satisfaction in medical care is important for understanding the patient's experiences of health care, but the meaning of "patient satisfaction" is unclear (81). Theories of satisfaction have suggested that 'satisfied' relates to the organization of the institution delivering the care, the professional activity when care is provided, and the outcome of the treatment as a change in the individual's health (81). In surgical spine care, patient satisfaction was not a valid measurement for quality and good surgical outcome, instead it represented the patient's satisfaction with the health-care service (82). Individuals with neck pain were more satisfied with manipulation therapy or home exercise intervention than with medication, and satisfaction was related to more information and advice in the manipulative and home-exercise groups (83). However, the relation between satisfaction and neck pain was weak 
(83). Patient satisfaction with treatment is often assumed to measure both care and outcome (81) but could possibly be more related to the delivering of care and less to treatment success. Satisfaction with the intervention may enhance the compliance with exercise regimes and is an important factor to evaluate in randomized control trials. 


\section{Rationale of the thesis}

The cervical spine is heavily dependent on muscular support $(15,41)$ and low endurance in the neck muscles may contribute to persistent neck pain in whiplash-associated disorders. An impaired neuromuscular function has been reported in the cervical spine $(27,29,66)$ but investigation of neck muscle function has been unsatisfactory and no gold standard is available for quantifying function of the deep neck muscles.

The effects of exercise interventions on neck muscle endurance in persistent WAD are limited and there is currently only limited evidence about effective treatment in persistent WAD $(10,59,60)$. Moreover, RCTstudies have not included individuals with neurological signs, WAD grade III. Consequently, the RCT-study in the present thesis is to our knowledge the first study to include WAD with neurological signs.

Evidence-based exercise programs with clear descriptions of contents, dosage and progression are needed to guide clinicians to provide better rehabilitation after whiplash injury. This is especially so for individuals with more severe symptoms and pain, as is the case in WAD grade III. Exercises $(65,80)$ and biopsychosocial interventions (52) are of benefit in idiopathic neck pain and in chronic pain. The present RCT-study is the first to evaluate the effectiveness of neck-specific exercises with or with-out behavioral approaches or general physical activity in ventral and dorsal neck muscle endurance in persistent WAD grades II and III.

The ultrasound studies included in this thesis are the first investigations of deep and superficial neck muscles in real-time video-sequences in individuals with persistent WAD. Ultrasonography can detect differences in the interplay between neck muscles in individuals with WAD versus healthy controls. Ultrasonography of neck muscles and the development of neck muscle models can be important diagnostics tools to investigate impaired mechanical neck muscle function in WAD and the monitoring of the response to exercises. 


\section{AIMS OF THE THESIS}

\section{General aim}

The overall aim of the thesis was to investigate mechanical neck muscle functions and evaluate effects of three different exercises interventions related to neck muscle function in individuals with persistent pain and disability after whiplash injury.

\section{Specific aims}

1. To compare the effects of three exercise interventions on neck muscle endurance, kinesiophobia, exercise compliance and patient satisfaction in individuals with persistent WAD.

2. To compare the mechanical neck muscle functions (deformation and deformation rate) in three ventral neck muscles during repetitive arm elevations between individuals with persistent WAD and healthy controls.

3. To compare the mechanical neck muscle functions (deformation and deformation rate) in five dorsal neck muscles during repetitive arm elevations between individuals with persistent WAD and healthy controls.

4. To develop neck muscle interaction models in persistent WAD and healthy controls.

For specific aims 2 and 3 the following hypotheses were tested:

Individuals with persistent pain and disability after whiplash injury have increased neck muscle deformation and deformation rate in the superficial $\mathrm{m}$. trapezius, $\mathrm{m}$. splenius and $\mathrm{m}$. sternocleidomastoid compared to healthy controls.

Individuals with persistent pain and disability after whiplash injury have decreased neck muscle deformation and deformation rate in the deep $\mathrm{m}$. multifidus/rotatores, $\mathrm{m}$. semispinalis cervices and capitis, and $\mathrm{m}$. longus capitis and longus colli compared to healthy controls. 


\section{METHODS}

\section{Study design}

This thesis is based on one prospective randomized controlled trial (study A) and one experimental case-control study (study B). Table 2 provides an overview of the studies and measurements.

Table 2. Overview of the studies in the thesis

\begin{tabular}{|c|c|c|c|c|}
\hline & Study A & \multicolumn{3}{|c|}{ Study B } \\
\hline Study design & $\begin{array}{l}\text { Multicenter, prospective, } \\
\text { randomized controlled study }\end{array}$ & \multicolumn{3}{|c|}{ Experimental case-control study } \\
\hline Participants & $\begin{array}{l}\text { Individuals with persistent pain } \\
\text { and disability after whiplash injury } \\
\qquad(\mathrm{n}=216)\end{array}$ & \multicolumn{3}{|c|}{$\begin{array}{l}\text { Individuals with persistent pain and disability after whiplash } \\
\text { injury (ventral muscles } n=26 \text {, dorsal muscles } n=40 \text { ). } \\
\text { Controls with no present or past neck problems }(n=26 \text { and } n=40 \text { ) }\end{array}$} \\
\hline & Paper I (Study A) & Paper II (Study B) & Paper III (Study B) & Paper IV (Study B) \\
\hline Aims & $\begin{array}{l}\text { To compare the effects } \\
\text { of three different exercise } \\
\text { regimes on neck muscle } \\
\text { endurance, kinesiophobia } \\
\text { exercise compliance and } \\
\text { patient satiscfaction. }\end{array}$ & $\begin{array}{l}\text { To compare deformation } \\
\text { and deformation rate } \\
\text { in three ventral neck } \\
\text { muscles between } \\
\text { individuals with WAD } \\
\text { and controls during } \\
\text { repetitive arm elevation. }\end{array}$ & $\begin{array}{l}\text { To compare deformation } \\
\text { and deformation rate } \\
\text { in five dorsal neck } \\
\text { muscles between } \\
\text { individuals with WAD } \\
\text { and controls, during } \\
\text { repetitive arm elevation. }\end{array}$ & $\begin{array}{l}\text { To develope a model } \\
\text { that can determine } \\
\text { impaired mechanical } \\
\text { neck-muscle function in } \\
\text { individuals with WAD. }\end{array}$ \\
\hline Methods & $\begin{array}{l}\text { Outcome measurements } \\
\text { were recorded at baseline } \\
\text { with three and six months } \\
\text { follow-up. }\end{array}$ & $\begin{array}{l}\text { Ultrasound measurments } \\
\text { of ventral neck muscles, } \\
\text { post-process analysis } \\
\text { with speckle tracking }\end{array}$ & $\begin{array}{l}\text { Ultrasound measurments } \\
\text { of dorsal neck muscles, } \\
\text { post-process analysis } \\
\text { with speckle tracking }\end{array}$ & $\begin{array}{l}\text { Ultrasound measurments } \\
\text { of ventral and dorsal neck } \\
\text { muscles, post-process } \\
\text { analysis with speckle tracking }\end{array}$ \\
\hline $\begin{array}{l}\text { Data } \\
\text { analysis }\end{array}$ & $\begin{array}{l}\text { One-way ANOVA } \\
\text { Chi-squared test } \\
\text { Kruskal-Wallis test } \\
\text { Mann-Whitney U test } \\
\text { Friedman ANOVA } \\
\text { Wilcoxon test } \\
\text { Linear mixed model }\end{array}$ & $\begin{array}{l}\text { Students t-test } \\
\text { Chi-squared test } \\
\text { Correlation and linear } \\
\text { regression. } \\
\text { Mixed design analysis } \\
\text { of variance, ANOVA } \\
\text { Friedman ANOVA } \\
\text { Wilcoxon signed-rank test } \\
\text { Kruskal-Wallis test } \\
\text { Mann-Whitney U test } \\
\text { Paired sample T-test }\end{array}$ & $\begin{array}{l}\text { Students T-test } \\
\text { Chi-squared test } \\
\text { Mann-Whitney U test } \\
\text { Mixed design analysis } \\
\text { of variance, ANOVA } \\
\text { Linear regression } \\
\text { Principal component } \\
\text { analysis } \\
\text { Partial least square } \\
\text { discriminant analysis } \\
\text { Orthogonal partial } \\
\text { least square discriminant } \\
\text { analysis }\end{array}$ & $\begin{array}{l}\text { Students T-test } \\
\text { Principal component } \\
\text { analysis } \\
\text { Projections to latent } \\
\text { structures } \\
\text { Partial least square } \\
\text { discriminant analysis }\end{array}$ \\
\hline
\end{tabular}




\section{Study population}

Participants with persistent pain and disability six months to three years after whiplash injury were recruited from February 2011 to May 2012. They were recruited from health care registers from primary health care centers, orthopedic clinics and hospital outpatient services in six counties. From the project leaders' clinical experiences, whiplash-associated disorders in the chronic state could be diagnosed as cervical pain. Thus, 7950 letters were sent to potential participants (Fig. 3), with cervical pain with or without radiculopathy or whiplash diagnosis. The letters contained basic study information, basic inclusion/exclusion criteria, and a prepaid return envelope. The potential participants were contacted by telephone to confirm inclusion/exclusion criteria. Finally, eligible participants underwent a clinical examination, performed by one of the study investigators to verify their diagnosis of WAD grade II or III.

\section{Inclusion and exclusion criteria}

Inclusion criteria were ongoing symptoms associated with a whiplash injury six months to three years before study entry with persistent neck pain greater than $20 \mathrm{~mm}$ measured on visual analog scale (VAS) and/or neck disability greater than 20\% measured with the Neck Disability Index (NDI). A manual examination had to find signs corresponding to WAD grade II or III and the participants' age should be between 18 and 63 years. They should have sufficient Swedish to understand instructions and be able to answer the questionnaires. In study $\mathrm{B}$, individuals also had to report neck pain on the right side of the neck and right-handedness to be included.

Exclusion criteria included potentially pre-existing conditions that could interact with the study results or were related to the person's ability to participate safely in the tests and exercise interventions, see Table 3. In study B participants with obesity affecting the ultrasound image were also excluded.

Table 3. Exclusion criteria in study A

\section{Exclusion criteria}

- Signs of traumatic brain injury at the time of whiplash injury (loss of consciousness retrograde and post-traumatic amnesia, disorientation, and confusion)

- Known or suspected serious pathology

- Previous fracture or luxation in cervical spine

- Contraindication to exercise

- Neuromuscular diseases

- Rheumatologic disease

- Severe mental illness

- Current alcohol or drug abuse 


\section{Participants, study A}

Study A, included 216 participants, 142 women and 74 men, mean age 40 years (SD, 11.4 years). One hundred and twenty-three had WAD grade II (neck pain and musculoskeletal signs) and 93 had WAD grade III (neck pain plus neurological signs). Participants were randomly allocated to one of three intervention groups; neck-specific exercise (NSE), neck-specific exercise with a behavioral approach (NSEB) or prescribed physical activity (PPA). Table 4 shows baseline characteristics and figure 3 the flowchart.

Table 4. Baseline characteristics for the three intervention groups.

\begin{tabular}{|c|c|c|c|c|}
\hline Variables & NSE group $(N=76)$ & NSEB group $(N=71)$ & PPA group $(\mathrm{N}=69)$ & P-value \\
\hline \multicolumn{5}{|l|}{ Variables mean (SD)[range] } \\
\hline Age, (years) & $38.1(11.3)[18-62]$ & $40.1(11)[19-63]$ & $42.9(10.7)[18-63]$ & 0.03 \\
\hline $\mathrm{BMI} \mathrm{kg/m2}$ & $25.7(4.0)[19-35]$ & $25.9(5.1)[18-45]$ & $26.7(4.9)[19-43]$ & 0.10 \\
\hline Injury duration* & $19.1(8.5)[6-36]$ & $20.3(8.9)[6-36]$ & $19.6(9.7)[6-36]$ & 0.69 \\
\hline \multicolumn{5}{|l|}{ Variables n (\% group) } \\
\hline Gender n (\%) female & $57(75 \%)$ & $47(66 \%)$ & $38(55 \%)$ & 0.04 \\
\hline Whiplash motor accident ${ }^{\dagger}$ & $65(86 \%)$ & $54(76 \%)$ & $54(82 \%)$ & 0.29 \\
\hline Whiplash other accident $^{*}$ & $11(14 \%)$ & $17(24 \%)$ & $12(14 \%)$ & 0.29 \\
\hline WAD grade II & $49(64 \%)$ & $33(46 \%)$ & $41(59 \%)$ & 0.08 \\
\hline WAD grade III & $27(36 \%)$ & $38(54 \%)$ & $28(41 \%)$ & 0.08 \\
\hline Previous treatment ${ }^{\S}$ & $64(85 \%)$ & $57(80 \%)$ & $53(78 \%)$ & 0.37 \\
\hline Work full-time & $43(56 \%)$ & $36(51 \%)$ & $37(54 \%)$ & 0.72 \\
\hline
\end{tabular}

NSE; neck-specific exercise, NSEB; neck-specific exercise with behavioral approach, PPA; prescription of physical activity, BMI; body mass index, WAD; whiplash-associated disorder

* Months since whiplash injury

${ }^{+}$Whiplash injury as a result of motor vehicle accident

\#Whiplash injury due to other accidents (e.g. fall, skiing, diving)

$\S$ Sought health care (physician, physiotherapist) for neck pain after the whiplash injury, before study entry. 
Assessed for eligibility

by letter $(n=7950)$ Letters sent to individuals seeking national care units in the preceding 6-36 months due to neck pain/whiplash

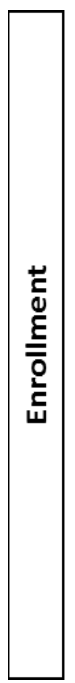

Answered letter, agreed to participate $(n=626)$

Assessed for eligibility by
telephone and physical
examination screening $(n=419)$

examination screening $(n=419)$

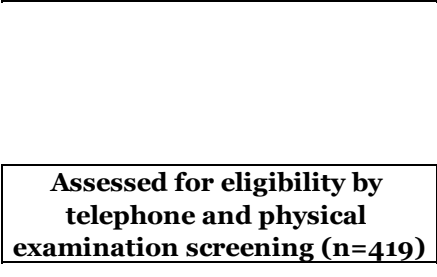

Excluded $(n=7324)$

Did not meet inclusion

criteria $(n=2173)$,

non-responders $(n=4548)$,

addressee unknown $(n=314)$,

declined participation $(\mathrm{n}=289)$
Excluded (n=203)
No whiplash injury $(n=15)$
whiplash injury $>3$ years ago $(n=37)$, working hours make it almost impossible to participate $(n=37)$, other illness or severe pain elsewhere $(n=42)$, traumatic brain injury $(n=3)$, fracture/luxation/op cervical spine $(n=4)$, travelling abroad, moved to another city $(n=8)$, insufficient command of Swedish language $(n=16)$, did not come to physical examination/no answer $(n=18)$, sickleave $>1$ months before whiplash injury $(\mathrm{n}=11)$, declined to participate $(\mathrm{n}=12)$

Randomized (n=216)

Neck specific exercise with behavior intervention (NSEB)

Allocated to intervention $(n=71)$ Never started intervention $(\mathrm{n}=3)$

Allocated to intervention $(n=76)$ Never started intervention $(n=6)$

\begin{tabular}{|c|c|}
\hline & Follow-up 3 months \\
\hline 홍 & $\begin{array}{l}\text { Lost to follow-up } 3 \text { months } \\
\text { (Lack of time/personal reason } n=6 \text {, } \\
\text { more pain after exercise } n=1 \text {, } \\
\text { unknown } n=4 \text {, severe disease } n=3 \text {, } \\
\text { pregnant } n=1)(n=15) \\
\quad \text { Analyzed }(n=61 ; 45 / 16)\end{array}$ \\
\hline
\end{tabular}

\begin{tabular}{|c|}
\hline Follow-up 3 months \\
Lost to follow-up 3 months \\
(Lack of time/personal reason $n=2$, \\
unknown $n=1$, moved $n=1)(n=4)$ \\
Analyzed $(n=67 ; 44 / 23)$
\end{tabular}

Follow-up 6 months Lost to follow-up 6 months (Lack of time/personal reason $n=8$, more pain after exercise $\mathrm{n}=\mathbf{1}$, unknown $n=10$, severe disease $n=3$ ) $(n=22)$

Analyzed (n=54; 39/15)
Follow-up 6 months

Lost to follow-up 6 months

(Lack of time/personal reason $n=4$, more pain after exercise $n=1$,

unknown $n=4$, moved $n=2)(n=11)$

Analyzed (n=60; 39/21)

\section{Prescribed physical activity (PPA) \\ Allocated to intervention $(n=69)$ Never started intervention $(\mathrm{n}=5)$} Lost to follow-up 3 months (Lack of time/personal reason $n=5$, unknown $n=3$, severe disease $n=4$ ) $(\mathrm{n}=12)$

Analyzed ( $\mathrm{n}=57 ; 29 / 28)$

Follow-up 6 months Lost to follow-up 6 months (Lack of time/personal reason $n=6$, more pain after exercise $n=1$, pregnant $n=1$, unknown $n=4$, moved $n=1$, severe disease $n=5$ ) $(\mathrm{n}=18)$ Analyzed $(\mathrm{n}=51 ; 23 / 28)$

\section{Follow-up 3 months}

Figure 3. Flow chart study A, participants' recruitment and retention $(\mathrm{n}=$ total number; women/men). 


\section{Participants study B}

The participants in study B were consecutively recruited for neck muscle ultrasound investigations from study A. Eligibility requirements included neck pain on the right side of the neck, and right-handedness.

Ultrasound measurements were recorded in 40 individuals with WAD and 40 healthy controls matched for age and sex.

In paper II, 26 individuals with persistent $\mathrm{WAD}$ (20 women and 6 men, mean age 37 years (SD; 10.9) and 26 controls matched for age and sex were included. Fourteen individuals (seven pairs of participants) were excluded due to bad image quality in either the WAD or matched controls images. In paper III, 40 individuals with persistent WAD, 28 women and 12 men, mean age 37 years (SD, 11.2 years) and 40 age- and gender-matched healthy controls were included.

In the development of the neck muscle interaction model (paper IV), 23 individuals with WAD ( 18 women and 5 men; mean age 36 years (SD; 11.2) and 23 matched controls were included (individuals from paper II). The analyses in paper II detected three individuals as outliers because they had a skew positive impact on the correlation and linear regression analysis. These three outliers and their matched controls were excluded from the neck muscle interaction analyses in paper IV. For baseline characteristics in papers II, III and IV, see Table 5 a, b and c.

The controls in study B were recruited from university staff, hospital staff and acquaintances. Exclusion criteria for controls were present or past neck problems, trauma to the neck, neck or low-back pain, rheumatologic or neurologic disease and generalized myalgia. 
Table 5 a. Baseline characteristics paper II

\begin{tabular}{lccc}
\hline Variables & $\begin{array}{c}\text { WAD } \\
(\mathrm{N}=26)\end{array}$ & $\begin{array}{c}\text { Healthy controls } \\
(\mathrm{N}=26)\end{array}$ & P-value \\
\hline Gender, $\mathrm{n}$ female/male & $20 / 6$ & $20 / 6$ & 1.0 \\
WAD grade 2/3, $\mathrm{n}$ & $18 / 8$ & $\mathrm{NS}$ & \\
Variables mean (SD) & & & \\
Age (years) & $37(10.9)$ & $37(10.9)$ & 0.96 \\
Injury duration $^{\mathrm{a}}$ & $22(7.7)$ & $\mathrm{NS}$ & \\
BMI $^{\mathrm{b}}$ male & $25(6.6)$ & $25(3.5)$ & 0.81 \\
BMI female $_{\text {Neck Disability Index }}^{\mathrm{c}}$ & $25(5.4)$ & $22(2.4)$ & 0.01 \\
Pain previous week $^{\mathrm{d}}$ & $34(13.4)$ & $1(1.6)$ & 0.001 \\
Variables median (IQR) $_{\text {Physical activity level }^{\mathrm{e}}}$ & $50(18.8)$ & $1(1.0)$ & 0.001 \\
\hline
\end{tabular}

Table 5 b. Baseline characteristics paper III

\begin{tabular}{lccc}
\hline Variables & $\begin{array}{c}\text { WAD } \\
(\mathrm{N}=40)\end{array}$ & $\begin{array}{c}\text { Healthy controls } \\
(\mathrm{N}=40)\end{array}$ & P-value \\
\hline $\begin{array}{l}\text { Gender, } \mathrm{n} \text { female/male } \\
\text { WAD grade 2/3, } \mathrm{n}\end{array}$ & $28 / 12$ & $28 / 12$ & 1.0 \\
Variables mean (SD) & $29 / 11$ & $\mathrm{NS}$ & \\
Age (years) & & & \\
Injury duration $^{\mathrm{a}}$ & $37.4(11.2)$ & $37.4(11.4)$ & 1.0 \\
BMI $^{\mathrm{b}}$ male & $21.2(8.5)$ & $\mathrm{NS}$ & \\
BMI female $^{25.0(4.8)}$ & $26.3(3.6)$ & 0.48 \\
Neck Disability Index $^{\mathrm{c}}$ & $24.5(6.4)$ & $22.5(2.5)$ & 0.14 \\
Pain previous week $^{\mathrm{d}}$ & $32.4(13.9)$ & $1.4(1.8)$ & $<0.001$ \\
Variables median (IQR) $^{\text {Physical activity level }^{\mathrm{e}}}$ & $45.9(18.7)$ & $1.1(2.2)$ & $<0.001$ \\
& & & \\
\hline
\end{tabular}


Table 5 c. Baseline characteristics paper IV

\begin{tabular}{lccc}
\hline Variables & $\begin{array}{c}\text { WAD } \\
(\mathrm{N}=23)\end{array}$ & $\begin{array}{c}\text { Healthy controls } \\
(\mathrm{N}=23)\end{array}$ & P-value \\
\hline $\begin{array}{l}\text { Gender, } \mathrm{n} \text { female/male } \\
\text { WAD grade 2/3, } \mathrm{n}\end{array}$ & $18 / 5$ & $18 / 5$ & 1.0 \\
Variables mean (SD) & $16 / 7$ & $\mathrm{NS}$ & \\
Age (years) & & & \\
Injury duration $^{\mathrm{a}}$ & $36.0(11.2)$ & $36.1(10.9)$ & 1.0 \\
BMI $^{\mathrm{b}}$ male & $22.0(7.7)$ & $\mathrm{NS}$ & \\
BMI female $^{24.0(6.6)}$ & $24.0(3.6)$ & 0.95 \\
Neck Disability Index $^{\mathrm{c}}$ & $27.0(7.9)$ & $22.0(2.3)$ & 0.03 \\
Pain previous week $^{\mathrm{d}}$ & $34.0(13.8)$ & $1.0(1.6)$ & $<0.001$ \\
Variables median (IQR) & $51.0(17.6)$ & $0.7(1.0)$ & $<0.001$ \\
Physical activity level $^{\mathrm{e}}$ & & & \\
\hline WAD & $2.0(2.0-3.0)$ & $4.0(3.0-4.0)$ & $<0.001$ \\
\hline
\end{tabular}

WAD: whiplash-associated disorders,

a) Months since whiplash injury, range 6 to 36 months.

b) Body Mass Index (BMI)

c) Neck Disability Index Score (0-100\%) was based on 10 items; higher scores represented higher disability.

d) Visual analogue scale (VAS), average pain in the prior week, range 0-100 $\mathrm{mm}$, higher rating represented higher pain intensity.

e) Physical activity level over the prior 12 months ( 1 = inactivity, 2 = low activity, 3 = moderate activity, $4=$ high activity)

\section{Ethical consideration}

The studies were approved by the Regional Ethics Review Board in Linköping and conducted according to the Declaration of Helsinki. All participants were informed orally and in writing about the studies. Participation was voluntary; they could decline to participate in, or could withdraw from, the study at any time with no negative consequences. Informed consent from participants in study A and written informed consent in study B were provided before study start. There was no known risk with the tests or interventions except for muscle soreness when exercise intervention began in study A. The soreness was expected to end after a couple of days. 


\section{Data collections}

For an overview of the measurements and tests included in the thesis, see

Table 6.

Table 6. Overview of measurements

\begin{tabular}{|c|c|c|c|c|c|}
\hline Outcome measures & Outcome variable & Paper I & Paper II & Paper III & Paper IV \\
\hline \multicolumn{6}{|l|}{ Self-reported } \\
\hline Descriptive items in a questionnaire & Background variables & $\mathrm{x}$ & $\mathrm{x}$ & $\mathrm{x}$ & $\mathrm{x}$ \\
\hline Visual Analogue Scale (VAS) & Neck pain & $\mathrm{x}$ & & & \\
\hline Tampa Scale of Kinesiophobia (TSK) & Fear of movement/(re)injury & $\mathrm{x}$ & & & \\
\hline Lickert scale (dissatisfied - satisfied) & Patient satisfaction of treatment & $\mathrm{x}$ & & & \\
\hline \multicolumn{6}{|l|}{ Clinical examinations } \\
\hline Neck Muscle Endurance (NME) & Neck endurance (seconds) & $\mathrm{x}$ & & & \\
\hline Real time ultrasound & Deformation and deformation rate & & $\mathrm{x}$ & $\mathrm{x}$ & $\mathrm{x}$ \\
\hline
\end{tabular}

\section{Study A}

Participants completed a questionnaire at baseline, and at the three- and six-month follow-ups. Neck muscle endurance was measured with the Neck Muscle Endurance (NME) test, and neck pain intensity was reported immediately before and after the NME on Visual Analogue Scale (VAS). The questionnaire included items related to background variables (Table 4), the Tampa Scale of Kinesiophobia (TSK-11), exercise compliance, and patient satisfaction with treatment. A clinical examination was performed by one of the study investigators, blinded to the participants' group allocation. The investigators were seven experienced physiotherapists in the six counties and were trained to undertake the strict testing protocol during the baseline and follow-up tests.

\section{Ventral and dorsal neck muscle endurance test}

The neck muscle endurance test (NME) has been reported to be of good reliability (ICC > 0.88) (84). NME was standardized and measured in seconds as previously described $(85,86)$.

The ventral NME was tested first in all participants, with the participant supine, legs straight, arms alongside the body, and head and cervical spine in a neutral position (Fig. 4). The instructions given were to slightly nod, retract the chin, and raise the head just above the examination table, such that a small head lift was performed in slight upper cervical flexion (85). Dorsal NME was measured with the participants positioned prone, legs straight, arms alongside the body, and head initially supported on the examination table (Fig. 4). The participants were instructed to lift their head just above the examination table with the tip of the chin pointing at the floor. Applied to the head was a load of $2 \mathrm{~kg}$ for women or $4 \mathrm{~kg}$ for men (85). 

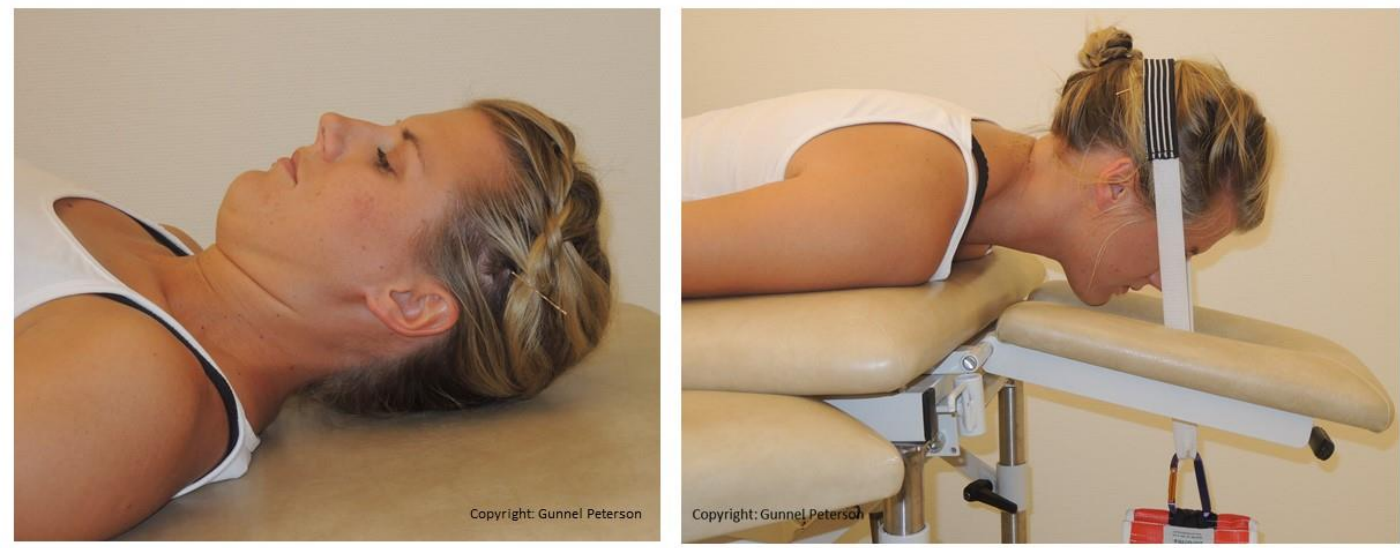

Figure 4. Ventral and dorsal neck muscle endurance (NME) test.

The participants were instructed to maintain the test position for as long as possible, but stop the test by returning the head to rest on the examination table if they felt pain radiating into the arm or were at the point of neck fatigue. They were also told to stop if they experienced severe neck pain or increased radiating pain to the $\operatorname{arm}(\mathrm{s})$. Endurance was measured in seconds using a stopwatch for both the ventral and the dorsal NME test. For familiarization, participants practiced the test before the official trial (nod when supine, chin pointing at floor and lifting head without weight when prone). The test leader verbally corrected the test position during the measurement if necessary.

\section{Neck pain intensity}

The pain intensity of the neck was measured immediately before and after the NME test, using a $100 \mathrm{~mm}$ VAS; o $\mathrm{mm}=$ no pain to $100 \mathrm{~mm}=$ worst imaginable pain. Moderate to good reliability and validity have been reported for the $\mathbf{0 - 1 0 0} \mathrm{mm}$ VAS (87). The scale has limitations in repeated measures due to intra-subject differences in the experience of pain (88). A reduction of $50 \%$ in individuals reported pain intensity has been considered substantial clinical improvement (89).

\section{Kinesiophobia}

Fear of movement and (re)injury was measured using the Tampa Scale for Kinesiophobia (TSK-11) short form and the two-factor model of the TSK11, including activity avoidance (TSK-AA) and somatic focus (TSK-SF). The TSK-11 shows moderate to good reliability and validity (90) and includes 11 items scored from 1 to 4 with a possible total score ranging from 11 to 44 . Higher scores indicating greater fear of movement and (re)injury. Subscale 
TSK-AA has 5 items with a total score ranging from 5 to 20, and the TSKSF includes 6 items with a total score ranging from 6 to 24 .

\section{Patient satisfaction}

The participants rated their satisfaction with the intervention at the sixmonth follow-up on a seven-point Likert scale, from 1 (very dissatisfied) to 7 (very satisfied) as an answer to the question "How is your experience of the intervention for your neck pain?"

\section{Exercise compliance}

Compliance with exercise was defined as at least 50\% attendance at the recommended intervention sessions (all three groups). Also included was attendance at the basic information for the NSE group and at least 50\% of the behavioral components for the NSEB group. Exercise compliance data was collected from the physiotherapists' diaries (NSE and NSEB groups) and the participants' exercise diaries (PPA group).

\section{Study B}

Participants completed a baseline questionnaire including items regarding age, height, weight, NDI, physical activity level, and neck pain intensity in the last week. The ventral and dorsal neck muscles were recorded using a B-mode 2-D ultrasound Vivid-i scanner (GE Healthcare, Horten, Norway). The ultrasound was equipped with a $12-\mathrm{MHz}$ linear transducer $(38 \mathrm{~mm})$, with the frame rate set to 235 frames/s. Post-process analyses of the ultrasound images were performed using speckle-tracking analyses.

Ultrasound measurements of dorsal neck muscles were recorded first. A physiotherapist identified the level of the fourth cervical vertebrae $\left(\mathrm{C}_{4}\right)$ by palpation of the spinous process and marked the skin with a pen. The ultrasound transducer was positioned in a transverse orientation at the level $\left(\mathrm{C}_{4}\right)$ on the dorsal right side of the neck. When the $\mathrm{C} 4$ spinous process was identified at the transverse image, the transducer was rotated $90^{\circ}$ in a longitudinal position and all dorsal ultrasound recordings were performed in this longitudinal position. Then the ventral neck muscles were recorded. The $\mathrm{C}_{4}$ level was verified with a transverse ultrasound projection of the bifurcation of the carotid artery at the right ventral side of the neck. The carotid artery is commonly observed at the $\mathrm{C}_{4}$ level (91). The transducer was then rotated to a longitudinal position and the ventral images were recorded in this position (Fig. 5). 

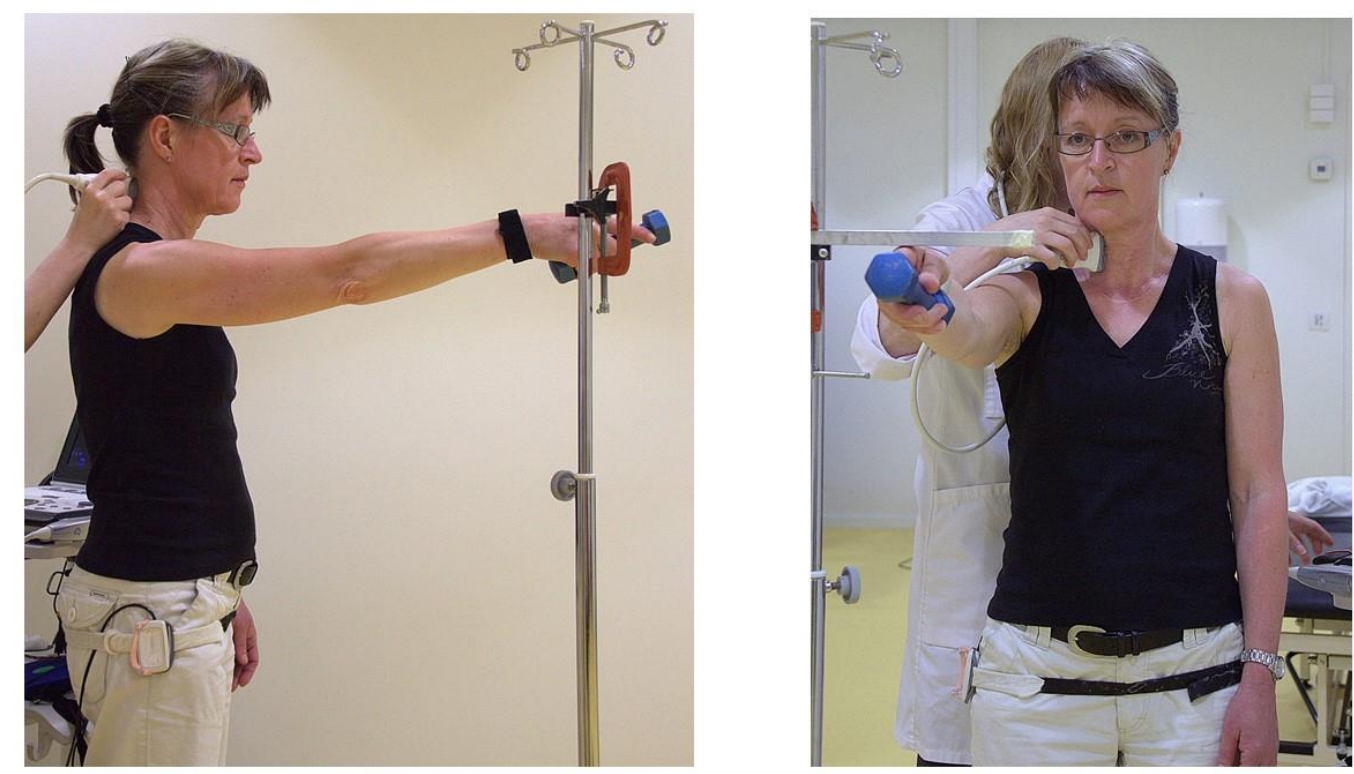

Figure 5. Ultrasound measurement of dorsal and ventral neck muscles.

A test included ten arm elevations and ultrasound images were taken of the first and tenth arm elevation. Many normal daily activities require tolerance of sustained neck loading and activities involving repeated arm lifting could increase neck pain in WAD (58). The participant held a weight of $0.5 \mathrm{~kg}$ (women) or $1 \mathrm{~kg}$ (men) in the right hand.

The arm was raised to 90 degrees, to an adjustable horizontal bar and the index finger was to touch the bar. A pair of customized contact switches were attached, one on the right hip and one on the right wrist. The contact signals were recorded in the ultrasound machine allowing synchronization of data and giving information of the start and stop of arm movements. A metronome was set to 40 beats per minute to keep a steady pace during the examination. The individual was asked to look at the bar, hold the head steady, lift the arm to the bar on the beat and then lower the arm to the switch contact on the next beat.

\section{Ultrasound analyses, speckle tracking}

The speckle tracking method was based on an algorithm developed by Kanade-Lukas-Tomasi $(92,93)$, and further developed by Farron et al. (94). It was implemented with an in-house software program written in Matlab 2013b. A region of interest (ROI) was manually placed in the first frame of the video sequence of the muscle, and the unique speckle pattern was tracked frame-by-frame through the video sequence (Fig. 6a). When the speckle pattern changes length with muscle lengthening or shortening, so does the length of the ROI. Three ROIs (each $10 \times 3.3 \mathrm{~mm}$ ) were positioned longitudinally to the muscle in each muscle covering $30 \mathrm{~mm}$ of the muscle of interest. Ultrasound with post-process speckle tracking has been validated against force measurements (35), and shows a positive 
relationship between the magnitude of muscle deformation recorded with speckle tracking and the magnitude of muscle activity in voluntary movement and electrical stimulation. The test-retest reliability of the speckle tracking analysis method has been reported to be excellent, ICC $0.71-0.97$ (95).

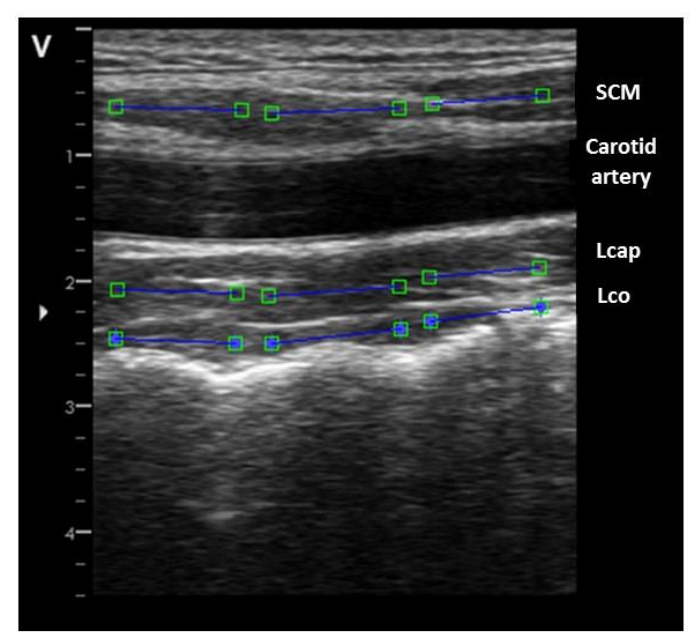

a

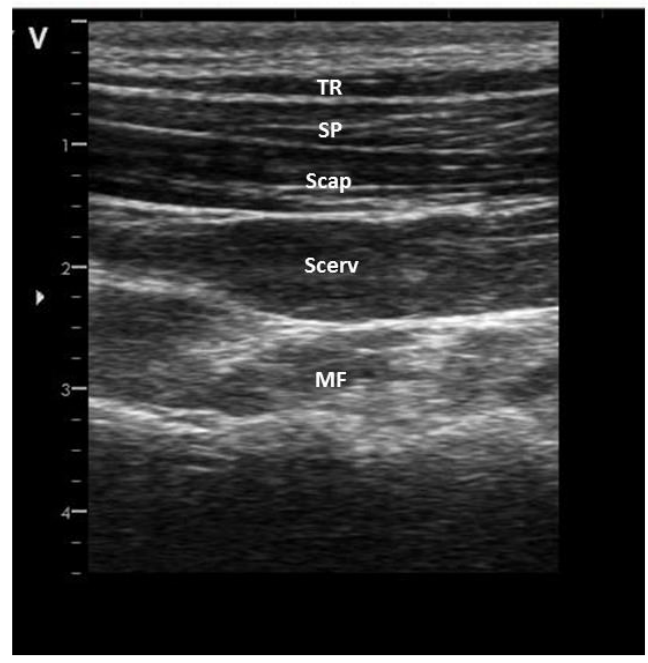

$\mathrm{b}$

Figure 6. Ultrasound images of ventral and dorsal neck muscles.

Three regions of interest were selected in each muscle for ventral and dorsal neck muscles. ROI's can be seen in the three ventral neck muscles (Fig. 6a); each indicated as a blue line with a square end.

a) Three ventral neck muscles; sternocleidomastoid (SCM), longus capitis (Lcap) and longus colli (Lco).

b) Five dorsal neck muscles; trapezius (TR), splenius capitis (SP), semispinalis capitis (Scap), semispinalis cervicis (Scerv) and multifidus (MF).

\section{Deformation and deformation rate}

To measure muscle deformation (elongation or shortening of the muscle) the percentage change from the original length of the ROI compared to rest was calculated (expressed as \% deformation). To quantify muscle deformation, the areas on the deformation curves were calculated (Fig. 7). The area under the deformation curve gives information about the change in deformation (percentage change from the beginning of the test) for every frames in the ultrasound imaging sequence. The method not only gives the total deformation area calculated, but also information about elongation and shortening of the muscle as well as the magnitude of the deformation at every time point during the test. Area under the curve is a common method to measure the sum of change over time in a very broad research fields (for example; cardiovascular tests (96) and blood concentration-time (97)). 
The trapezoidal rule (Equation 1) where $\mathrm{A}$ is the area, $\mathrm{t}$ is time between samples and $\mathrm{y}_{\mathrm{n}}$ is the current ROI position at sample point $\mathrm{n}$, was used as a basis for the area calculation.

$$
A=\frac{t}{2}\left(\mathrm{y}_{1}+2 \mathrm{y}_{2}+2 \mathrm{y}_{3}+. .+2 \mathrm{y}_{\mathrm{n}-2}+2 \mathrm{y}_{\mathrm{n}-1}+\mathrm{y}_{\mathrm{n}}\right) \quad \text { (Equation 1) }
$$

The muscle deformation rate was expressed as the amount of deformation per time unit (\% deformation/s) and was presented as the root mean square (RMS). RMS values gives information about the local tissue velocity of deformation. All ultrasound images were coded during the post-process analyses. Thus, the person analyzing the speckle-tracking data was blinded to the affiliation.

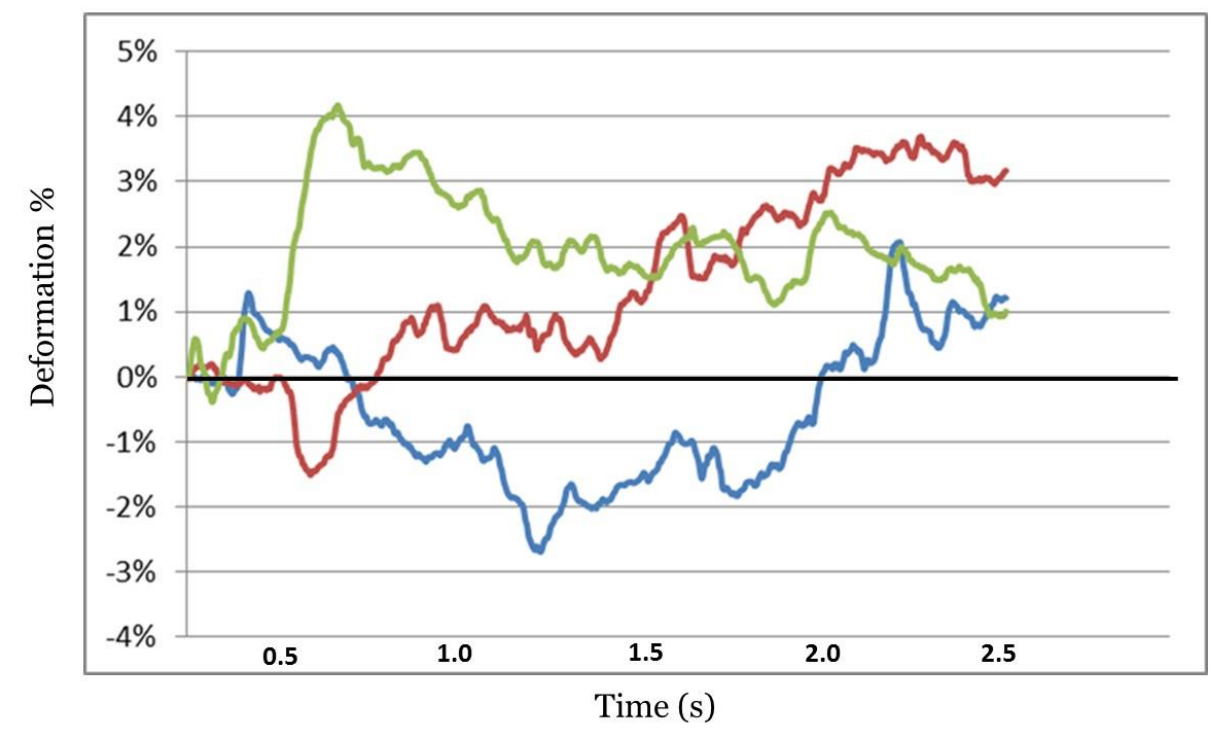

Figure 7. Muscle deformation area in three ventral neck muscles during one arm elevation.

Muscle shortening is the negative values (area below zero) and muscle elongation is the positive values (area above zero). The total deformation area is the sum of negative and positive values. When the line crosses the $0 \%$ line, the muscle switches from elongation to shortening and vice versa.

\section{Interventions study A}

The study interventions (Table 9) were conducted by 69 physiotherapists working in primary care in six different Swedish counties, thus minimizing the distance for participants to go to the intervention session. The physiotherapists received from the project leaders one day of theoretical and practical training before study start. They could also contact the project leaders if they need further advice regarding the interventions. 


\section{Neck-specific exercise (NSE)}

The participants were supervised by a physiotherapist twice weekly for 12 weeks, with additional home exercise. They were informed about anatomical and physiological factors related to symptoms. The exercises were initially aimed to facilitate deep neck muscle activation and thereafter designed to improve neck muscle endurance (Fig. 8). The content, dosage and progression of the neck-specific exercise program are described in details online at Academic Archives (98). The exercise program also included exercises for scapulae, low back, abdomen and stretching if needed. The participants were instructed to avoid pain aggravation during exercise. After the 12 weeks they were instructed to continue with neckspecific and general exercise outside the physiotherapy clinic.
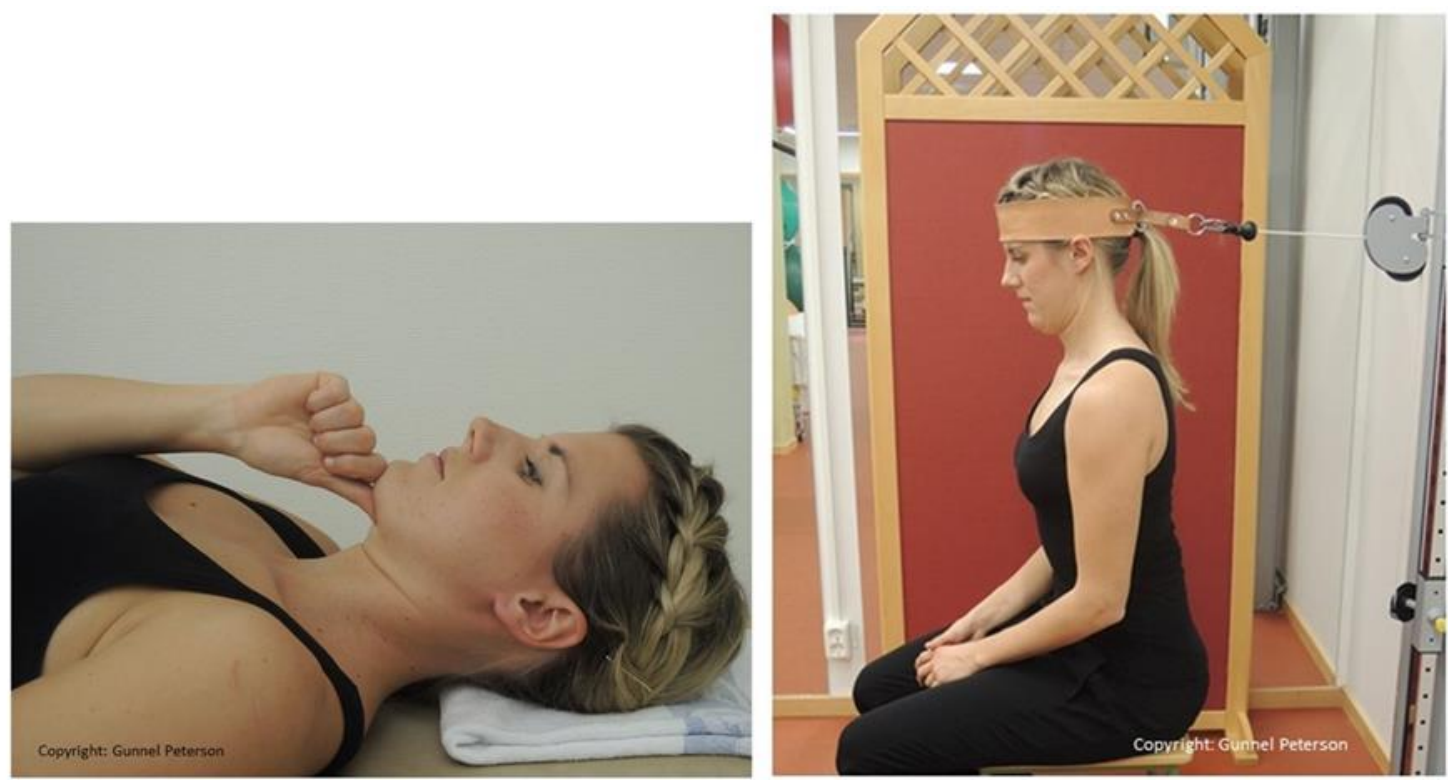

Figure 8. Example of neck-specific exercises

\section{Neck-specific exercise with behavioral approach (NSEB)}

The neck-specific exercises were identical to those in the NSE group (98). But in contrast to the NSE group, the participants performed the training in small steps to ensure success (graded activity) despite some pain, but to avoid increased pain radiating in the arms or a cumulative elevation of pain level throughout the program. The behavioral approach included setting specific activity goals, education in neurophysical and neurobiological processes underlying chronic pain, coping strategies, relaxation and body awareness techniques, and strategies for dealing with neck pain relapse. The NSEB group was also instructed to continue with neck-specific and general exercise outside the physiotherapy clinic after the 12 weeks. 


\section{Prescription of physical activity (PPA)}

The participants had one or two appointments with a physiotherapist, which included a motivational interview session and a physical examination. They got an individualized physical exercise program, which did not include neck-specific exercises. The exercises were performed at non-health care location, for instance at home, or at a gym. 
Table 9. Description of the three interventions

\section{Neck-specific exercise (NSE)}

Week 1 Neck-specific exercise aimed at facilitating the deep neck muscles Basic information on neck muscle function and how to avoid aggravation of pain

Week 2-3 Isometric neck-specific exercise in supine and sitting positions Instruction in good body posture to minimize postural strain Introduction to neck-specific gym exercise

Week 4-12 Continued training in gym and home excercise with gradual progression

Week 12 Information to continue with both general and neck-specific exercise outside the physiotherapy clinic, prescription of physical activity

\section{Neck-specific exercise with behavioral approach (NSEB)}

Week 1-2 Specific activity goal setting, specified for time and designed to be reachable during the 12-week rehabilitation program

Education in processes underlying chronic pain Information about coping strategies and recovering from relapse of pain Neck-specific exercise to facilitate the deep neck muscles Instruction in relaxation exercises and body awareness techniques for postural control

Week 3 Isometric neck-specific exercise in supine and sitting positions Information on the influence of thoughts on behavior

Week 4-5 Introduction to neck-specific gym excercise Specific activity goal exercise and breathing exercise

Week 6-7 Continued training in gym and home exercise with gradual progression Reinforcement of processes in chronic pain.

Week 8-10 Follow-up of specific activity goal exercises, continued neck-specific gym exercises

Week 11-12 Strategies for dealing with relapse of neck pain Follow-up of specific activity goal exercise, continued neck-specific gym exercises Information to continue with both general and neck-specific exercise outside the physiotherapy clinic, prescription of physical activity

\section{Prescription of physical activity group (PPA)}

Week 1 Physical examination and motivational interviewing Instruction in physical exercise program not including neck-specific exercises

Week 2-12 Physical exercises at home or selected location outside of health care system, possibility for one follow-up with the physiotherapist Able to phone the physiotherapist to ask questions during the first 12 weeks 


\section{Statistical analyses}

In study A paper I, the study sample size was based on the primary outcome of the NDI in the randomized controlled trial (99), and 63 participants per group were required for detecting a minimal clinically important NDI outcome of $7 \%$. A total of 216 participants were recruited to account for drop-outs and the analyses were made on an intention-to treat basis. In paper I, the demographic variables were compared using one-way analyses of variance (ANOVA) and Kruskal-Wallis test for non-normally distributed data. Chi-square test was used for binary outcomes. In study B paper II, III and IV the two-tailed unpaired Students t-test was used for parametric demographic variables, Mann Whitney U test for non-parametric data and the chi-square test for binary outcomes. Statistical significance was set at an a level of 0.05 .

\section{Group comparison}

The neck muscle endurance results in paper I were analyzed with linear mixed model conducted with time (3 levels; baseline, three and six months), group ( 3 levels; NSE, NSEB and PPA), and gender (2 levels; men and women) as fixed effects. Ventral or dorsal neck muscle endurance was the dependent variable. Included in the model were participants with baseline data and at least one more measurement (three and/or six months). Statistical p-values were reported for the; overall change over time; differences between groups; differences between gender; interaction between time and group; interaction between time, group and gender. There were significant differences between gender in ventral NME, so posthoc analyses were stratified for gender. All NME measurements were log transformed $\left(\log ^{10}\right)$ because data were strongly positively skewed and variance were significantly different (Levence's test $\mathrm{p}<0.05$ ). Differences between groups in neck pain, patient satisfaction and kinesiofobia (TSK11) were analysed with Kruskal-Wallis test and post-hoc comparison were evaluated with the Mann-Whitney $U$ test. To define within-group differences with respect to time Friedman's test was used, and the findings were further clarified using Wilcoxon signed-rank test. The exercise compliance was dichotomized (compliant, non-compliant) according to attendance (defined as at least $50 \%$ attendance at the recommended intervention sessions) and analyzed using a chi-square test.

In paper II the deformation measurements were skewed and nonparametric tests were applied. The deformation rate measurements were normally distributed and parametric tests were used. To evaluate differences between individuals with WAD and healthy controls in deformation rate a mixed design analysis of variance (ANOVA) with Bonferroni correction was used. The two groups (control and WAD) were the between-subjects variable, the three muscles (SCM, Lcap, and Lco) were the within-subject variables, and the analysis was adjusted for the duration of each arm elevation. The deformation data were positiveskewed and Levene's test showed that the assumptions of variance were 
violated $(\mathrm{p}<0.05)$ and the Friedman ANOVA and the Mann Whitney U test were used. For two group analyses of differences in the deformation between the first and tenth arm elevation the Wilcoxon signed-rank test was used, and the paired samples $t$ test for deformation rates. Effect sizes were calculated for the deformations and deformation rates.

For dorsal neck muscles analyses in paper III a mixed design analysis of variance (ANOVA) with Bonferroni correction was used. The ANOVA was used to evaluate between-subject factor of group (two levels: WAD and controls) and within-group factor of deformation and deformation rate (five levels, one for each muscle). The analyses were adjusted for the duration of each arm elevation and sex. The assumptions of variance were violated (Levene's test $p<0.05$ ) in deformation (first arm elevation) and deformation rate (tenth arm elevation) and the data were $\log ^{10}$ transformed.

\section{Correlation and linear regression of deformation and deformation rate}

In paper II, correlation of deformation among the three ventral neck muscles (SCM, Lcap, Lco) during the first and tenth arm elevations were evaluated with Spearman's rho test and for deformation rate with Pearson's correlation. Linear regression models were used to investigate the relationships of the deformations and the deformation rate among the three muscles (SCM/Lcap, SCM/Lco, Lcap/Lco) for individuals in both groups (control and WAD).

The relationships between pairs of dorsal neck muscles in paper III were analyzed. Adjusted $\mathrm{R}^{2}$ values were reported and the strength of the linear relationship was reported as follows: weak, $0.1-0.3$; moderate, o.31-0.6; strong, > $0.61(100)$.

\section{Outliers}

One outlier (WAD) in the deformation rate and one outlier from each group (WAD/Control) in the deformation were detected (paper II). These three outliers had a skew positive impact on the correlation and linear regression analysis and were excluded. In study III, six outliers were detected in deformation, three in the WAD group (one women and two men) and three in the control group (all men) and seven outliers in deformation rate (one in the WAD group and six controls, all men). Men had much greater variation in deformation and deformation rate with many outliers and only women were further analyzed regarding the linear relationship between muscles and multivariate analyses. Three outliers were detected in paper IV, all of them men (one WAD and two controls) and they were excluded from further analyses. 


\section{Multivariate statistics}

The strength in the multivariate statistics is the possibility to identify underlying patterns in large datasets from complex, highly correlated neck muscle interaction data. Multivariate data analysis was performed in Simca 13.o (MKS Umetrics, Umeå, Sweden) and Evince 2.6 (UmBio AB, Umeå, Sweden) (101). Principal component analysis (PCA) is designed to extract systematic variation in the dataset and was applied to obtain an overview of the data. Projection to latent structures (PLS) can be used to identify pattern in multivariate data sets. To analyze the differences between the WAD and control groups partial least squares discriminant analysis (PLSDA) was used. PLS-DA is a regression extension of PCA, and orthogonal partial least squares discriminant analysis (OPLS-DA) was used in paper III to improve interpretability (101).

\section{Interaction terms}

The data analyzed with the multivariate techniques included a total of 24 variables in paper IV; the total deformation area, elongation and shortening area, and deformation rate from the three ventral neck muscles and a total of 40 variables in paper III; the total deformation area, elongation and shortening area, and deformation rate from five dorsal neck muscles during the first and tenth arm elevations. All possible two-way combinations of interaction terms, including quadratic terms, between these variables were evaluated, resulting in 324 variables in paper IV and 860 variables in paper III. Prior to calculating the interaction between the variables $a$ and $b$, the variables were mean centered and scaled to unit variance. The interaction between variables $a$ and $b$ can be calculated with element-wise multiplication where $\bar{x}_{a}$ and $\bar{x}_{b}$ are the means of the two variables $a$ and $b$ and $s_{a}$ and $s_{b}$ are the standard deviations (Equation 2). The quadratic terms were logarithmically transformed with base 10 prior to further analysis.

$i_{a b}=\frac{a-\bar{x}_{a}}{s_{a}} \frac{b-\bar{x}_{b}}{s_{b}}$

(Equation 2)

The strength of the multivariate models in this study was determined by $\mathrm{R}^{2} \mathbf{X}$, the explained variance in the $\mathbf{X}$-matrix (deformation and deformation rates variables); $\mathrm{R}^{2} \mathbf{Y}$, the explained variance in the $\mathbf{Y}$-matrix (healthy control or individuals with $\mathrm{WAD}$ ); and $\mathrm{Q}^{2} \mathbf{Y}$, the predictive explained variance in $\mathbf{Y}$. The maximum value for each is 1.0 and symbolizes a perfect model. Both groups (control and WAD) were normally distributed. The two groups were checked for equal variances which resulted in a rejected null hypothesis $(\mathrm{p}=0.017)$ and the two-sample t-test assuming unequal variances for differences between the WAD and control groups was used. 


\section{Variable influence of projection (VIP)}

In order to analyze important variables in a complex PLS model the most important variable can be detected using VIP (101). The higher VIP value (cut-off value often 1.0 or higher), the more influence the variable has on the explained $\mathbf{y}$ variable. VIP sorting made it possible to summarize the most important muscle interactions, involved in the difference in muscle interaction between individuals with WAD and healthy controls in paper IV. 


\section{RESULTS}

\section{The effect of three different exercise interventions on neck muscle endurance test, pain intensity, kinesiophobia, exercise compliance and patient satisfaction (Paper I)}

In study A, paper I, the 216 individuals were randomized to three exercise groups, NSE $(n=76)$, NSEB $(n=71)$ and PPA $(n=69)$. The baseline characteristics were similar in the three groups, except that participants in the NSE group were younger and more women were included than in the PPA group (Table 4). At three months, 185 participants (85\%) were tested and $165(77 \%)$ at six months. There were no significant differences in any baseline characteristics or baseline measurement between those who dropped out and those who completed the intervention $(p>0.26)$.

\section{Dorsal Neck Muscle Endurance}

A total of 182 individuals (116 women, 66 men) were included in the linear mixed model (Table 10). There was no significant group*time* gender interaction effect $(F=1.3, p=0.25)$, but a significant group-by-time interaction effect $(\mathrm{F}=4.1, \mathrm{p}=0.003)$. Both the NSE and NSEB groups ( $\mathrm{F}$ $=6.8$ to $5.5, \mathrm{p}<0.05)$ improved in dorsal NME from baseline to six months compared to the PPA group $(\mathrm{F}=0.42 \mathrm{p}=0.66)$. The baseline dorsal NME score for men differed between the three groups at baseline and the differences were close to significant $(\mathrm{p}=0.08)$. When baseline dorsal NME values was included as covariate in the linear analyses, the results were unchanged (Peterson, unpublished results 2016).

\section{Ventral Neck Muscle Endurance}

For ventral NME, 185 individuals (118 women, 67 men) were included in the linear mixed model (Table 10). There were no significant interaction effects between group*time*gender $(F=1.4, p=0.23)$ or group*time interaction $(\mathrm{F}=1.8, \mathrm{p}=0.13)$, but a significant group by gender interaction effect $(\mathrm{F}=3.2, \mathrm{p}=0.04)$. When stratified for gender, there were significant differences between groups for men at six months. Men in the NSE and NSEB groups showed higher ventral NME compared to men in the PPA group $(\mathrm{F}=4.2, \mathrm{p}=0.02)$.

\section{Neck pain intensity}

Pain intensity before and after the NME test was decreased for the NSE group at three months $(\mathrm{p}<0.05)$ compared to the PPA group. Both the 
NSE and NSEB groups showed decreased pain after the NME test at six months' follow-up compared to the PPA group $(\mathrm{p}=0.04)($ Table 11).

Table 10. Neck muscle endurance for the three groups; NSE, NSEB and PPA at baseline, three- and six months' follow-ups.

\begin{tabular}{|c|c|c|c|c|c|c|c|c|c|}
\hline \multirow[b]{2}{*}{ Variable } & \multirow[b]{2}{*}{ Period } & \multicolumn{3}{|c|}{ Group, geometric mean, 95\% confidence interval (95\% CI) } & \multicolumn{5}{|c|}{$P$ values* } \\
\hline & & NSE & NSEB & PPA & $P_{\mathrm{t}}$ & $P_{\mathrm{g}}$ & $P_{\mathrm{s}}$ & $P_{\mathrm{t}^{* \mathrm{~g}}}$ & $P_{\mathrm{t}^{*} \mathrm{~g}^{* \mathrm{~s}}}$ \\
\hline \multicolumn{10}{|l|}{ Ventral NME $^{\dagger}$} \\
\hline \multirow[t]{3}{*}{ Whole group } & Baseline & $19(15-26)$ & $25(19-32)$ & $22(16-30)$ & & & & & \\
\hline & 3 months & $21(18-28)$ & $29(23-39)$ & $25(19-35)$ & & & & & \\
\hline & 6 months & $28(22-38)$ & $34(26-45)$ & $23(17-32)$ & $<.01$ & .07 & $<.01$ & .13 & $.23^{\ddagger}$ \\
\hline \multirow[t]{3}{*}{ Women } & Baseline & $15(12-22)$ & $18(14-24)$ & $20(13-34)$ & & & & & \\
\hline & 3 months & $19(15-25)$ & $21(17-29)$ & $21(14-34)$ & & & & & \\
\hline & 6 months & $23(18-31)$ & $24(17-34)$ & $24(17-35)$ & & & & & \\
\hline \multirow[t]{3}{*}{ Men } & Baseline & $36(20-66)$ & $41(27-62)$ & $36(21-66)$ & & & & & \\
\hline & 3 months & $37(21-66)$ & $52(34-81)$ & $29(19-46)$ & & & & & \\
\hline & 6 months & $54(30-105)$ & $59(42-87)$ & $22(14-39)$ & & $<.02 \S$ & & & \\
\hline \multicolumn{10}{|l|}{ Dorsal NME ${ }^{\dagger}$} \\
\hline \multirow[t]{3}{*}{ Whole group } & Baseline & $41(29-62)$ & $44(32-63)$ & $42(28-65)$ & & & & & \\
\hline & 3 months & $57(42-79)$ & $64(46-93)$ & $35(23-56)$ & & & & & \\
\hline & 6 months & $86(62-123)$ & $84(60-120)$ & $42(28-66)$ & $<.01$ & .06 & .11 & $<.01$ & $.25^{\ddagger}$ \\
\hline \multirow[t]{3}{*}{ Women } & Baseline & $37(23-59)$ & $34(23-154)$ & $49(28-91)$ & & & & & \\
\hline & 3 months & $53(36-79)$ & $49(32-76)$ & $43(24-78)$ & & & & & \\
\hline & 6 months & $75(50-115)$ & $65(42-102)$ & $55(32-98)$ & & & & $<.029$ & \\
\hline \multirow[t]{3}{*}{ Men } & Baseline & $68(36-132)$ & $67(40-120)$ & $36(21-68)$ & & & & & \\
\hline & 3 months & $71(38-135)$ & $101(56-186)$ & $31(17-60)$ & & & & & \\
\hline & 6 months & $144(74-282)$ & $128(72-234)$ & $35(19-68)$ & & & & $<.029$ & \\
\hline
\end{tabular}

NME; neck muscle endurance, NSE; neck-specific exercise, NSEB; neck-specific exercise with behavioral approach, PPA; prescription of physical activity. Values are presented as geometric mean (back transformed $\log ^{10}$ ) and $95 \%$ confidence interval (CI).

* $\mathrm{P}$ values reported for the; overall change over time $\mathrm{P}_{\mathrm{t}}$; differences between group $\mathrm{P}_{\mathrm{g}}$; differences between gender $\mathrm{P}_{\mathrm{s}}$; interaction between group and time $\mathrm{P}_{t^{*} \text { g; }}$ interaction between time, group and gender $\mathrm{P}_{t^{*} \mathrm{~g}^{*} \mathrm{~s}}$

†Neck muscle endurance in seconds for the groups, geometric mean $(95 \% \mathrm{CI})$ \# P values for the main linear mixed model analyses, group*time ${ }^{*}$ gender interaction effect (group; NSE, NSEB and PPA, time; baseline, three and six months, sex; women and men). The p-values\$" show the significant differences between groups from the linear mixed model.

$\S$ Significant differences between groups in ventral NME at six months. I Significant differences between groups in time ${ }^{*}$ group interaction effect in dorsal NME. 
Table 11. Pain intensity measured immediately before and after the NME test and the Tampa Scale of Kinesiophobia measurements at baseline and six months for the three intervention groups, NSE, NSEB and PPA.

\begin{tabular}{|c|c|c|c|c|c|c|c|c|c|c|c|c|c|c|}
\hline \multirow{2}{*}{ Variables } & \multicolumn{8}{|c|}{ Group median, inter-quartile range (IQR) and range [ ] } & \multicolumn{6}{|c|}{ Treatment effects and $P$ values $\dagger$} \\
\hline & & $\mathbf{n}$ & NSE & $\mathbf{n}$ & NSEB & $\mathbf{n}$ & PPA & $\mathbf{P}$ & NSE-PPA & $\boldsymbol{P}$ & NSEB-PPA & $\boldsymbol{P}$ & NSE-NSEB & $\boldsymbol{P}$ \\
\hline \multirow[t]{3}{*}{ VAS before $\mathrm{NME}^{\neq}$} & Baseline & 76 & $26(14-53)[0-95]$ & 71 & $30(12-53)[0-89]$ & 69 & $32(23-53)[0-94]$ & 0.41 & & & & & & \\
\hline & 3 months & 62 & $17(2-39)[0-97]$ & 66 & $23(4-45)[0-85]$ & 55 & $30(10-57)[0-100]$ & 0.05 & -5.0 & .02 & -3.0 & .16 & -2.0 & .27 \\
\hline & 6 months & 55 & $11(3-11)[0-92]^{*}$ & 59 & $21(5-39)[0-85]^{*}$ & 51 & $24(6-62)[0-91]$ & 0.09 & -7.0 & & -2.0 & & -5.0 & \\
\hline \multirow[t]{3}{*}{ VAS after $\mathrm{NME}^{\S}$} & Baseline & 76 & $33(24-58)[0-97]$ & 71 & $43(17-60)[0-95]$ & 69 & $42(26-63)[4-97]$ & 0.44 & & & & & & \\
\hline & 3 months & 62 & $24(5-48)[0-95]$ & 66 & $32(9-55)[0-98]$ & 55 & $41(21-64)[0-100]$ & 0.03 & -11.0 & .01 & -5.0 & .09 & -6.0 & .39 \\
\hline & 6 months & 52 & $25(6-44)[0-97]^{*}$ & 56 & $27(9-54)[0-77]^{*}$ & 51 & $40(16-48)[0-87]$ & 0.04 & $-7 \cdot 5$ & .04 & $-5 \cdot 5$ & .05 & -2.0 & .94 \\
\hline \multirow[t]{2}{*}{ TSK - $11^{\pi}$} & Baseline & 76 & $22(18-27)[12-37]$ & 71 & $21(17-26)[12-41]$ & 67 & $21(16-28)[12-36]$ & 0.95 & & & & & & \\
\hline & 6 months & 54 & $19(15-23)[11-36]$ & 57 & $19(15-25)[11-40]$ & 52 & $21(15-26)[11-43]$ & 0.47 & -2.5 & & -2.0 & & -0.5 & \\
\hline \multirow[t]{2}{*}{ TSK-AA $^{* *}$} & Baseline & 76 & $12(10-15)[6-22]$ & 71 & $12(9-15)[6-23]$ & 67 & $12(9-15)[6-21]$ & 0.76 & & & & & & \\
\hline & 6 months & 54 & $11(8-14)[5-21]^{*}$ & 57 & $10(8-13)[6-22]^{*}$ & 52 & $12(8-15)[6-23]$ & 0.24 & -2.0 & & -1.0 & & -1.0 & \\
\hline \multirow[t]{2}{*}{$\mathrm{TSK}_{-S F^{\dagger \dagger}}$} & Baseline & 76 & $9(7-12)[5-17]$ & 71 & $10(7-13)[5-19]$ & 67 & $10(7-12)[5-19]$ & 0.68 & & & & & & \\
\hline & 6 months & 54 & $8(6-10)[5-16]^{*}$ & 57 & $8.5(6-13)[5-18]$ & 52 & $9(6-11)[5-20]$ & 0.27 & -0.5 & & 0.5 & & -1.0 & \\
\hline
\end{tabular}

Values are presented as median, inter-quartile range (IQR) and [range].

* Significant with-in group differences with respect to time $\mathrm{p}<0.05$

+ Treatments effects at follow-up time (three and six months). If significant between-group differences in the Kruskal-Wallis test are evident, the p-values for post-hoc comparisons are shown. For outcomes; a negative effect favors the first group (the underlined group (NSE-PPA, NSEB-PPA, NSE-NSEB).

$\$$ \$VAS o to 100 , higher scores indicating higher pain intensity, median, inter-quartile range (IQR) for the groups. Pain intensity measured immediately before $¥$ and after $\$$ the NME tests.

"TSK-11; total score short form, 11 items, from 11 to 44, higher scores indicate higher fear of movement and (re)injury, TSK-AA**

subscale activity avoidance, 5 items, from 5 to 20, TSK-SF†t; subscale somatic focus, 6 items, from 6 to 24.

NME; neck muscle endurance, NSE; neck specific exercise, NSEB; neck specific exercise with behavioral approach, PPA;

prescription of physical activity, TSK; Tampa Scale of Kinesiophobia 


\section{Kinesiophobia}

There was no difference between groups in TSK $(P>0.24)$. From baseline to the six-month follow-up, the NSE group showed significant improvements in total TSK-11 score, and on the subscales for activity avoidance and somatic focus $(P<0.01)$. The NSEB group only showed improvement on the activity avoidance subscale $(P<0.03)$. For both the NSE and NSEB groups, these improvements were small (1 to 3 points). The PPA group revealed no significant improvements over time $(P>0.19)$.

\section{Patient satisfaction and exercise compliance}

Sixty-six percent in the NSE group and $62 \%$ in the NSEB group reported that they were very satisfied with their treatment (score of 6 and 7 on the Likert scale) at three months' follow-up. There were significantly lower proportions of satisfied participants in the PPA group (7\%; $<<0.01)$. These differences remained at six months' follow-up (NSE; 55\%, NSEB; $67 \%$, PPA; $19 \%), \mathrm{p}<0.01)$. Compliance to exercise did not significantly differ between groups. At three months the proportions of compliant participant were $73 \%($ NSE $n=43), 74 \%($ NSEB $n=44)$ and $50 \%($ PPA $n=19),(p=$ 0.07). At six months all three groups had 50 - $53 \%$ compliance ( $p>0.90)$.

\section{Mechanical neck muscle function, deformation and deformation rate (Papers II, III and IV)}

\section{Comparisons between the WAD and control group in deformation}

For ventral neck muscles (paper II), the only significantly different finding when each muscle was analyzed separately, was that the SCM was less elongated in the $\mathrm{WAD}$ group compared to the control group during the first arm elevation (WAD; 1.2 , controls; $2.6, \mathrm{p}=0.02$ ). There were no significant group by deformation interaction effect ( $\mathrm{F}=0.2$ to $2.0, p>0.10$ ) or differences between groups $(\mathrm{F}=0.02$ to $0.55, p>0.46)$ in dorsal neck muscles deformation (paper III), but a significant group by gender interaction effect for both the first $(\mathrm{F}=3.9, p<0.01)$ and tenth $(\mathrm{F}=2.7, p$ $<0.04$ ) arm elevations. Men in the control group showed greater deformation in all muscles ( $\mathrm{F}=11.3$ to $35.5, p<0.001)$ compared to women, but this difference was not seen in the WAD group $(\mathrm{F}=1.3$ to 0.39 , $p>0.25)$. 


\section{Linear relationship between pairs of muscles in deformation}

There was a stronger positive linear relationship between the muscle pairs SCM/Lcap and SCM/Lco, in ventral neck muscles for healthy controls compared to the WAD group. The linear relationship increased from the first (controls; $\mathrm{R}^{2}=0.25$ to 0.35 , WAD; $\mathrm{R}^{2}=0.00$ to 0.03 ); to the tenth arm elevations (controls; $\mathrm{R}^{2}=0.43$ to 0.53 , WAD; $\mathrm{R}^{2}=0.02$ to 0.08 ); (paper II). Only between Lcap/Lco during the tenth arm elevation was the linear relationship stronger in individuals with WAD compared to controls $\left(\mathrm{R}^{2}=\right.$ 0.57 vs. 0.51), (Fig. 9 a-f).

For dorsal neck muscles (paper III), there were stronger positive linear relationships between the two deepest neck muscles (semispinalis cervices and multifidus) for women in the control group during the first $\left(\mathrm{R}^{2}=0.61\right.$ vs. $\left.\mathrm{R}^{2}=0.15\right)$ and tenth arm elevations $\left(\mathrm{R}^{2}=0.32 \mathrm{vs} . \mathrm{R}^{2}=0.01\right)$ compared to women in the WAD group (Table 11). Women in the WAD group exhibited moderate relationships between more pairs of muscles during the first arm elevation compared to controls $\left(\mathrm{R}^{2}=0.32\right.$ to 0.47$)$. 


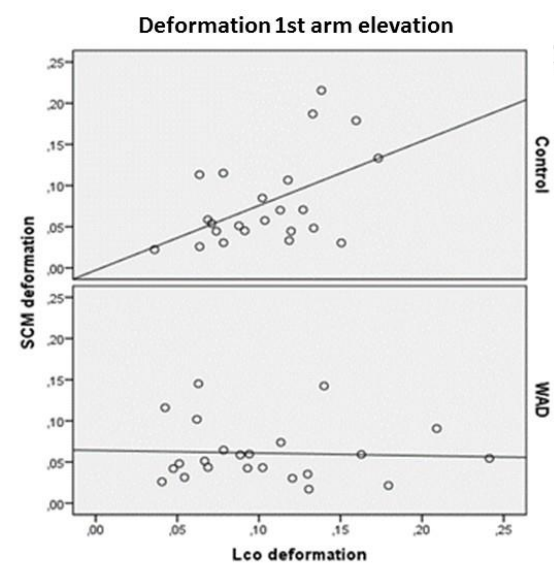

a)
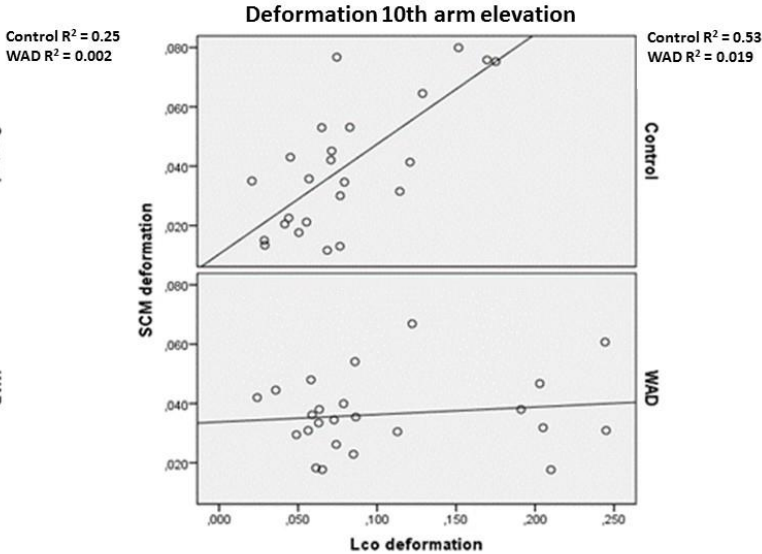

b)

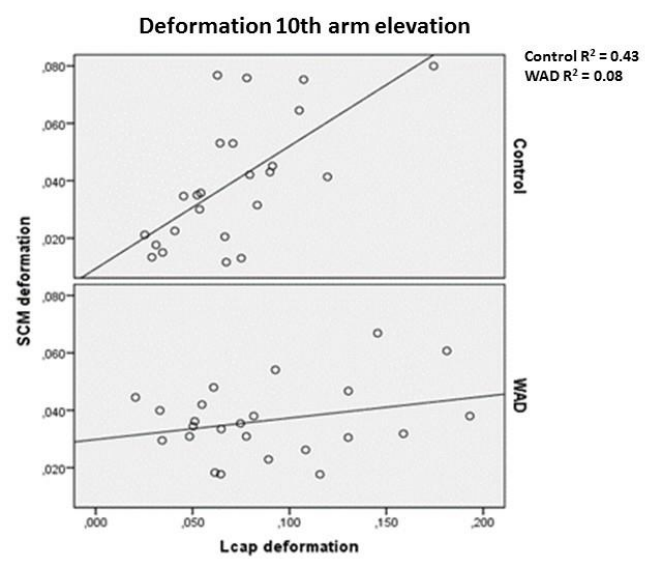

d)
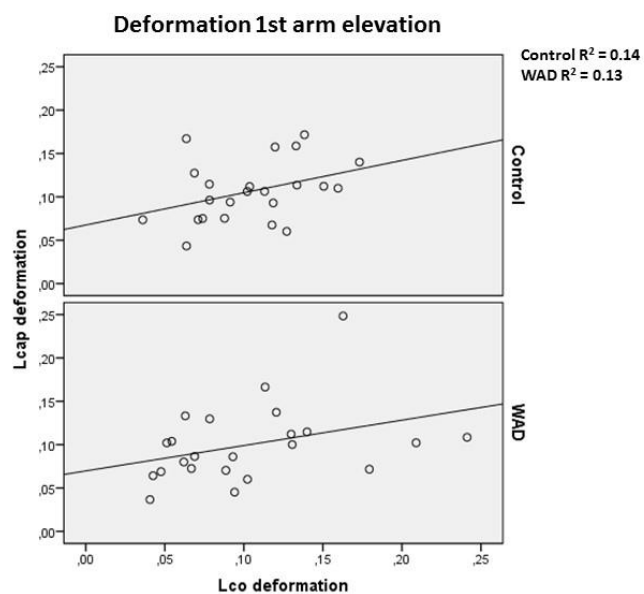

e)

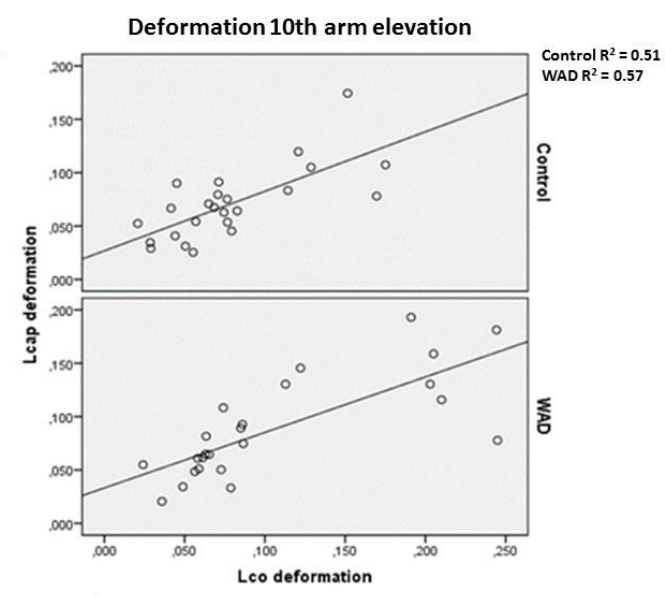

f) 
Figure 9 a-f. Linear relationships between total deformation areas of ventral neck muscle pairs are shown for the first and tenth arm elevations. (a,b) Relationships between sternocleidomastoid (SCM) and longus colli (Lco) muscles: (top panels) Controls showed weak linear relationship during the first arm elevation $\left(\mathrm{R}^{2}=0.25\right)$ and moderate linear relationship during the tenth arm elevation $\left(\mathrm{R}^{2}=0.53\right)$; (bottom panels) individuals with WAD showed no linear relationships $\left(\mathrm{R}^{2}<0.02\right)$.

(c,d) Relationships between SCM and longus capitis (Lcap) muscles: (top panels) Controls showed higher linear relationships (moderate) during the tenth arm elevations $\left(\mathrm{R}^{2}=0.43\right)$ compared to the first $\left(\mathrm{R}^{2}=0.35\right)$; (bottom panels) individuals with WAD showed no linear relationships $\left(\mathrm{R}^{2}=0.08\right.$ to 0.03$)$.

(e,f) Relationships between Lcap and Lco: Both groups showed weak linear relationships during the first arm elevations and moderate linear relationships during the tenth arm elevations; (top panels) controls $\left(\mathrm{R}^{2}=0.14\right.$ to 0.51$)$; (bottom panels $)$ individuals with $\mathrm{WAD}\left(\mathrm{R}^{2}=0.13\right.$ to 0.57$)$.

\section{Comparison between the WAD and control groups in deformation rate}

In paper II (ventral neck muscles) a significant main effect between groups was observed in the deformation rate during the tenth arm elevation, $\mathrm{F}$ $(1,48)=5.3(\mathrm{p}<0.01)$, where individuals with WAD had higher deformation rates in the longus colli muscle compared to controls $\mathrm{F}(1,48)$ $=4.6$. No significant between-group effect was observed during the first arm elevation, $F(1,46)=0.81(\mathrm{p}>0.40)$.

For dorsal neck muscles (paper III), there was a significant group by deformation rate interaction effect for the first $(\mathrm{F}=3.3, p<.04)$ and tenth ( $\mathrm{F}=5.9, p<0.01)$ arm elevation and a significant main effect between gender $(F=25.0$ to $19.1, p<0.001)$. The WAD group had higher deformation rates in the multifidus muscle during the first and tenth (only women) arm elevations compared to the control group. Men had a higher deformation rate in all muscles compared to women in both the WAD $(\mathrm{F}=$ 5.6 to $7.4, p<0.03$ ) and control groups ( $\mathrm{F}=18.9$ to $19.3, p<0.001)$.

\section{Linear relationship between pairs of muscles in deformation rate}

For ventral neck muscles (paper II), the positive linear relationships were strong for $\mathrm{SCM} / \mathrm{Lco}\left(\mathrm{R}^{2}=0.70\right)$ and moderate for Lcap/Lco $\left(\mathrm{R}^{2}=0.53\right)$ in the control group during the first and tenth arm elevations. The relationship between SCM/Lcap increased from the first to tenth arm elevations $\left(\mathrm{R}^{2}=0.43\right.$ to 0.71$)$. In the WAD group, the linear relationship decreased from the first to tenth arm elevations for all three muscle pairs $\left(\mathrm{R}^{2}=0.44\right.$ to 0.07$)$ (Fig. $\left.10 \mathrm{a}-\mathrm{f}\right)$. 
For dorsal neck muscles (paper III), there were stronger positive relationships between the muscles during both the first and tenth arm elevations for women in the control group $\left(\mathrm{R}^{2}=0.24\right.$ to 0.82$)$ compared to the WAD group $\left(\mathrm{R}^{2}=0.05\right.$ to 0.74$)$, except for trapezius/semispinalis cervicis and semispinalis capitis/semispinalis cervicis during the tenth arm elevation (Table 12).

For women in the WAD group, the deep multifidus muscle had a weaker relationship with the other four investigated muscles than in the control group during both the first $\left(\mathrm{R}^{2}=0.05\right.$ to $0.41 \mathrm{vs}$. 0.24 to 0.56$)$ and tenth arm elevations $\left(\mathrm{R}^{2}=0.07\right.$ to 0.64 vs. 0.49 to 0.68 ) (Fig. $\left.11 \mathrm{a}-\mathrm{d}\right)$. 


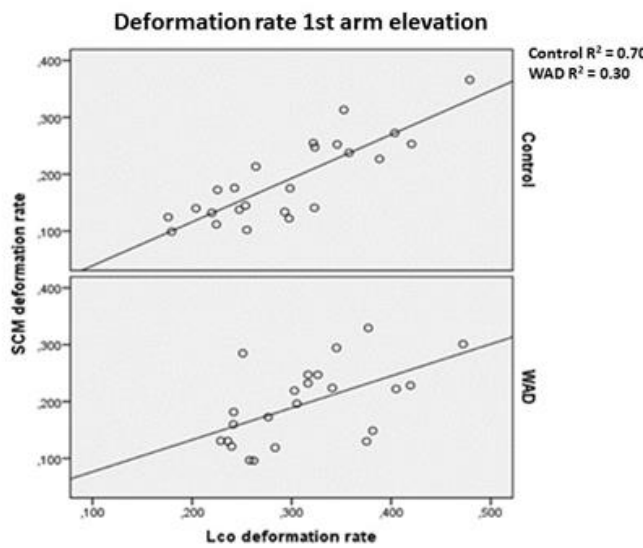

a)

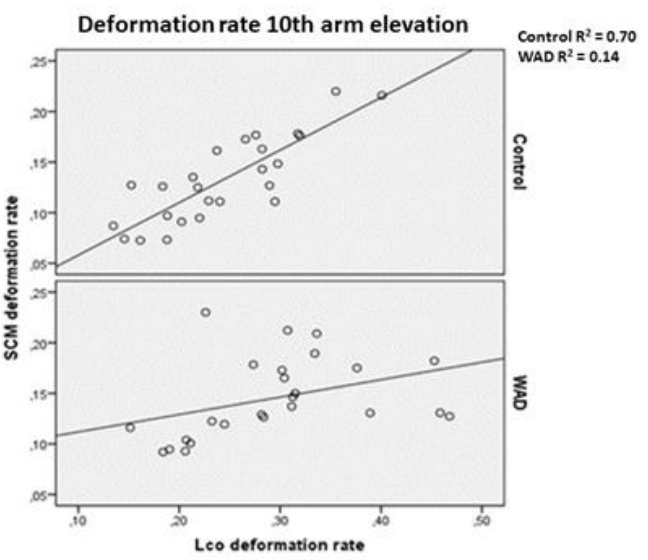

b)

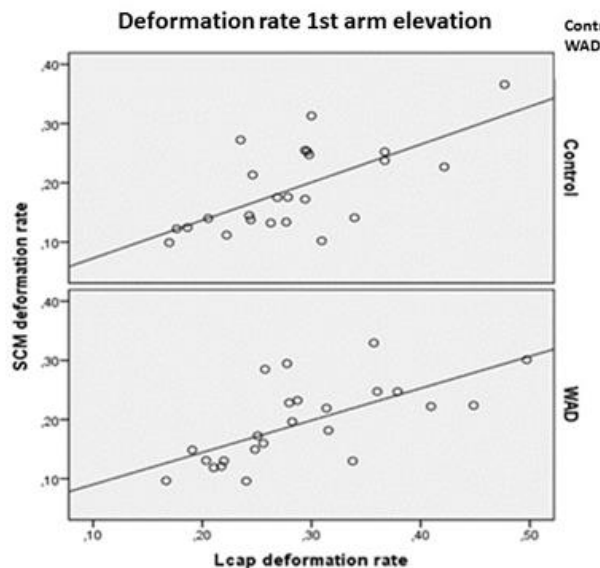

c)
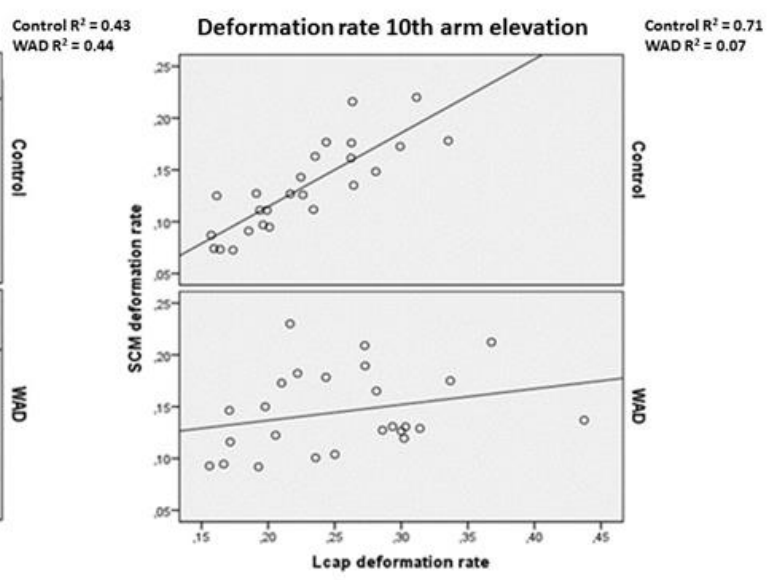

d)

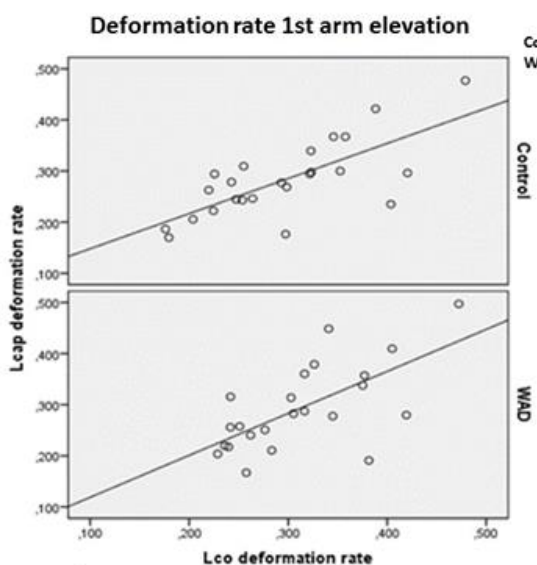

e)

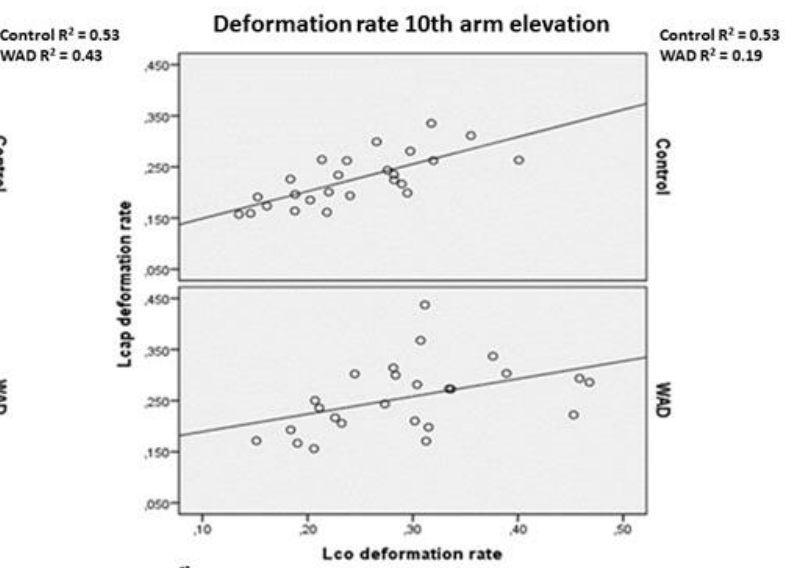

f) 
Figure 10 a-f. Linear relationships between deformation rates of ventral neck muscle pairs for the first and tenth arm elevations.

(a,b) Relationships between sternocleidomastoid (SCM) and longus colli (Lco) muscles: (Top panels) Controls had a strong linear relationship during both the 1st and the 10th arm elevations $\left(\mathrm{R}^{2}=0.70\right)$; (bottom panels) a weak linear relationships during the tenth arm elevations $\left(\mathrm{R}^{2}=0.14\right)$ compared to the first (moderate; $\mathrm{R}^{2}=0.30$ ) was seen in the WAD group.

(c,d) Relationships between SCM and Longus capitis (Lcap) muscles: (Top panels) Controls showed a moderate linear relationship during the first arm elevations (moderate; $\mathrm{R}^{2}=0.43$ ); compared to the strong relationship at the tenth $\left(\mathrm{R}^{2}=0.71\right)$ (bottom panels) individuals with WAD showed a weak linear relationship during the tenth arm elevations $\left(\mathrm{R}^{2}=0.07\right)$ compared to the first (moderate; $\mathrm{R}^{2}=0.44$ ).

(e,f) Relationships between Lcap and Lco muscles: (Top panels) controls showed similar linear relationships during the first and tenth arm elevations (moderate; $\mathrm{R}^{2}=0.53$ ); (bottom panels) individuals with WAD showed a moderate linear relationship during the first arm elevations $\left(\mathrm{R}^{2}=0.43\right)$, decreased to weak at the tenth arm elevations $\left(\mathrm{R}^{2}=0.19\right)$. 
Table 11. Linear relationships in deformation between dorsal neck muscle pairs for women.

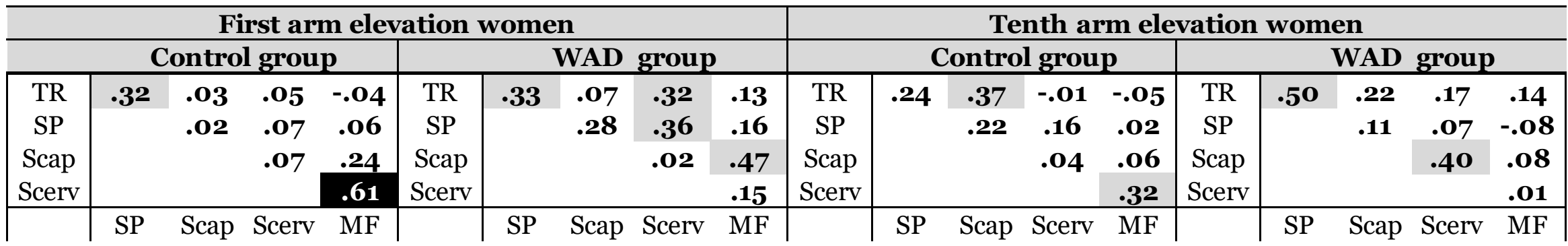

Data are adjusted $\mathrm{R}^{2}$ values. Grey shading indicates a moderate relationship $\left(\mathrm{R}^{2}=0.30-0.60 ; p<0.02\right)$ and black shading a strong relationship $\left(\mathrm{R}^{2}=0.61 ; p<0.001\right)$ between muscle pairs. Abbreviations: TR, trapezius; SP, splenius capitis; Scap, semispinalis capitis; Scerv, semispinalis cervicis; MF, multifidus/rotatores.

Table 12. Linear relationships in deformation rate between dorsal neck muscle pairs for women.

\begin{tabular}{|c|c|c|c|c|c|c|c|c|c|c|c|c|c|c|c|c|c|c|c|}
\hline & \multicolumn{9}{|c|}{ First arm elevation women } & \multicolumn{10}{|c|}{ Tenth arm elevation women } \\
\hline \multicolumn{5}{|c|}{ Control group } & \multicolumn{5}{|c|}{ WAD group } & \multicolumn{5}{|c|}{ Control group } & \multicolumn{5}{|c|}{ WAD group } \\
\hline TR & .76 & .73 & .28 & .24 & TR & .61 & .28 & .24 & .07 & TR & .71 & .61 & .24 & .49 & TR & .63 & .21 & $\cdot \mathbf{3 1}$ & .11 \\
\hline SP & & .82 & .55 & .33 & SP & & .52 & .37 & .05 & SP & & .66 & .64 & .68 & SP & & .44 & .45 & .07 \\
\hline Scap & & & .57 & .38 & Scap & & & .33 & .17 & Scap & & & .49 & .58 & Scap & & & .74 & .43 \\
\hline Scerv & & & & .56 & Scerv & & & & .41 & Scerv & & & & .65 & Scerv & & & & .64 \\
\hline & $\mathrm{SP}$ & Scap & Scerv & $\mathrm{MF}$ & & SP & Scap & Scer & $\mathrm{MF}$ & & SP & Scap & Scert & MF & & $\mathrm{SP}$ & Scap & Scerv & MF \\
\hline
\end{tabular}

Data are adjusted $\mathrm{R}^{2}$ values. Grey shading indicates a moderate relationship $\left(\mathrm{R}^{2}=0.30-0.60 ; p<0.02\right)$ and black shading a strong relationship $\left(\mathrm{R}^{2}=0.61-0.82 ; p<0.001\right)$ between muscle pairs. Abbreviations: TR, trapezius; SP, splenius capitis; Scap, semispinalis capitis; Scerv, semispinalis cervicis; MF, multifidus/rotatores 

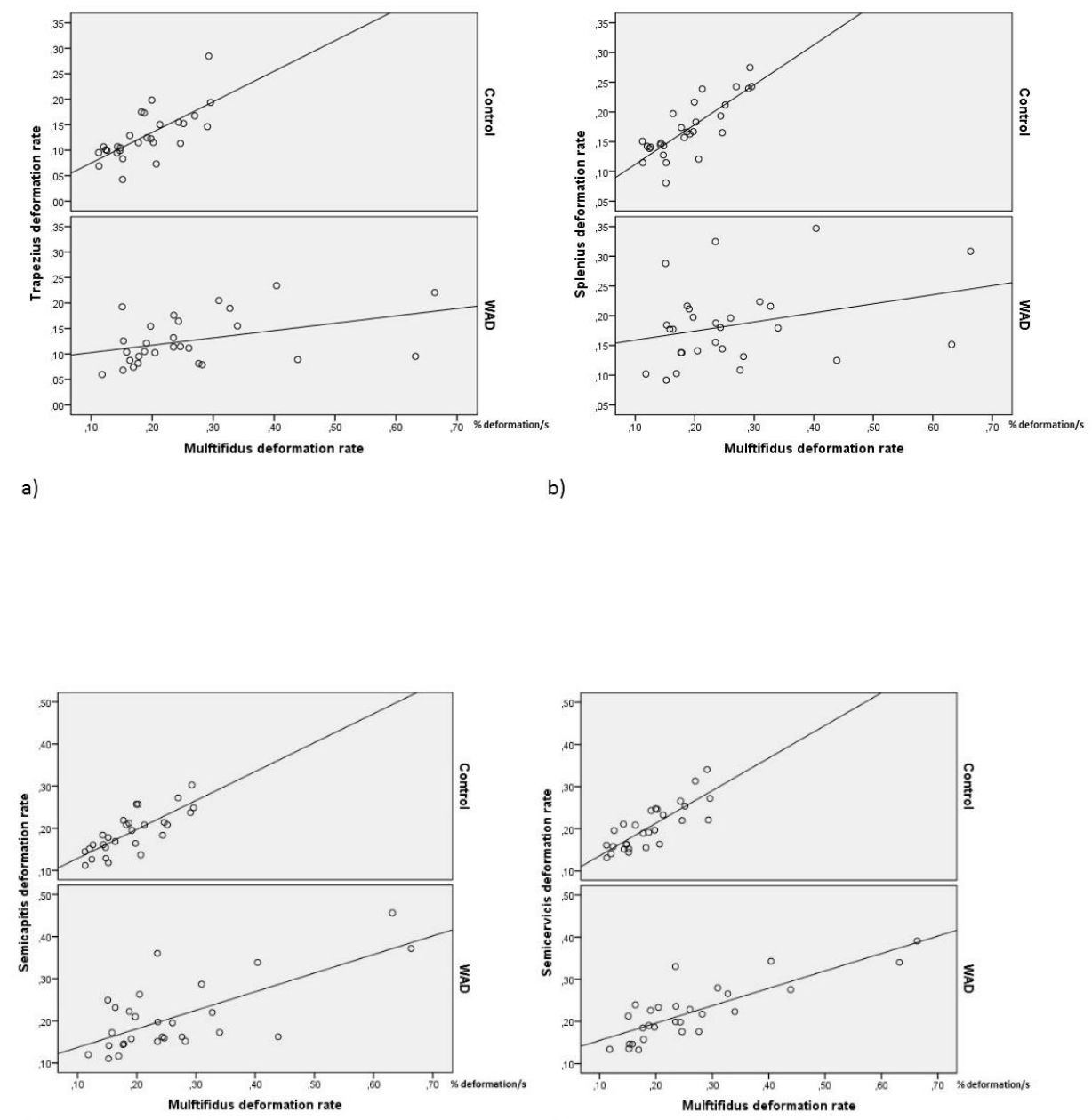

c)

d)

Figure 11 a-d. Linear relationships between the deformation rates of muscle pairs in women during the tenth arm elevation.

a) Linear relationship between the trapezius and multifidus (MF) muscles; (top panels); Controls showed a moderate relationship $\left(\mathrm{R}^{2}=0.49\right)$, compared to a weak relationship in individuals with $\mathrm{WAD}\left(\mathrm{R}^{2}=0.11\right)$ (bottom panel).

b) Linear relationship between the splenius and MF muscles; (top panel) controls exhibited a strong relationship between the muscles $\left(\mathrm{R}^{2}=0.68\right)$ compared to a weak relationship in individuals with WAD $\left(\mathrm{R}^{2}=0.07\right)$ (bottom panel).

c) Linear relationship between the semispinalis capitis and MF muscles; controls (top panel) and individuals with WAD (bottom panel) exhibited a moderate relationship between the muscles (controls, $\mathrm{R}^{2}=0.58$; $\mathrm{WAD}, \mathrm{R}^{2}=$ $0.42)$.

d) Linear relationship between the semispinalis cervicis and MF muscles; Controls (top panel) and individuals with WAD (bottom panel) exhibited a strong relationship between the semispinalis cervicis and MF muscles (controls, $\left.\mathrm{R}^{2}=0.65 ; \mathrm{WAD}, \mathrm{R}^{2}=0.64\right)$. 


\section{Neck muscle interactions in individuals with persistent WAD and healthy controls}

Interaction terms were created for every possible combination of two variables in deformation and deformation rate for the five dorsal neck muscles (paper III) and the three ventral neck muscles (paper IV). These can be divided into three different types; 1 ) interactions in the first arm elevation, 2) interactions in the tenth arm elevation, 3) interactions between the first and tenth arm elevations. The third type is not an actual muscle interaction, instead it can be viewed as a relation between the first and tenth arm elevation.

\section{Principal component analysis (PCA) of interactions between muscles}

In paper III, PCA was used to compress the 40 variables (deformation and deformation rate in five muscles during the first and tenth arm elevation) into a model with four components $\left(\mathrm{R}^{2} \mathrm{X}=0.58\right)$. No differences were seen between the WAD and control groups but differences between men and women (Fig. 12). PCA modelling of the data set regarding interaction terms of the total 860 variables, revealed that men exhibited a much larger variation with many severe outliers.

The total 324 variables (paper IV) were investigated in a PCA model with five principal components $\left(\mathrm{R}^{2} \mathrm{X}=0.61\right)$ and the score plot for the first two components explained $24.4 \%$ and $9.9 \%$ of the variation in deformation and deformation rate (Fig. 13a). Three serious outliers were detected (all of them men) and they were excluded from further analyses. The PCA model with the outlier removed showed that individuals with WAD were positioned to the right to a higher degree, which indicated a difference between the WAD and control groups (Fig. 13b). 


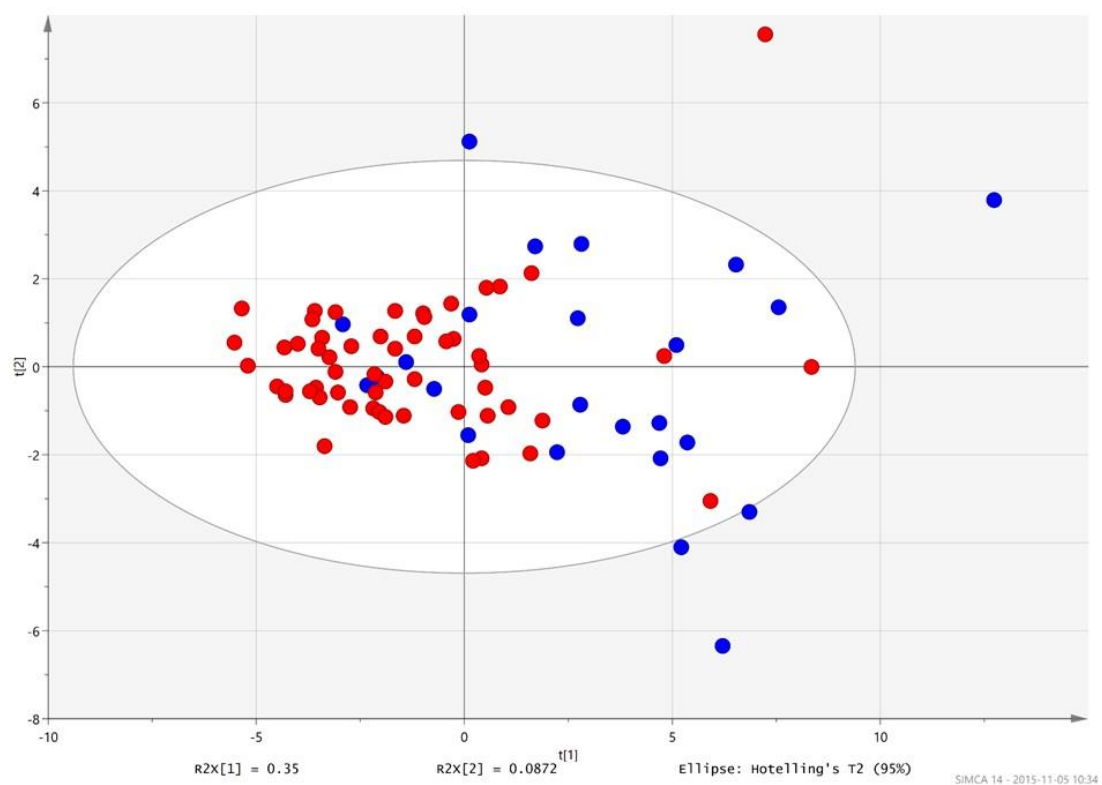

Figure 12. PCA score plot for the first two components created for the 40 deformation and deformation rate variables (paper III). Men (blue dots) tend to be situated more to the right, which indicates differences between men and women (red dots). Men also had a more heterogeneous spread and more outliers than women.

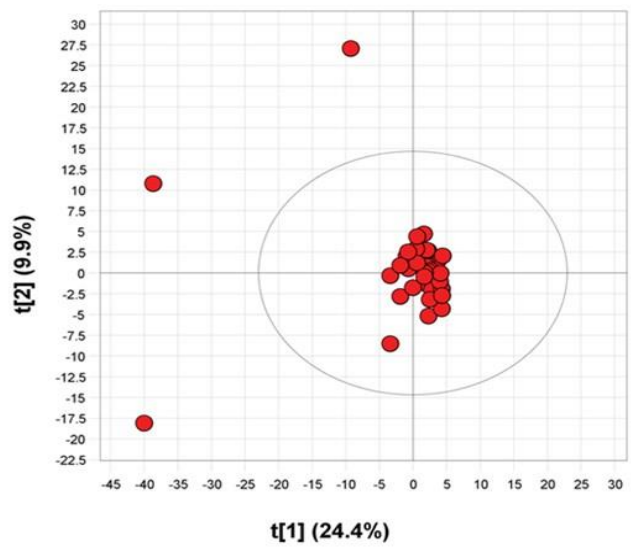

a)

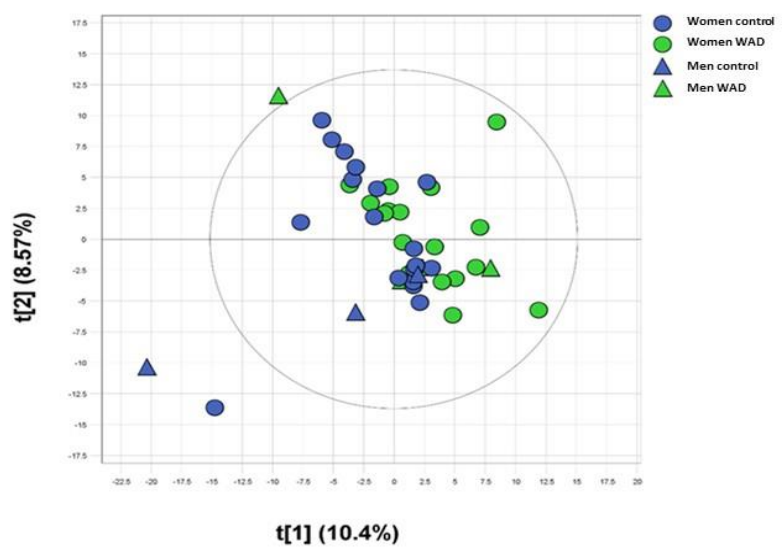

b)

Figure 13 a-b. The PCA analysis including all 324 variables of deformation and deformation rate in the three ventral neck muscles (paper IV).

a) The first two components explained $24.4 \%$ and $9.9 \%$ respectively and detected three serious outliers (one WAD and two healthy controls) and one moderate outlier, all men.

b) The score plot with the three severe outliers removed, showed a more homogenous sample, even if there are some moderate outliers. A small shift to the right in the first component was seen for individuals with WAD (green dots) compared to healthy controls (blue dots) indicating a differences between the groups. 


\section{Differences between the WAD and control groups using} partial least squares discriminant analysis (PLS-DA) and orthogonal partial least squares discriminant analysis (OPLSDA)

In paper III, only women were included in the OPLS-DA modelling because the men had much larger variation with many severe outliers, detected in the PCA analyses. The best model included deformation rate from the first and tenth arm elevations with an $\mathrm{R}^{2} \mathrm{Y}$ of 0.47 and $\mathrm{Q}^{2} \mathrm{Y}$ of 0.16 using one predictive and three orthogonal components. The deformation rate in multifidus for the first and tenth arm elevations separated the WAD and control groups (Fig. 14).

\section{Deformation rate}

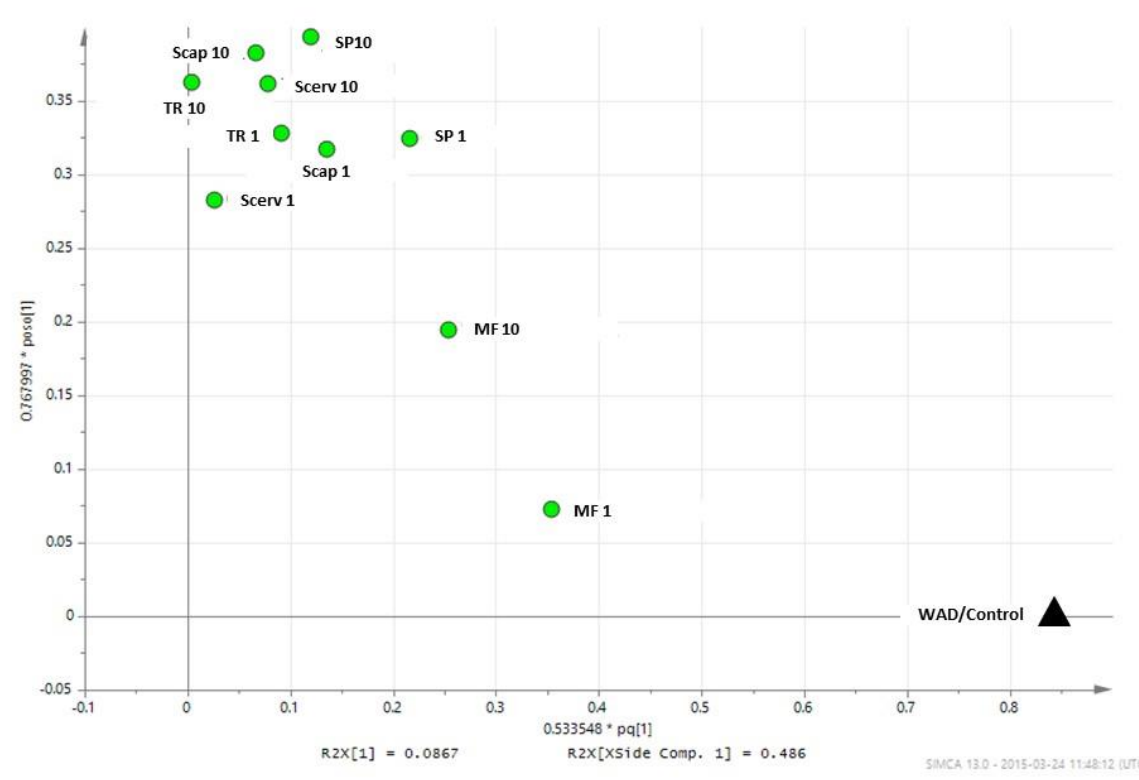

Figure 14. Loading plot for the OPLS-DA model of dorsal neck muscles. The loading plot shows which variables separate individuals with WAD from controls. The deformation rate of the multidfidus muscle at the first and tenth arm elevations were positioned closest to $\mathrm{Y}$ (WAD/control, triangle). The plot shows the loading vectors of the model; the correlated (important variable) loading is on the $\mathrm{x}$-axis, and the orthogonal loading is on the y-axis. There is one loading value for each variable included in the model. Loading values with higher values on the $\mathrm{x}$-axis are more important than values close to zero.

Abbreviations: TR, trapezius; SP, splenius capitis; Scap, semispinalis capitis; Scerv, semispinalis cervicis; MF, multifidus/rotatores ; 1 , the first arm elevation; 10 , the tenth arm elevation.

In ventral neck muscles (paper IV) the PLS-DA model including all 324 variables revealed differences between the WAD and control groups $\left(\mathrm{R}^{2} \mathbf{Y}\right.$ $\left.=0.50, \mathrm{Q}^{2} \mathbf{Y}=0.21\right)$. Using a discriminant cut-off of 0.5 , thirty-one $(72 \%)$ of the individuals were correctly classified as WAD or control. A total of 12 individuals were wrongly classified, seven healthy controls being classified 
as WAD and five individuals with WAD were classified as healthy controls. All 324 variables were ranked according to their variable importance (variable influence on projection [VIP]). The effective cut-off value was 0.99 , which corresponded to the $80^{\text {th }}$ variable. Accordingly, 80 variables exhibiting the highest VIP values were selected for further analysis. A twocomponent PLS model $\left(\mathrm{R}^{2} \mathrm{Y}=0.72, \mathrm{Q}^{2} \mathrm{Y}=0.59\right)$ was calculated with high prediction efficiency but the validation procedure showed a similar effect to the full model with 324 variables.

The PLS weight plot explored the characteristics of the 80 most important interactions (Fig. 15). A majority (52 variables) were positively correlated with healthy controls and the remaining 28 variables were directly related to muscle interactions or muscle relationships in the WAD group (Fig. 16). The 80 interactions also included quadratic interaction terms, four in the control group and three in the WAD group (see paper IV). A quadratic interaction term describes the interaction between a variable and itself and model non-linear effects.

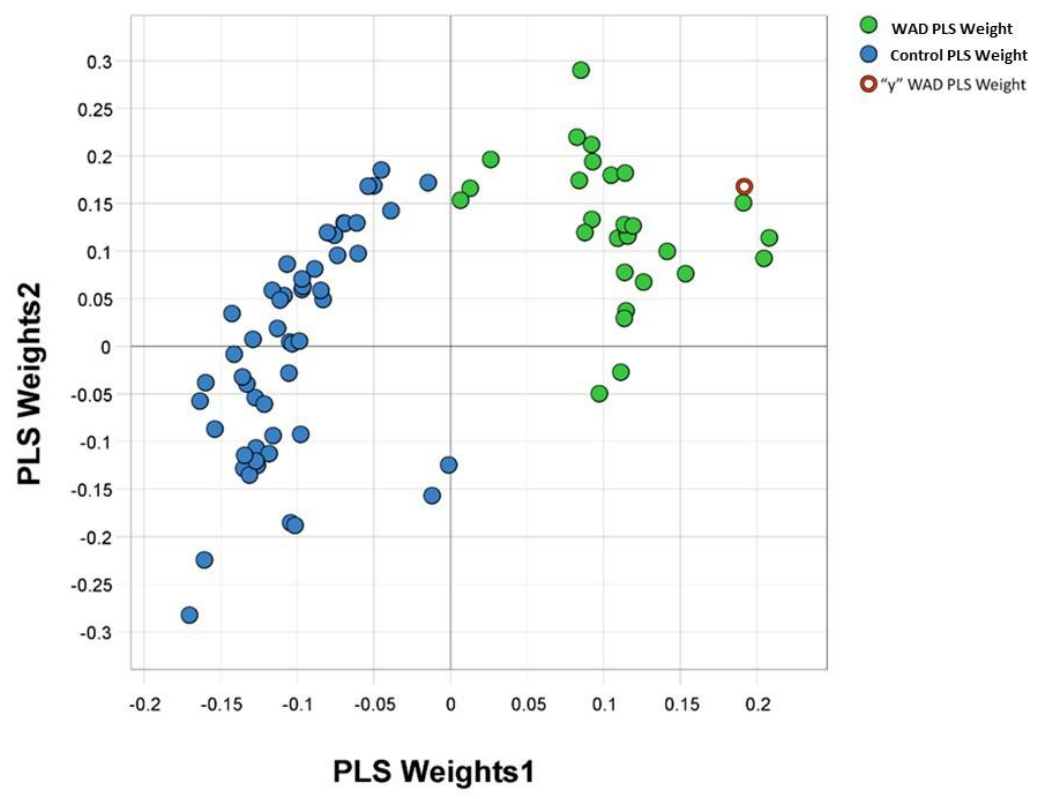

Figure 15. Projection to latent structure (PLS) weights in individuals with whiplash-associated disorder (WAD) and healthy controls. PLS is a regression extension of principal component analysis and showed that 52 interactions between deformation and deformation rate in the three ventral neck muscles were positively correlated to healthy controls (blue dots). The remaining 28 variables, of the in total 80 variables, were correlated to WAD (green dots). 
a)

\begin{tabular}{|c|c|c|c|c|}
\hline \multicolumn{3}{|c|}{ Healthy controls } & \multicolumn{2}{|c|}{ WAD } \\
\hline SCM Elongation & $\leftrightarrow$ & SCM Shortening & SCM Shortening & $\leftrightarrow \quad$ Lcap Rate \\
\hline SCM Elongation & $\leftrightarrow$ & SCM Tot.deform & SCM Tot.deform & $\leftrightarrow \quad$ Lcap Rate \\
\hline SCM Elongation & $\leftrightarrow$ & Lcap Tot.deform & Lcap Elongation & $\leftrightarrow \quad$ Lcap Short. \\
\hline SCM Elongation & $\leftrightarrow$ & Lco Shortening & Lcap Elongation & $\leftrightarrow \quad$ Lcap Tot.deform \\
\hline SCM Shortening & $\leftrightarrow$ & SCM Tot.deform & Lcap Elongation & $\leftrightarrow \quad$ Lco Elongation \\
\hline SCM Shortening & $\leftrightarrow$ & Lcap Shortening & Lcap Elongation & $\leftrightarrow \quad$ Lco Shortening \\
\hline SCM Shortening & $\leftrightarrow$ & Lcap Tot.deform & Lcap Elongation & $\leftrightarrow \quad$ Lco Tot.deform \\
\hline SCM Tot.deform & $\leftrightarrow$ & Lcap Shortening & Lcap Tot.deform & $\leftrightarrow \quad$ Lcap Rate \\
\hline SCM Tot.deform & $\leftrightarrow$ & Lcap Tot.deform & Lco Tot.deform & $\leftrightarrow \quad$ Lco Shortening \\
\hline SCM Tot.deform & $\leftrightarrow$ & Lco Shortening & & \\
\hline SCM Tot.deform & $\leftrightarrow$ & Lco Tot.deform & & \\
\hline SCM Rate & $\leftrightarrow$ & Lcap Shortening & & \\
\hline SCM Rate & & Lco Shortening & & \\
\hline SCM Rate & & Lco Tot.deform & & \\
\hline
\end{tabular}

b)

\begin{tabular}{|c|c|c|c|c|c|}
\hline \multicolumn{3}{|c|}{ Healthy controls } & \multicolumn{3}{|c|}{ WAD } \\
\hline SCM Elongation & $\leftrightarrow$ & SCM Tot.deform & SCM Elongation & $\leftrightarrow$ & Lco Elongation \\
\hline SCM Elongation & $\leftrightarrow$ & Lcap Shortening & Lcap Elongation & $\leftrightarrow$ & Lcap Rate \\
\hline SCM Elongation & $\leftrightarrow$ & Lcap Tot.deform & Lcap Shortening & $\leftrightarrow$ & Lcap Tot.deform \\
\hline SCM Elongation & $\leftrightarrow$ & Lco Shortening & Lcap Tot.deform & $\leftrightarrow$ & Lco Shortening \\
\hline SCM Elongation & $\leftrightarrow$ & Lco Tot.deform & Lco Shortening & & Lco Tot.deform \\
\hline SCM Elongation & $\leftrightarrow$ & Lco Rate & & & \\
\hline SCM Shortening & $\leftrightarrow$ & SCM Rate & & & \\
\hline SCM Shortening & $\leftrightarrow$ & Lcap Rate & & & \\
\hline SCM Tot.deform & $\leftrightarrow$ & Lco Shortening & & & \\
\hline SCM Tot.deform & $\leftrightarrow$ & Lco Tot.deform & & & \\
\hline SCM Tot.deform & $\leftrightarrow$ & SCM Rate & & & \\
\hline SCM Tot.deform & $\leftrightarrow$ & Lcap Rate & & & \\
\hline SCM Tot.deform & $\leftrightarrow$ & Lco Rate & & & \\
\hline SCM Rate & & Lco Shortening & & & \\
\hline
\end{tabular}

c)

\begin{tabular}{|c|c|c|c|c|}
\hline \multicolumn{3}{|c|}{ Healthy controls } & \multicolumn{2}{|c|}{ WAD } \\
\hline SCM Elongation & $\leftrightarrow$ & Lcap Shortening & Lcap Elongation & $\leftrightarrow \quad$ Lcap Elongation \\
\hline SCM Elongation & $\leftrightarrow$ & Lcap Tot.deform & Lcap Elongation & $\leftrightarrow \quad$ Lco Tot.deform \\
\hline SCM Elongation & $\leftrightarrow$ & Lco Elongation & Lcap Tot.deform & $\leftrightarrow \quad$ Lcap Rate \\
\hline SCM Elongation & $\leftrightarrow$ & Lco Shortening & Lco Elongation & $\leftrightarrow$ SCM Elongation \\
\hline SCM Elongation & $\leftrightarrow$ & Lco Tot.deform & Lco Elongation & $\leftrightarrow \quad$ Lcap Elongation \\
\hline SCM Shortening & $\leftrightarrow$ & Lco Elongation & Lco Elongation & $\leftrightarrow \quad$ Lcap Shortening \\
\hline SCM Shortening & $\leftrightarrow$ & Lco Tot.deform & Lco Elongation & $\leftrightarrow \quad$ Lcap Tot.deform \\
\hline SCM Tot.deform & $\leftrightarrow$ & SCM Elongation & Lco Elongation & $\leftrightarrow$ Lco Elongation \\
\hline SCM Tot.deform & $\leftrightarrow$ & Lcap Tot.deform & Lco Elongation & $\leftrightarrow \quad$ Lco Shortening \\
\hline SCM Tot.deform & $\leftrightarrow$ & Lco Elongation & Lco Elongation & $\leftrightarrow \quad$ Lco Tot.deform \\
\hline SCM Tot.deform & $\leftrightarrow$ & Lco Shortening & Lco Elongation & $\leftrightarrow \quad$ SCM Rate \\
\hline SCM Tot.deform & $\leftrightarrow$ & Lco Tot.deform & & \\
\hline Lcap Shortening & $\leftrightarrow$ & Lcap Shortening & & \\
\hline Lcap Shortening & $\leftrightarrow$ & Lcap Tot.deform & & \\
\hline Lcap Tot.deform & $\leftrightarrow$ & SCM Elongation & & \\
\hline Lco Shortening & $\leftrightarrow$ & Lcap Elongation & & \\
\hline Lco Shortening & $\leftrightarrow$ & Lcap Tot.deform & & \\
\hline Lco Shortening & $\leftrightarrow$ & SCM Rate & & \\
\hline Lco Tot.deform & & SCM Rate & & \\
\hline Lco Rate & & SCM Rate & & \\
\hline
\end{tabular}


Figure 16. Variable influence of projection (VIP)

a, b) The most important two-way interactions between neck muscles in deformation and deformation rate during the first (a) and tenth (b) arm elevations that separate WAD from controls. In healthy controls, 14 interactions were seen during the first and tenth arm elevations and 9 interactions were present for the first arm elevation which decreased to 5 in the tenth arm elevation for the WAD group.

c) The interaction terms between the first and tenth arm elevations do not indicate muscle interplay. The interaction should be seen as a relationship between the first and tenth arm elevations that distinguishes the WAD and control group in this multivariate model. Twenty interactions were seen in the control group and 11 in the WAD group.

Abbreviations: SCM, sternocleidomastoid; Lcap, longus capitis; Lco, longus colli; Tot.deform, total deformation area (the sum of shortening and elongation); shortening, muscle deformation shortening; elongation, muscle deformation elongation; rate, deformation rate.

The WAD group had fewer muscle interactions compared to the control group during the first arm elevation (WAD: 9 [39\%], controls: 14 [61\%]) and the muscle interaction decreased in the WAD group at the tenth arm elevation (WAD: 5 [26\%], controls: 14 [73\%]). Sternocleidomastoid was involved in all interactions in the control group during the first and tenth arm elevations unlike the WAD group. In the WAD group, the interaction between muscles included elongation for the two deepest muscles, longus capitis and longus colli, which was not seen in the control group during the first or tenth arm elevation (Fig. 16a and b)

The third interaction type (Fig. 16c) is not an actual muscle interaction, but can be seen as a relationship between the first and tenth arm elevation, distinguishing individuals with WAD from healthy controls. More interactions were observed in the control group (20 [65\%]) compared to the WAD group (11 [35\%]). In the WAD group, $91 \%$ of the interactions included elongation of the two deep neck muscles longus capitis and longus colli, and sternocleidomastoid was not presented during the first arm elevation. For controls, sternocleidomastoid was involved in the interactions at the first arm elevation and the feature of the deep neck muscles was shortening. 


\section{Differences in ventral neck muscle function after three months neck-specific exercises compared to waiting-list}

Twenty-six individuals in study B were consecutively randomly assigned to neck-specific exercise (NSE, 3 men and 10 women, mean age; 39 years [SD 11.9]) or continued on the waiting-list (WL, 2 men and 11 women mean age; 36 years [SD 10.3]) for three months. Ultrasound measurements were performed at baseline and after three months. There were no differences in ventral neck muscles interactions between the two groups at baseline (PCA analyses; $p=0.24$ ), see Fig. 17a. After three months there were significant differences between the groups (Fig. 16b; $\mathrm{p}<0.03$ ). Seven individuals in the NSE group were improved and showed a neck-muscle interaction model more similar to that of healthy controls in paper IV. No-one was improved in the WL group (Fig. 17b).

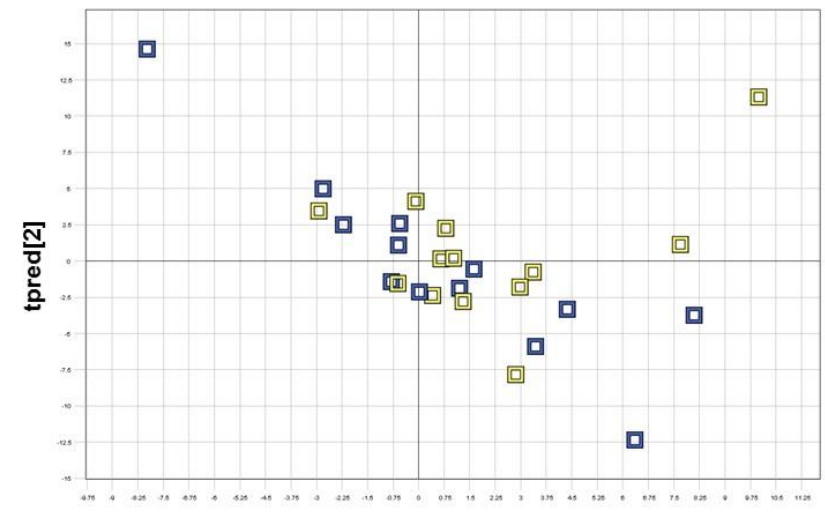

a) tpred[1]

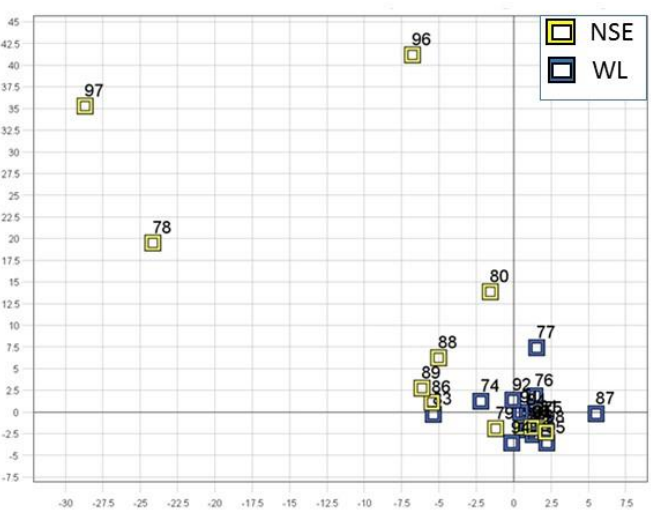

b) tpred[1]

Figure 17 a-b. PCA sore plot

a) There were no significant differences at baseline between the neck-specific exercise group (13 individuals, yellow squares) and the waiting-list group (13 individuals, blue squares)

b) At three months, there were significant differences between the two groups ( $p$ $<0.03$ ). Seven of the individuals in the neck-specific exercise group (yellow squares) were positioned more to the left in the model after three months of neck-specific exercises, indicating a ventral neck muscle pattern more equal to that of healthy controls (see figure $13 \mathrm{~b}$ ) 
For those seven (three men and four women) out of 13, with improved ventral neck muscle interactions, a tendency to increased ventral neck muscle endurance was seen compared to non-improved both at baseline (improved; median 22 seconds, IQR 19-54, non-improved; median 12 seconds, IQR 6-30; $\mathrm{p}=0.08$ ) and three months' follow-up (improved; median 50 seconds, IQR, 36-74, non-improved; median 18 seconds, IQR, $13-34 ; \mathrm{p}=0.11$ ). There were no significant differences between improved and non-improved groups regarding pain intensity before the NME test, neck disability index, age or BMI ( $p>0$. 43). The dorsal neck muscle endurance was increased in the improved group compared to the nonimproved both at baseline (improved; median 52 seconds, IQR 28-110, non-improved; median 27 seconds (IQR; 13-75), and at three months' follow-up (improved; median 114 seconds (IQR; 43-226); non-improved; median 50 seconds (IQR; 36-74) but the differences were not significant ( $p$ $>0.10)$. 


\section{DISCUSSION}

\section{Main findings}

The main results from the randomized control study showed that neckspecific exercise with and without a behavioral approach (the NSE and NSEB groups) significantly improved dorsal neck muscle endurance compared to prescribed physical activity (the PPA group). The neck pain was also significantly decreased in the NSE and NSEB groups immediately after the endurance test compared to the PPA group at six months. The results are promising for improved neck muscle function after neckspecific exercise in persistent WAD.

Ultrasound real-time investigation of superficial and deep neck muscles revealed altered interplay between pairs of neck muscles in the WAD group compared to controls. An individual muscle pattern in healthy controls was seen, with equal deformation and deformation rate between pairs of neck muscles, but this interplay between muscles was weakened or not found in individuals with WAD. Moreover, two different ventral neck muscle models were revealed in individuals with WAD and healthy controls. There were fewer interactions between muscles and fewer neck muscles combinations involved in the two-way interactions in the WAD group. This non-invasive ultrasound method stands to make a major breakthrough in the assessment and diagnosis of mechanical neck muscle function in WAD.

\section{Discussion of the results}

\section{The effect of three different exercise interventions on neck muscle endurance and pain intensity}

In contrast to previous RCT-study showing that exercise does not improve function (69), the findings in paper I showed enhanced neck muscle endurance for the ventral (only men) and the dorsal neck muscles in the NSE and NSEB groups. The first stage of the neck-specific exercises was targeted to activate and enhance endurance in the deep flexor, extensor and rotator neck muscles. The next stage was to improve endurance in the superficial neck muscles with the deep muscle activated, e.g. to perform the exercises with postural control of the neck. When deep neck muscle endurance increases, the ability to maintain a stable cervical spine may improve and the exercises program can progress. This exercise strategy may protect the cervical spine and facet joints from overload. Though people do not normally go around with a load tied round their head as in the NME test, if the neck is flexed the weight of the head itself can increase 
neck pain (102). In neck pain, the ability to maintain an upright posture was reduced and the individuals showed a more forward head posture (103). The facet joints and capsule are sources of pain after whiplash injury $(12,14)$ and activities with flexed neck position or forward head posture may maintains the pain in WAD. The pain intensity measured immediately after the neck muscle endurance test was decreased in the two neck specific exercise groups. A tendency to between-group differences in substantial clinical improvement was seen. At six months, $40 \%$ of the participants in the NSE group, $35 \%$ in the NSEB group and $24 \%$ in the PPA group had decreased pain $\geq 50 \%$ after the NME test compared to baseline $(p=0.09$; Peterson, unpublished results 2016). Moreover, only in the NSE and NSEB groups was muscle endurance time increased. Improved neck muscle endurance and decreased pain after test indicated that neck-specific exercise can improve the capacity to tolerate sustained loading of the neck. The neck-specific exercise regimens (NSE and NSEB) also improved selfreported neck function and reduced analgesics drug at six months (104) and the neck function was still significantly improved at one- and two-year followed up compared to the PPA group (105). The neck-specific exercises were also of great benefit compared to no intervention (106) and were the only factor that consistently gave higher odds of treatment success (107). The neck-specific exercises in paper I differed from those in earlier studies (68-71) which only trained the deep ventral neck muscles or used more generalized exercises, and this could explain the discrepancy in results. No previous studies have included participants with neurological signs (WAD grade III) at study entrance this may also contribute to the differences in results $(68-71)$.

For women, there were no significant differences between the three groups for ventral neck muscle endurance and the median endurance time were equal in the three groups (23 to 24 seconds) at six months' follow-up. Earlier studies $(85,108-111)$ have reported ventral endurance time from 15 (111) to 36 seconds (85) for women without neck pain and the cut-off value for subnormal endurance was set to 23 seconds (85). Thus, the results indicate that women in all three groups were within the normal range for ventral neck muscle endurance at six months. However, the ventral neck muscle endurance in women with-out neck pain were only $24 \%$ to $78 \%$ of men's $(85,110,111)$. Neck pain is more prevalent among women (112) and women have a slightly increased risk of WAD (1). This may indicate the need of ventral neck muscle endurance training for women with-out neck pain, and thereby also for women with WAD.

Ventral (for men) and dorsal neck muscle endurance (men and women) was considerably lower at the six-month follow-up in the NSE and NSEB groups compared to neck healthy individuals. Women only had $22 \%$ of the dorsal neck muscle endurance reported in pain-free individuals (85) and men showed $35 \%$ (dorsal muscles) and $51 \%$ (ventral muscles) of the corresponding endurance values (85). Although the participants in the NSE 
and NSEB group doubled their endurance time in the dorsal muscles and increased the ventral endurance time by $33-50 \%$, the results imply that a longer training period is needed in persistent WAD to maximize improvements.

There were no significant differences between the NSE and NSEB groups. The NSEB group experienced a more rapid improvement in dorsal neck muscle endurance and the NSE group a more rapid improvement in neck pain intensity before and after the endurance test. The participants in the NSE group were instructed to avoid increased pain during exercise as per recommendation for treatment in chronic WAD (113). Increased pain in $\mathrm{WAD}$, from a biological point of view, can facilitate and enhance hypersensitive sensory disturbance and induce change in muscle activity (113) and decrease the possibility to achieve normal motor control. In the NSEB group, the behavioral approach included education (114) aimed to decrease fear of pain and fear-avoidance beliefs. The participants were instructed to continue exercise despite pain but they should avoid a cumulative elevation of pain level and increased arm pain due to nerve engagement. The differing approaches in the NSE and NSEB groups seemed to be important up to three months' follow-up. However, at six months there were equal improvements in both groups in neck muscle endurance test and pain intensity. In clinical practice, the physiotherapist may choose the best exercise for the actual patient and determine what is most important; rapidly increased pain; to include behavioral approaches to reduce pain-related fear; or acceptance of some pain to gain rapid improvement in neck muscle endurance. The NSEB group showed also improvement in dizziness (115) and pain disability (116), while the NSE group improved in kinesiophobia, anxiety and catastrophizing (116) compared to the PPA group. These results further strengthen the need to individualize the treatment both in clinical practice and in future research. A more general physical activity as in the PPA group, seeking to enhance aerobic fitness, showed no significant improvements at group level in the PPA group but for some individuals this intervention had effect.

\section{The effect of three exercise interventions on kinesiophobia, exercise compliance and patient satisfaction}

There were no significant differences between the three groups in kinesiophobia. Only the NSE group improved from baseline to six months in the TSK-11 score. Experienced physiotherapists leading patients through non-painful exercises with enhanced severity of exercises are likely to improve their patients' self-efficacy and reduce fear. The most important part in the self-efficacy theory (117) stipulates that self-efficacy increases and fear is reduced through repeated success. In this case (paper I), that neck exercises became possible to performe without increased neck pain. However, the improvements in TSK were small. Low baseline score indicates that kinesiophobia may not have been a great problem for the 
participants in this study (paper I) which would make it difficult to detect clinically important change (118).

Individuals in the NSE and NSEB groups were more satisfied with their treatment, and at the three-month follow-up they tended to be more compliant (the differences approached significance) with their exercise program compared to the PPA group. For those compliant at three months' follow-up, dorsal NME were improved over time in the NSE and NSEB groups and at three and six months' follow-up they were significantly more improved compared to the PPA group $(\mathrm{p}=0.05)$. Ventral NME was also improved over time in the NSE group $(\mathrm{p}<\mathrm{0.01})$. There were no significant changes over time or between groups changes among non-compliant participants in NME (Peterson, unpublished data 2016). Exercise compliance was set to at least $50 \%$ attendance and the results indicate that a training level below that limit does not provide improvement in the neckspecific exercise groups. However, the study was not designed for these subgroups analyses, there was also more missing self-reported data (38\%) in compliance for the PPA group at three months so the results need to be interpreted with caution.

Participants in the NSE and NSEB groups had regular meetings with the physiotherapist, got more information and education and their greater satisfaction could be related to this $(82,83)$. A more satisfied patient may come to the exercise meetings and thus be more likely to improve if the delivered treatment is effective. Also, effective treatment that improves function and decreases pain may make a participant more compliant. However, there were weak correlation between satisfaction and compliance; $r=0.21, p<0.05$, satisfaction and improved ventral; $r=0.19$, $\mathrm{p}<0.05$, or dorsal neck muscle endurance; $\mathrm{r}=0.24, \mathrm{p}<0.01$ and decreased pain immediately after the endurance test $\mathrm{r}=-0.25, \mathrm{p}<0.01$ (Peterson, unpublished data 2016). This is in accordance with other studies reporting weak correlation between satisfaction and effect of treatment $(82,83)$. The question in paper I was directed to satisfaction with the intervention and thus, the answer may be more related to how the exercises were conducted in the NSE, NSEB and PPA groups.

\section{Mechanical neck muscle function, deformation and deformation rate}

There were few significant differences between individuals with WAD and healthy controls in deformation and deformation rate when comparing each neck muscle separately between the two groups (WAD/control). Deformation rate in the deepest neck muscle were increased in the WAD group compared to the control group and the superficial ventral muscle sternocleidomastoid was more elongated in the control group. Thus, our hypotheses that deformation and deformation rate would be increased in 
the superficial neck muscles and decreased in the deep neck muscles in the WAD group, were not confirmed.

The hypotheses described above were based on previous theories and studies. The pain adaption model suggested that pain reduce contraction in agonist muscles which is a strategy to protect the spine from further injury and pain (48). Magnetic resonance imaging and still-image ultrasound studies have shown higher amount of fatty infiltrate in the ventral and dorsal neck muscles, especially in the deep multifidus and longus capitis/colli muscles $(21,67)$ and reduced cross-sectional area of the deepest dorsal neck muscles (26) in WAD. In addition, EMG studies have reported increased activity in the superficial muscles and delayed and decreased activity in the deep neck muscles in individuals with WAD and non-traumatic neck pain $(27,30,119)$. The deep ventral and dorsal muscles are assumed to maintain the postural control and stability of the cervical spine due to their close attachment to the vertebrae $(15,41)$ and as neck pain altered the activation in the deep muscles (31), neck pain is believed to decrease the stability in the spine. The alteration in muscle characteristics in WAD based on these earlier studies $(21,26,27,30,67$, 119) was the reason for the present hypotheses and for assuming similar findings in real-time ultrasound measurements. However, the hypotheses were not confirmed, instead a highly individual muscle pattern was revealed (papers II and III) when the interplay between muscles was investigated and there were significant differences between the WAD and control groups.

In controls, the results showed an individual muscle pattern of low deformation and deformation rates or high deformation and deformation rates between pairs of muscles. The diminished relationships between muscles in the WAD group may indicate an irregular interplay between muscle pairs, especially between the superficial and the deep neck muscles. The direct attachment of the deep multifidus muscle to the cervical facet capsule (120) may be a source of increased neck pain in WAD, as the multifidus muscle showed a significantly higher deformation rate in women in the WAD group and weaker interplay with the other neck muscle layers, indicating overuse or disuse of the deep muscle.

\section{Neck muscle interactions in individuals with persistent WAD and healthy controls}

The results in paper IV, revealed two different neck muscle interaction models in individuals with persistent WAD and healthy controls. The postural test of the ventral neck muscles showed an important difference between the two groups. In total, 80 muscle interactions were detected to be primarily involved in the models that separate the WAD group from healthy controls. The majority, 52 interactions, were positively correlated to healthy controls. The remaining 28 interactions were related to 
individuals with WAD and the superficial muscle sternocleidomastoid was only involved a few times. The lower number of interactions in the WAD group may indicate reduced motor variability in the interplay between neck muscles in individuals with persistent WAD. There are incredibly many ways to combine muscle activities to perform a specific motor task (36). Reduced motor variability has been seen in experimental and chronic pain $(39,121,122)$. Moreover, results in recently published studies (49-51) show individual-specific changes in motor variability in pain.

Earlier studies have reported increased activity in the superficial sternocleidomastoid muscle in individuals with chronic neck pain compared to healthy controls $(27,28,119,123)$ when measured with EMG or fMRI. In paper IV, the superficial sternocleidomastoid muscle was involved in all fourteen interactions in the control group during both the first and tenth arm elevations but only a few times in the WAD group. The discrepancy compared to earlier studies may be due to different measurement methods. EMG measures the electrical activation of the muscle, fMRI the T2 relaxation time of muscle water after activity whereas real-time ultrasound measures the deformation and deformation rate in the muscles.

The interactions between muscle pairs included shortening of the deep muscles in healthy controls and only the WAD group showed elongation of the deep muscles during the first and tenth arm elevation task (Fig. 16a and b). The deep ventral muscles are assumed to maintain the postural control and stability of the cervical spine (41). Elongation of the deep muscles may reflect passive elongation and difficulties to maintain postural control in the WAD group. These findings are more in accordance with earlier studies showing reduced activation in the deep ventral neck muscles in chronic neck pain $(31,119)$. The 80 most prominent variables resulted in a model with high prediction efficiency $\left(\mathrm{Q}^{2} \mathrm{Y}=0.59\right)$. The use of multivariate statistics that can handle many highly correlated variables and calculation of mechanical real-time neck muscle deformation area and deformation rate has greatly improved our knowledge of altered neck muscle function in WAD. The results show great promise for improved diagnosis in WAD.

After three months of neck-specific exercises, improvement in interaction between ventral neck muscles and tendency to improved ventral neck muscle endurance were seen in seven individuals out of thirteen (Peterson, unpublished results, 2016). Results from a small pilot study need to be interpreted with caution. Notwithstanding, the results suggest that improved endurance in ventral neck muscles is related to improved interactions between ventral neck muscles. The results also indicate that some individuals need longer training or other exercises since six individuals in the neck-specific exercise group showed no improvement in ventral neck muscle endurance or in interaction between neck muscles. 


\section{Methodological considerations}

\section{Generalization of the results}

The participants in the RCT-study (study A, paper I) were comparable with participants included in previous studies of persistent WAD based on mean age, proportion of men and women, neck disability and neck pain $(68,70$, 71). Included in the present thesis, were individuals with WAD grades II and III, thus the results can also be generalized to patients with neurological signs after WAD. No other study has evaluated exercise regimes for WAD grade III. The study sample was heterogeneous regarding neck pain, neck muscle endurance and self-reported neck disability with a large variation between participants. This reflects the "real" patient in clinical work but the results cannot be generalized to individuals non-fluent in Swedish, or to individuals with WAD that also have other severe disease as they were excluded from the study. Participants were recruited from primary health care centers, orthopedic clinics and hospital outpatient service in six different counties and the results can be generalized to these settings. The study intervention was conducted by 69 physiotherapists working in primary care that have received one day of theoretical and practical training. A strength of the study (paper I) is that the neck-specific exercises can be implemented in clinical practice within a day, and no other specialist knowledge beyond ordinary physiotherapist skills in primary care is needed.

The participants in study B (papers II-IV) were recruited from study A. They were slightly younger (mean; $36-37$ year) and have higher pain intensity (mean VAS; $46-51 \mathrm{~mm}$ ) than participants in study A (mean; 40 year, pain intensity VAS; $34 \mathrm{~mm}$ ), but were comparable in gender and neck disability. More women than men were included in the study. Also, the results in deformation and deformation rate showed differences between men and women. More men were excluded from the analyses for much greater variation in deformation and deformation rate. Thus the results are more representative for women.

\section{The effect of three exercise interventions on neck muscle endurance and pain}

The baseline dorsal NME score for men was close to significant between the three groups at baseline $(\mathrm{p}=0.08)$. Baseline NME score was included as covariate in the linear analyses and the results remained unchanged. Thus, the baseline differences did not affect the results.

The neck muscle endurance test has shown moderate to excellent intrarater (ICC; 0.68 - 0.93) and inter-rater reliability (ICC; $0.67-0.88$ ) for ventral $(84,110,124,125)$ and dorsal neck muscles (ICC; 0.80 - 0.94) (84, 126). Although the test is highly reliable the standard error of measurement is large. Variation between individuals' endurance capabilities is large both 
for ventral $(84,86,109,110,124,127)$ and dorsal neck muscles $(84,86$, 127). The standard error of measurement for ventral neck muscles varies between 5 to 15 seconds $(84,110,124,125,128)$, and to be confident that the change is real, the minimal detectable change (MDC) should be greater than 17 seconds in individuals with neck pain (84). For dorsal NME, the standard error of measurement was 26 and 35 seconds in individuals with neck pain $(84,126)$ and the MDC needed to be greater than 70 seconds (84). For both ventral and dorsal NME, the variation increases with longer test time.

To evaluate whether the changes in NME are important, values to compare with should be derived from studies with the same population. However, no MDC values for individuals with WAD were published when the present analyses were conducted, and values from individuals with neck pain were used to evaluate the findings in paper I (84). Significantly more individuals in the NSE and NSEB groups (32\%) improved more than 17 seconds at the six-month follow-up in ventral NME compared to the PPA group (16\%, p $<$ 0.05). For dorsal NME, significantly more individuals in the NSE and NSEB group increased the endurance time with 70 seconds compared to the PPA groups (NSE; $26 \%$, NSEB; 32 \%; PPA; $10 \%$, p = 0.03) (Peterson, unpublished data 2016). As the sample size calculation was based on the primary outcome on the Neck Disability Index there may have been insufficient data to detect a difference between groups. Statistical power is the possibility that a study will detect an effect of the treatment if there is one, and depends on the sample size. The power is recommended to be > 0.80 and was calculated for ventral and dorsal neck muscle endurance (PASS, 13.0.8). The power to detect time by group interaction effect was 0.31 for ventral NME and 1.0 for dorsal NME. The power was 1.0 for both ventral and dorsal NME regarding change over time. Thus, the sample size for ventral NME was too low and further studies need to include more participants to detect an effect between groups.

The NME test measure isometric muscle endurance over a period of time, i.e. while maintain a static contraction. The test provides a gross estimation of muscle endurance; it cannot distinguish between deep and superficial muscles and may depend on the individuals' experience of pain (129). The ventral NME test with the chin tucked, activates both the deep and superficial muscles (130) and activity in the superficial muscles may mask an impaired function in the deep muscles. Also fear avoidance beliefs (17) may influence the test, if increased pain during the test is associated with fear of increasing the damage. However, the correlation between the neck muscle endurance test (NME) and fear avoidance beliefs (TSK) was weak to moderate at six-month follow-ups (ventral NME, $r=-.26$, dorsal NME; $\mathrm{r}=-.31, \mathrm{p}=0.01$ (Peterson, unpublished data 2016).

The NME test can easily be used in clinical settings but presents considerable measurement error with large variation between individuals 
as presented in previous studies (84-86, 109-111, 124-128). Nevertheless, the findings in paper I with significant improved endurance time as well as decreased pain after test following neck-specific exercise interventions, indicate improved tolerance of sustained loading of the neck. The test is also more reliable in women with lower endurance time (110), but needs further evaluation for individuals with whiplash injury. The pain intensity during and immediately after the test needs to be analyzed together with the NME test results.

\section{Validity and limitations of ultrasound}

One challenge in ultrasound measurement is image quality. When the ultrasound wave propagates through the body, its intensity will be reduced by the distance travelled and echoes from deeper tissues are weaker than those from similar superficial tissues (32). Other artefacts are reverberations and mirror-images due to echoes being returned from strongly-reflecting interfaces or returning echoes from a reciprocal path. Both artefacts display a false ultrasound image (131). Refraction is a change in the direction of the ultrasound waves when passing from one tissue to another with different acoustic impedance. Refraction may cause the examined tissue to be wider or misplaced (131). However, the neck muscles have no tissues of high acoustic impedance between the different layers and reverberations and mirror-image artefacts appear in images of liquid-filled areas or posterior to the diaphragm. Ultrasound machines now have also improved spatial and contrast resolution, reducing image noise and improving wall definition. Time-gain control makes it possible to increase the size of the ultrasound echoes from deeper tissues and thereby get a clear ultrasound image.

The accuracy of ultrasound recording depends on the ability of the operator to obtain the measurements and then interpret the ultrasound image. Learning curves for echocardiography to assess cardiac function and anatomy reportedly show $89 \%$ accuracy after four lessons of 45 minutes (132). To our knowledge, no studies have investigated the learning curve for musculoskeletal ultrasound imaging. The physiotherapist performing our ultrasound examinations received in total more than 100 hours of training, including 20 hours of training by a biomedical engineer before study start. The speckle tracking analyses were performed by a physiotherapist with three years' experience of the method. The heart muscle has a very complex movement pattern compared to the neck muscle as tested in study B. Thus, if echocardiography could be assessed with good accuracy after three hours' training (132), we believe that the training for the present ultrasound measurements was sufficient to achieve accuracy in the neck muscle investigations and analyses.

The transducer placement could have been limited due to the lack of significant anatomical landmarks. However, the $\mathrm{C}_{4}$ spinous process and 
vertebral column were used as reference points in the dorsal images and the bifurcation of the carotid artery (commonly at the $\mathrm{C}_{4}$ level) (91), in the ventral images. Another potential limitation was that the ROI was selected manually for each muscle. Like in EMG investigations, the ROI may not adequately represent the whole muscle. However, three ROIs were placed in each muscle of interest covering $30 \mathrm{~mm}$ of the muscle (transducer size $38 \mathrm{~mm}$ ): this larger area minimizes the differences between inidviduals and increases measurment accuracy. Changes in head kinematics might also have affected the deformation and deformation rates measurements. The ventral and dorsal neck muscles were measured during arm elevation to 90 degrees and the individuals were specifically instructed to hold their head steady during the test. Thus, it is reasonable to assume that head movement has not affected the data and does not significantly account for the difference between WAD and controls in papers II-IV.

The reliability of 2D ultrasound with speckle tracking analyze has been tested, showing that longitudinal deformation is an effective method for quantifying left ventricle heart function $(133,134)$. Speckle tracking have been validated against force for the biceps brachi muscle (35). Voluntary contraction force and deformation curves showed good resemblance. Intersubject variability was found to be higher than intra-subject variability, indicating that the largest variance exists between different subjects but with good reproducibility for each individual (35). The intra-test reliability of the speckle tracking analysis method is excellent in neck muscles (ICC 0.71-0.97) (95).

Dorsal neck muscle deformation has been validated against force in 19 neck-healthy individuals (Peterson et al. unpublished data 2016). The relationship between force and deformation area (mean value of three tests) for five dorsal neck muscles showed strong positive relationships (five participants, $\mathrm{R}^{2}$; 0.74 to 0.99 ), or moderate to strong curve-linear relationships for 14 participants (one moderate $\mathrm{R}^{2}$; $0.46,13$ strong $\mathrm{R}^{2} ; 0.63$ to 0.99). The results showed high intra-subject variability between deformation and percent of maximal voluntary contraction. Some individuals had high deformation area while others had low at the same MVC level. There are many different ways to perform a voluntary movement when several muscles are available. Thus, the redundancy of the neck muscles allowed for many different solutions for achieving the same external results $(39,40)$. The 14 participants with non-linear correlations showed a linear relationship between force and deformation area from $10 \%$ of maximal voluntary isometric contraction (MVC) to a peak in 60\% MVC and a slope of the curve after $60 \%$ MVC. These results resemble those for the biceps brachi muscle (35) where deformation was relatively high already at $30 \%$ of MVC during voluntary isometric contraction and the authors suggested that force and deformation are not directly proportional. Electromyography studies have shown findings with non-linear relations between force and EMG, related to the proportion of fiber type (135). Muscles with mixed type I and II fibers showed non-linear relation with 
force. Both type I and II fibers were seen in neck muscles in neck pain patients who underwent spinal fusion (136).

Deformation of muscles can represent passive or active elongating or shortening, and no conclusion on the degree of active or passive muscle deformation can be drawn from these studies (papers II-IV). The models developed in paper IV were however able to detect differences between individuals with WAD and healthy controls.

\section{Validation of the multivariate model}

In paper IV, the model was validated with respect to quality and significant components, with leave-p-out cross-validation. Cross-validation is used for assessing how results can be generalized to an independent data set. The cross-validation procedure excluded one-third (14-15) of the individuals from the creation of a reduced PLS-DA model (28-29 individuals) of the co-variation between the 324 variables and the $\mathbf{y}$ variable (WAD patient or control). Patient status (WAD or control) was then predicted for the excluded one-third (14-15 individuals) by the reduced PLS-DA model. The validation process was created for all 324 variables and also for the VIP model including the 80 most important variables. The test sets procedure was repeated three times followed by consolidation of the prediction outcome of all three procedure runs. All $\mathrm{Q}^{2} \mathbf{Y}$ values reported in paper IV were derived from the cross-validation. The validation procedure was undertaken to ensure that variation in the data actually reflected the differences between WAD and healthy controls. To use this crossvalidation method, where one third of the participants were left out and predicted at a time, allowed for a robust validation for the sample data. If cross-validation employs a model where only a few individuals at a time are left out for prediction, a similar model is used for all predictions and only small deviations are allowed from the full model. Excluding a larger portion as in paper IV, the sample data will allow for a larger deviation from the original model. In this case, a more independent model can be created for each validation round and more importantly, the final prediction outcome will be less dependent on more or less the same model.

\section{Gender differences}

Men showed significantly higher ventral neck muscle endurance compared to women (men; median 36 sec., women 19 sec., p <0.001) and higher dorsal muscle endurance, as the men's load were heavier (men $4 \mathrm{~kg}$ load median $66 \mathrm{sec}$., women $2 \mathrm{~kg}$ load, $39 \mathrm{sec} ., \mathrm{p}=0.06$ ) in paper 1 . Men in the NSE and NSEB groups improved significantly in ventral NME compared to the PPA group, but for women, there were no differences between the three groups. Men showed greater variations and higher values in both deformation and deformation rate for ventral and dorsal neck muscles, indicating different mechanical neck muscle function compared to women's. Especially for the dorsal neck muscles, the gender differences were large both in the WAD and control groups. Only 12 men were included 
in each group, too few for subgroup analyses of men. Men's larger muscle size and greater strength compared to women's (137) may explain the differences in neck muscle endurance, the greater variations in muscle deformation and deformation rate as well as gender differences in muscle interplay in papers II, III and IV. 


\section{CONCLUSION}

Neck-specific exercises with or with-out a behavioral approach improved neck muscle endurance and decreased pain immediately after endurance testing compared to prescription of physical activity. Participants in the two neck-specific exercise groups were more satisfied with treatment. Improved endurance and decreased pain imply improved capacity to tolerate sustained loading of the neck after neck-specific training in individuals with persistent pain after whiplash injury. Addition of the behavioral approach led to faster improvements in neck muscle endurance whereas the neck-specific exercise groups experienced a more rapid decrease in pain intensity. No other differences were seen between these two groups. The results suggest that neck-specific exercises should be considered for individuals with persistent disability after whiplash injury.

Real-time ultrasound investigations of neck muscles with speckle-tracking analyses revealed new insight into mechanical neck muscle function. Individuals' with-out neck pain showed an individual interplay between superficial and deep ventral neck muscles. This interplay was not found in individuals with whiplash-associated disorder. Altered function of the deep dorsal neck muscles was also seen in individuals with persistent whiplashassociated disorder.

Men had greater deformation and higher deformation rates compared to women and men seems to have different mechanical neck muscle functions compared to women's.

A model for mechanical ventral neck muscle function was developed. The model can distinguish individuals with persistent whiplash-associated disorders from individuals with-out neck pain. The results are promising for improved diagnosis in neck muscle function after whiplash injury. 


\section{CLINICAL IMPLICATIONS}

The neck-specific exercise program with or without a behavioral approach provides clinical guidance in content, dosage and progression to improve neck muscle endurance in individuals with persistent whiplash-associated disorders. Individuals with neurological signs, WAD grade III, have not been included in earlier RCT studies. The present results showed that the two neck-specific exercise programs were of benefit for individuals with WAD grades II and III.

In clinical practice, the physiotherapist may choose neck-specific exercises because they have the best effect in persistent WAD grades II and III. However, the best exercise program fitting the actual patient needs to be identified; whether rapidly decreased pain is most important, or a behavioral approach should be included to reduce pain-related fear, and/or rapid improvement in neck muscle endurance. More general physical activity as in the PPA group with the goal of improving aerobic fitness showed no significant improvements at group level in the PPA group. However, for some individuals this intervention had effect, and prescription of physical activity can be the best choice for someone in the clinical setting.

Altered function was detected in the interplay between superficial and deep neck muscles in individuals with persistent WAD. These findings imply the need for neck-specific exercise targeted to both ventral and dorsal neck muscles. 


\section{FUTURE RESEARCH}

The great variation in neck muscle endurance and difficulties to attain improvement above measurement error imply the need for further research to evaluate measurements of neck muscle endurance. To identify the level of sufficient neck muscle endurance for humans to avoid and prevent neck pain is a challenging but essential research question.

The results in paper I were based on intention-to-treat analyses at group level. Further research needs to identify predictors for the individual's response, or non-response, to different exercise programs. Moreover, the dosage and progression in the exercises need to be further investigated.

The participants in the neck-exercise groups with or without a behavioral approach were supervised by a physiotherapist twice weekly for 12 weeks. The positive results in paper I can be tested in interventions with less contact with physiotherapists. This can save physiotherapist time and thereby reduce waiting-list and save patients' time if they can exercise at home.

Men's deformtion and deformation rate differed compared to women's. Previous studies have included more women than men and studies including more men are warranted.

The experimental ultrasound investigations with speckle-tracking analyses in study B showed differences in mechanical neck muscle function in individuals with WAD compared to healthy controls. These findings can be a basis for further research aiming to improve the diagnostics of impaired mechanical neck muscle function and to evaluate responses to neck muscle exercises. This is important not only for individuals with WAD, and could be extended to individuals with neck pain due to other circumstances. 


\section{SUMMARY IN SWEDISH}

Bakgrund: Kvarstående smärta och nedsatt funktion efter whiplashskada är vanligt och så många som 50 \% har whiplash-relaterade symptom (whiplash-associated disorders; WAD) mer än ett år efter skadan. Orsaken till WAD är okänd trots att forskning pågått $\mathrm{i}$ årtionden och behandlingsmetoder saknas. En förändrad funktion i nackmusklerna kan orsaka nackbesvär men metoder för att undersöka både de ytliga och djupare musklerna saknas.

Syfte: Det övergripande syftet med avhandlingen var att undersöka funktionen i nackmusklerna, samt att utvärdera hur tre olika träningsinterventioner påverkade nackmusklernas funktion hos personer med långvariga besvär efter whiplashskada.

Metod: Två studier ingick i avhandlingen. Studie A var en randomiserad, kontrollerad studie med 216 deltagare där tre olika träningsprogram utvärderades. De tre träningsprogrammen var; 1) nack-specifik träning; 2) nack-specifik träning med tillägg av beteendemedicinska metoder och 3) allmän fysisk träning via fysisk aktivitet på recept. Mätningar utfördes av uthållighet i nackmuskler, nacksmärta före och efter test av uthållighet, rörelserädsla och nöjdhet med träningsprogrammet. Resultaten av träningen jämfördes mellan de tre olika grupperna efter 3 och 6 månader (delarbete I). Studie B var en experimentell fall-kontroll studie där deltagarna rekryterades från den randomiserade studien. Många personer med WAD får mer nacksmärta när de arbetar med armarna i axelhöjd. För att undersöka vad som händer i nackmusklerna när armarna lyfts, filmades musklerna med ultraljud vid tio upprepade lyft av armen. Deformationen, dvs. förlängning och förkortning inne $\mathrm{i}$ muskeln och deformationshastigheten (hur fort förlängningen och förkortning sker) analyserades i delarbete II-IV. I delarbete II, där de främre nackmusklerna undersöktes, ingick 26 personer med WAD och 26 personer utan nackbesvär. De bakre nackmusklerna undersöktes hos 40 personer med WAD och jämfördes med 40 personer utan nackbesvär i delarbete III. Totalt 46 personer, 23 med WAD och 23 utan nackbesvär ingick i utvecklandet av en modell för hur de främre musklerna samarbetar i delarbete IV.

Resultat: Delarbete I: Deltagarna i de båda nack-specifika träningsgrupperna (grupp 1 och 2) fick bättre uthållighet i nackmusklerna, hade mindre smärta efter uthållighetstest och var mer nöjda med träningen jämfört med gruppen som fick fysisk aktivitet på recept, grupp 3. Det var ingen skillnad mellan grupperna i rörelserädsla.

Delarbete II: Det fanns ett samspel mellan de djupa och ytliga främre musklerna avseende deformation och deformationshastighet hos personer utan nackbesvär. Var deformationen hög i den ytliga muskeln var den hög 
även i den djupa och vice versa, låg deformation i både ytlig och djup muskulatur. Det samspelet var mycket svagare eller saknades helt hos personer med WAD. Resultatet var detsamma för deformationshastighet. Delarbete III: Deformationshastigheten var högre i den djupa bakre nackmuskel, som sitter närmast halsryggraden, hos personer med WAD vid första och tionde armlyftet (endast kvinnor) i jämförelse med personer utan nackbesvär. Kvinnor med WAD hade också ett svagare samspel mellan de två djupaste bakre nackmusklerna i jämförelse med personer utan nackbesvär.

Delarbete IV: Samspelet mellan de främre nackmusklerna är förändrat och två olika modeller har utvecklats, en för personer med WAD och en för personer utan nackbesvär. Modellerna ger möjlighet att upptäcka förändrad nackmuskelfunktion efter whiplashskada.

Slutsats: Nack-specifik träning och nack-specifik träning med tillägg av beteendemedicinska metoder kan förbättra uthålligheten i nackmusklerna. Minskad smärta efter testet tyder också på bättre belastningstålighet av nacken i dessa två grupper. Förändringen i samarbetet mellan muskler tyder på att en försämrad förmåga att hålla halsryggrad stabil när armarna lyfts hos personer med WAD. Resultaten av studien är lovande då det kan leda till bättre möjligheter att diagnostisera förändringar i nackmusklerna efter whiplashskada. 


\section{ACKNOWLEDGEMENTS}

There are so many people that have contribute to this work in various way and to my learning during these years as a PhD-student, with discussion, support and guidance. Thanks to you all. In particular, I would like to thank the following for their crucial support:

Professor Anneli Peolsson, my main tutor and co-author. For your guidance, always positive attitude, combining collegial discussion and honest friendship during this research journey, a journey that long started 04.00 am and ended $22.00 \mathrm{pm}$, when all the ultrasound measurements were recorded in six counties. You also introduced me to researchers in the University of Queensland, Brisbane, Australia as well as to researchers in Göttingen, Germany. Thank you for your rapid replies and for commenting without delay.

Associate professor Åsa Dedering, co-supervisor and co-author. Thanks for valuable help and discussion, especially during the year when my main tutor was in Brisbane.

Associate professor Thorne Wallman, co-supervisor and co-author. Thanks for guidance during the research process, as well as valuable guidance and support in the "big world of research".

Hans G Eriksson, statistician at the Centre for Clinical Research Sörmland. Thanks for your excellent statistical guidance, your patience with all statistical questions, and all our hours spent of discussing the results during these years.

David Nilsson, PhD, senior research engineer, co-worker and coauthor. Without your help it would have been very difficult, almost impossible, to analyze the ultrasound images and understand and interpret the multivariate statistical methods.

Maria Landén Ludvigsson, my previous fellow PhD-student (now PhD). Thanks for the fantastic work you always do, regardless of circumstances. I can always rely on you. Thanks for all discussions, rapid answers by e-mail, the "traveling" in the research world, and all hard work and fun we have shared. It would have been impossible to realize this large RCT-study without these good cooperation, friendship and hard work. You are a very valuable person.

Anna Hermansen and Johanna Wibault, my previous fellow PhD-students (now PhDs) in the neck research group. Thanks for all discussion that helped me understand who to "research", for always answering e-mails regarding research questions and for being so good friends. Thanks also, Johanna, for randomizing all the participants in the RCT-study. 
Thomas Overmeer, PhD, my co-worker and co-author. Thank you for sharing your knowledge regarding behavioral management in physiotherapy and helping me with the behavioral approach in the RCTstudy.

Margaretha Jönsson, Karina Juhlin, Saga Carlsson, physiotherapist and study investigators in Västmanland, Sörmland and Örebro. Thank you for your thoroughly performed tests of the participants in the RCT-study in "my" three districts.

Professor Deborah Falla, co-author, for inviting me to Göttingen to discuss ultrasound measurement and for valuable contributions in paper IV.

Shaun O'Leary, $\mathrm{PhD}$, my supervisor during my visit to the Cervical Spine and Whiplash Research Unit, University of Queensland, Brisbane, Australia. Thanks for discussion regarding results and interpretation of the results as a co-author in paper I.

Julia Treleaven, PhD, thanks for sharing both your room and your knowledge of dizziness in WAD with me during my five-week visit to the the Cervical Spine and Whiplash Research Unit at the University of Queensland.

My former and present managers at Sörmland County Council; Karin Karlberg, Pernilla Järnvall-Hint, Helena Gustafsson and Aina Nilsson. You have always encouraged me, giving me support and the possibility to take leave of absence from clinical work so I could be a PhDstudent.

My colleagues in Katrineholm and Eskilstuna for your support and interest in my research and for being such good friends in the clinical "real" world.

Thanks also to all the 70 physiotherapists, administrative personal Christina Ottorp and Anneli Engström, librarian Susanne Heljedal, as well as all WAD participants and other study investigators who participated in the project. Without you there would have been no results!

The Centre for Clinical Research Sörmland at Uppsala University Sweden, Uppsala-Örebro Regional Research Council Sweden, the Swedish government in cooperation with the Swedish Social Insurance Agency through the REHSAM Foundation, the Swedish Research Council and the Swedish Medical Association gave financial support to the research project. Staffs there also have my thanks.

Finally and foremost, my beloved family, Sten, my husband, for your love and patience during these seven years with the long working days. To have a good dinner ready when I came home and for interesting discussion about 
ventilation control systems that give me new insights into the regulation of muscle force. Erika and Simon, my co-authors in papers II and III and my beloved children. Your intelligence and helpfulness have been invaluable for taking a step further into research about neck muscle function as you created and developed the program that calculated neck muscle deformation area and deformation rate. Thanks Marcus and Vera, appreciated son and daughter in law, for always being interested in my research, for relaxing holidays, skiing and hiking tours. To my sources of joy, relaxation, fun and love Albin, Moa and Birgit, my grandchildren who are the true researchers in this fantastic world, you discover new things every day and help me see all the fantastic things that surround us. 


\section{REFERENCES}

1. Holm LW, Carroll LJ, Cassidy JD, Hogg-Johnson S, Cote P, Guzman J, et al. The burden and determinants of neck pain in whiplash-associated disorders after traffic collisions: results of the Bone and Joint Decade 2000-2010 Task Force on Neck Pain and Its Associated Disorders. Spine. 2008;33(4 Suppl):S52-9.

2. Styrke J, Stalnacke BM, Bylund PO, Sojka P, Bjornstig U. A 10-year incidence of acute whiplash injuries after road traffic crashes in a defined population in northern Sweden. Pm R. 2012;4(10):739-47.

3. Carroll LJ, Holm LW, Hogg-Johnson S, Cote P, Cassidy JD, Haldeman S, et al. Course and prognostic factors for neck pain in whiplash-associated disorders (WAD): results of the Bone and Joint Decade 2000-2010 Task Force on Neck Pain and Its Associated Disorders. J Manipulative Physiol Ther. 2009;32(2 Suppl):S97-S107.

4. Kongsted A, Qerama E, Kasch H, Bendix T, Bach FW, Korsholm L, et al. Neck collar, "act-as-usual" or active mobilization for whiplash injury? A randomized parallel-group trial. Spine. 2007;32(6):618-26.

5. Leth-Petersen S, Rotger GP. Long-term labour-market performance of whiplash claimants. J Health Econ. 2009;28(5):996-1011.

6. Sterner Y, Gerdle B. Acute and chronic whiplash disorders - a review. J Rehabil Med. 2004;36(5):193-209.

7. Rodriquez AA, Barr KP, Burns SP. Whiplash: pathophysiology, diagnosis, treatment, and prognosis. Muscle Nerve. 2004;29(6):768-81.

8. Walton DM, Macdermid JC, Giorgianni AA, Mascarenhas JC, West SC, Zammit CA. Risk factors for persistent problems following acute whiplash injury: update of a systematic review and meta-analysis. J Orthop Sports Phys Ther. 2013;43(2):31-43.

9. Nijs J, Van Oosterwijck J, De Hertogh W. Rehabilitation of chronic whiplash: treatment of cervical dysfunctions or chronic pain syndrome? Clin Rheumatol. 2009;28(3):243-51.

10. Verhagen AP, Scholten-Peeters GG, van Wijngaarden S, de Bie RA, Bierma-Zeinstra SM. Conservative treatments for whiplash. Cochrane Database Syst Rev. 2007(2):CDoo3338.

11. Spitzer WO, Skovron ML, Salmi LR, Cassidy JD, Duranceau J, Suissa S, et al. Scientific monograph of the Quebec Task Force on WhiplashAssociated Disorders: redefining "whiplash" and its management. Spine. 1995;20(8 Suppl):1S-73S.

12. Siegmund GP, Winkelstein BA, Ivancic PC, Svensson MY, Vasavada A. The anatomy and biomechanics of acute and chronic whiplash injury. Traffic injury prevention. 2009;10(2):101-12.

13. Kristjansson E, Leivseth G, Brinckmann P, Frobin W. Increased sagittal plane segmental motion in the lower cervical spine in women with chronic whiplash-associated disorders, grades I-II: a case-control study using a new measurement protocol. Spine. 2003;28(19):2215-21.

14. Chen HB, Yang KH, Wang ZG. Biomechanics of whiplash injury. Chin J Traumatol. 2009;12(5):305-14. 
15. Panjabi MM. The stabilizing system of the spine. Part I. Function, dysfunction, adaptation, and enhancement. J Spinal Disord. 1992;5(4):383-9.

16. Jansen GB, Edlund C, Grane P, Hildingsson C, Karlberg M, Link H, et al. Whiplash injuries: diagnosis and early management. The Swedish Society of Medicine and the Whiplash Commission Medical Task Force. Eur Spine J. 2008;17 Suppl 3:S355-417.

17. Poorbaugh K, Brismee JM, Phelps V, Sizer PS, Jr. Late whiplash syndrome: a clinical science approach to evidence-based diagnosis and management. Pain Pract. 2008;8(1):65-87.

18. Soderlund A, Denison E. Classification of patients with whiplash associated disorders (WAD): reliable and valid subgroups based on the Multidimensional Pain Inventory (MPI-S). Eur J Pain. 2006;10(2):113-9.

19. Sterling M. A proposed new classification system for whiplash associated disorders--implications for assessment and management. Man Ther. 2004;9(2):60-70.

20. Elliott J, Jull G, Noteboom JT, Galloway G. MRI study of the crosssectional area for the cervical extensor musculature in patients with persistent whiplash associated disorders (WAD). Man Ther. 2008;13(3):258-65.

21. Elliott JM, O'Leary S, Sterling M, Hendrikz J, Pedler A, Jull G. Magnetic resonance imaging findings of fatty infiltrate in the cervical flexors in chronic whiplash. Spine. 2010;35(9):948-54.

22. Elliott JM, Pedler AR, Jull GA, Van Wyk L, Galloway GG, O'Leary SP. Differential changes in muscle composition exist in traumatic and nontraumatic neck pain. Spine. 2014;39(1):39-47.

23. Ulbrich EJ, Aeberhard R, Wetli S, Busato A, Boesch C, Zimmermann H, et al. Cervical muscle area measurements in whiplash patients: Acute, 3, and 6 months of follow-up. J Magn Reson Imaging. 2012;36(6):1413-20.

24. Elliott JM, Courtney DM, Rademaker A, Pinto D, Sterling MM, Parrish TB. The Rapid and Progressive Degeneration of the Cervical Multifidus in Whiplash: An MRI Study of Fatty Infiltration. Spine. 2015;40(12):E694700.

25. Cagnie B, Dolphens M, Peeters I, Achten E, Cambier D, Danneels L. Use of muscle functional magnetic resonance imaging to compare cervical flexor activity between patients with whiplash-associated disorders and people who are healthy. Phys Ther. 2010;90(8):1157-64.

26. Kristjansson E. Reliability of ultrasonography for the cervical multifidus muscle in asymptomatic and symptomatic subjects. Manual therapy. 2004;9(2):83-8.

27. Jull G, Kristjansson E, Dall'Alba P. Impairment in the cervical flexors: a comparison of whiplash and insidious onset neck pain patients. Man Ther. 2004;9(2):89-94.

28. Juul-Kristensen B, Clausen B, Ris I, Jensen RV, Steffensen RF, Chreiteh SS, et al. Increased neck muscle activity and impaired balance among females with whiplash-related chronic neck pain: a cross-sectional study. J Rehabil Med. 2013;45(4):376-84.

29. Schomacher J, Farina D, Lindstroem R, Falla D. Chronic trauma-induced neck pain impairs the neural control of the deep semispinalis cervicis muscle. Clin Neurophysiol. 2012;123(7):1403-8. 
30. Falla D, Jull G, Hodges PW. Feedforward activity of the cervical flexor muscles during voluntary arm movements is delayed in chronic neck pain. Exp Brain Res. 2004;157(1):43-8.

31. Falla DL, Jull GA, Hodges PW. Patients with neck pain demonstrate reduced electromyographic activity of the deep cervical flexor muscles during performance of the craniocervical flexion test. Spine. 2004;29(19):2108-14.

32. Hoskins P, Martin K, Thrush A. Diagnostic ultrasound : physics and equipment. Cambridge: Cambridge University Press; 2010.

33. Nesbitt GC, Mankad S, Oh JK. Strain imaging in echocardiography: methods and clinical applications. Int J Cardiovasc Imaging. 2009;25 Suppl 1:9-22.

34. Peolsson M, Lofstedt T, Vogt S, Stenlund H, Arndt A, Trygg J. Modelling human musculoskeletal functional movements using ultrasound imaging. BMC Med Imaging. 2010;10:9.

35. Lopata RG, van Dijk JP, Pillen S, Nillesen MM, Maas H, Thijssen JM, et al. Dynamic imaging of skeletal muscle contraction in three orthogonal directions. J Appl Physiol. 2010;109(3):906-15.

36. Bernstejn NA. The co-ordination and regulation of movements. Oxford: Pergamon Press; 1967.

37. Shumway-Cook A, Woollacott MH. Motor control : translating research into clinical practice. Baltimore, Md: Lippincott Williams \& Wilkins; 2007.

38. Mathiassen SE, Moller T, Forsman M. Variability in mechanical exposure within and between individuals performing a highly constrained industrial work task. Ergonomics. 2003;46(8):800-24.

39. Muceli S, Falla D, Farina D. Reorganization of muscle synergies during multidirectional reaching in the horizontal plane with experimental muscle pain. J Neurophysiol. 2014;111(8):1615-30.

40. Peterson BW. Current approaches and future directions to understanding control of head movement. Prog Brain Res. 2004;143:369-81.

41. Mayoux-Benhamou MA, Revel M, Vallee C, Roudier R, Barbet JP, Bargy F. Longus colli has a postural function on cervical curvature. Surg Radiol Anat. 1994;16(4):367-71.

42. Vasavada AN, Li S, Delp SL. Influence of muscle morphometry and moment arms on the moment-generating capacity of human neck muscles. Spine. 1998;23(4):412-22.

43. Keshner EA, Campbell D, Katz RT, Peterson BW. Neck muscle activation patterns in humans during isometric head stabilization. Exp Brain Res. 1989;75(2):335-44.

44. Siegmund GP, Blouin JS, Brault JR, Hedenstierna S, Inglis JT. Electromyography of superficial and deep neck muscles during isometric, voluntary, and reflex contractions. J Biomech Eng. 2007;129(1):66-77.

45. Bexander CS, Hodges PW. Cervico-ocular coordination during neck rotation is distorted in people with whiplash-associated disorders. Exp Brain Res. 2012;217(1):67-77.

46. Vikne H, Bakke ES, Liestol K, Engen SR, Vollestad N. Muscle activity and head kinematics in unconstrained movements in subjects with chronic neck pain; cervical motor dysfunction or low exertion motor output? BMC Musculoskelet Disord. 2013;14:314. 
47. Roland MO. A critical review of the evidence for a pain-spasm-pain cycle in spinal disorders. Clinical biomechanics. 1986;1(2):102-9.

48. Lund JP, Donga R, Widmer CG, Stohler CS. The pain-adaptation model: a discussion of the relationship between chronic musculoskeletal pain and motor activity. Can J Physiol Pharmacol. 1991;69(5):683-94.

49. Hodges PW, Coppieters MW, MacDonald D, Cholewicki J. New insight into motor adaptation to pain revealed by a combination of modelling and empirical approaches. Eur J Pain. 2013;17(8):1138-46.

50. Hug F, Hodges PW, Tucker KJ. Effect of pain location on spatial reorganisation of muscle activity. Journal of electromyography and kinesiology : official journal of the International Society of Electrophysiological Kinesiology. 2013;23(6):1413-20.

51. Gizzi L, Muceli S, Petzke F, Falla D. Experimental Muscle Pain Impairs the Synergistic Modular Control of Neck Muscles. PLoS One. 2015;10(9):e0137844.

52. Gatchel RJ, Peng YB, Peters ML, Fuchs PN, Turk DC. The biopsychosocial approach to chronic pain: scientific advances and future directions. Psychol Bull. 2007;133(4):581-624.

53. Leeuw M, Goossens ME, Linton SJ, Crombez G, Boersma K, Vlaeyen JW. The fear-avoidance model of musculoskeletal pain: current state of scientific evidence. J Behav Med. 2007;30(1):77-94.

54. Williamson E, Williams M, Gates S, Lamb SE. A systematic literature review of psychological factors and the development of late whiplash syndrome. Pain. 2008;135(1-2):20-30.

55. Vangronsveld K, Peters M, Goossens M, Linton S, Vlaeyen J. Applying the fear-avoidance model to the chronic whiplash syndrome. Pain. 2007;131(3):258-61.

56. Sullivan MJ, Adams H, Martel MO, Scott W, Wideman T. Catastrophizing and perceived injustice: risk factors for the transition to chronicity after whiplash injury. Spine. 2011;36(25 Suppl):S244-9.

57. Turk DC, Wilson HD. Fear of pain as a prognostic factor in chronic pain: conceptual models, assessment, and treatment implications. Curr Pain Headache Rep. 2010;14(2):88-95.

58. Sullivan MJ, Lariviere C, Simmonds M. Activity-related summation of pain and functional disability in patients with whiplash injuries. Pain. 2010;151(2):440-6.

59. Teasell RW, McClure JA, Walton D, Pretty J, Salter K, Meyer M, et al. A research synthesis of therapeutic interventions for whiplash-associated disorder (WAD): part 4 - noninvasive interventions for chronic WAD. Pain Res Manag. 2010;15(5):313-22.

60. Teasell RW, McClure JA, Walton D, Pretty J, Salter K, Meyer M, et al. A research synthesis of therapeutic interventions for whiplash-associated disorder (WAD): part 5 - surgical and injection-based interventions for chronic WAD. Pain Res Manag. 2010;15(5):323-34.

61. Lord SM, Barnsley L, Bogduk N. Percutaneous radiofrequency neurotomy in the treatment of cervical zygapophysial joint pain: a caution. Neurosurgery. 1995;36(4):732-9.

62. Lord SM, Barnsley L, Wallis BJ, McDonald GJ, Bogduk N. Percutaneous radio-frequency neurotomy for chronic cervical zygapophyseal-joint pain. N Engl J Med. 1996;335(23):1721-6. 
63. McDonald GJ, Lord SM, Bogduk N. Long-term follow-up of patients treated with cervical radiofrequency neurotomy for chronic neck pain. Neurosurgery. 1999;45(1):61-7.

64. Carragee EJ, Hurwitz EL, Cheng I, Carroll LJ, Nordin M, Guzman J, et al. Treatment of neck pain: injections and surgical interventions: results of the Bone and Joint Decade 2000-2010 Task Force on Neck Pain and Its Associated Disorders. Spine (Phila Pa 1976). 2008;33(4 Suppl):S153-69.

65. Gross A, Kay TM, Paquin JP, Blanchette S, Lalonde P, Christie T, et al. Exercises for mechanical neck disorders. Cochrane Database Syst Rev. 2015;1:CDoo4250.

66. Woodhouse A, Vasseljen O. Altered motor control patterns in whiplash and chronic neck pain. BMC Musculoskelet Disord. 2008;9:90.

67. Elliott J, Jull G, Noteboom JT, Darnell R, Galloway G, Gibbon WW. Fatty infiltration in the cervical extensor muscles in persistent whiplashassociated disorders: a magnetic resonance imaging analysis. Spine. 2006;31(22):E847-55.

68. Stewart MJ, Maher CG, Refshauge KM, Herbert RD, Bogduk N, Nicholas M. Randomized controlled trial of exercise for chronic whiplashassociated disorders. Pain. 2007;128(1-2):59-68.

69. Vikne J, Oedegaard A, Laerum E, Ihlebaek C, Kirkesola G. A randomized study of new sling exercise treatment vs traditional physiotherapy for patients with chronic whiplash-associated disorders with unsettled compensation claims. J Rehabil Med. 2007;39(3):252-9.

70. Soderlund A, Lindberg P. Cognitive behavioural components in physiotherapy management of chronic whiplash associated disorders (WAD)--a randomised group study. G Ital Med Lav Ergon. 2007;29(1 Suppl A):A5-11.

71. Michaleff ZA, Maher CG, Lin CW, Rebbeck T, Jull G, Latimer J, et al. Comprehensive physiotherapy exercise programme or advice for chronic whiplash (PROMISE): a pragmatic randomised controlled trial. Lancet. 2014;384(9938):133-41.

72. Jull GA, Falla D, Vicenzino B, Hodges PW. The effect of therapeutic exercise on activation of the deep cervical flexor muscles in people with chronic neck pain. Manual therapy. 2009;14(6):696-701.

73. Falla D, Jull G, Hodges P, Vicenzino B. An endurance-strength training regime is effective in reducing myoelectric manifestations of cervical flexor muscle fatigue in females with chronic neck pain. Clin Neurophysiol. 2006;117(4):828-37.

74. Falla D, O'Leary S, Farina D, Jull G. The change in deep cervical flexor activity after training is associated with the degree of pain reduction in patients with chronic neck pain. Clin J Pain. 2012;28(7):628-34.

75. Schomacher J, Falla D. Function and structure of the deep cervical extensor muscles in patients with neck pain. Man Ther. 2013;18(5):3606.

76. Jull G, Treleaven J, Falla D, Sterling M, O'Leary S. A therapeutic exercise approach for cervical disorders. In: Boyling J, Jull G, editors. Grieves' Modern Manual Therapy of the Vertebral Column. 3 ed. Edinburgh: Elsevier Churchill Livingstone, 2004:451-470.

77. Ang BO, Monnier A, Harms-Ringdahl K. Neck/shoulder exercise for neck pain in air force helicopter pilots: a randomized controlled trial. Spine. 2009;34(16):E544-51. 
78. Bartholomew JB, Lewis BP, Linder DE, Cook DB. Post-exercise analgesia: replication and extension. J Sports Sci. 1996;14(4):329-34.

79. Sluka KA, O'Donnell JM, Danielson J, Rasmussen LA. Regular physical activity prevents development of chronic pain and activation of central neurons. J Appl Physiol. 2013;114(6):725-33.

80. Physical activity in the prevention and treatment of disease. Stockholm: Swedish National Institute of Public Health; 2010.

81. Sitzia J, Wood N. Patient satisfaction: a review of issues and concepts. Soc Sci Med. 1997;45(12):1829-43.

82. Godil SS, Parker SL, Zuckerman SL, Mendenhall SK, Devin CJ, Asher AL, et al. Determining the quality and effectiveness of surgical spine care: patient satisfaction is not a valid proxy. Spine J. 2013;13(9):1006-12.

83. Leininger BD, Evans R, Bronfort G. Exploring patient satisfaction: a secondary analysis of a randomized clinical trial of spinal manipulation, home exercise, and medication for acute and subacute neck pain. J Manipulative Physiol Ther. 2014;37(8):593-601.

84. Edmondston SJ, Wallumrod ME, Macleid F, Kvamme LS, Joebges S, Brabham GC. Reliability of isometric muscle endurance tests in subjects with postural neck pain. J Manipulative Physiol Ther. 2008;31(5):34854 .

85. Peolsson A, Almkvist C, Dahlberg C, Lindqvist S, Pettersson S. Age- and sex-specific reference values of a test of neck muscle endurance. J Manipulative Physiol Ther. 2007;30(3):171-7.

86. Peolsson A, Kjellman G. Neck muscle endurance in nonspecific patients with neck pain and in patients after anterior cervical decompression and fusion. J Manipulative Physiol Ther. 2007;30(5):343-50.

87. Carlsson AM. Assessment of chronic pain. I. Aspects of the reliability and validity of the visual analogue scale. Pain. 1983;16(1):87-101.

88. Wewers ME, Lowe NK. A critical review of visual analogue scales in the measurement of clinical phenomena. Research in Nursing \& Health. 1990;13(4):227-36.

89. Dworkin RH, Turk DC, Wyrwich KW, Beaton D, Cleeland CS, Farrar JT, et al. Interpreting the clinical importance of treatment outcomes in chronic pain clinical trials: IMMPACT recommendations. J Pain. 2008;9(2):105-21.

90. Roelofs J, Sluiter JK, Frings-Dresen MH, Goossens M, Thibault P, Boersma K, et al. Fear of movement and (re)injury in chronic musculoskeletal pain: Evidence for an invariant two-factor model of the Tampa Scale for Kinesiophobia across pain diagnoses and Dutch, Swedish, and Canadian samples. Pain. 2007;131(1-2):181-90.

91. Civelek E, Kiris T, Hepgul K, Canbolat A, Ersoy G, Cansever T. Anterolateral approach to the cervical spine: major anatomical structures and landmarks. Technical note. Journal of neurosurgery Spine. 2007;7(6):669-78.

92. Lucas BD, Kanade T. An Iterative Image Registration Technique with an Application to Stereo Vision. Procedings of the $7^{\text {th }}$ International Joint Conference on Artificial Intelligence 674-679, 1981.

93. Tomasi C, Kanade T. Detection and Tracking of Point Features, Computer Science Department, Carnegie Mellon University, April, 1991 
94. Farron J, Varghese T, Thelen DG. Measurement of tendon strain during muscle twitch contractions using ultrasound elastography. IEEE Trans Ultrason Ferroelectr Freq Control. 2009;56(1):27-35.

95. Peolsson A, Peolsson M, Jull G, Lofstedt T, Trygg J, O'Leary S. Preliminary evaluation of dorsal muscle activity during resisted cervical extension in patients with longstanding pain and disability following anterior cervical decompression and fusion surgery. Physiotherapy. 2015;101(1):69-74.

96. Padilla J, Johnson BD, Newcomer SC, Wilhite DP, Mickleborough TD, Fly AD, et al. Normalization of flow-mediated dilation to shear stress area under the curve eliminates the impact of variable hyperemic stimulus. Cardiovascular ultrasound. 2008;6:44.

97. Halim MA, Nampoory MR, Johny KV, Donia F, Hamid MH, Said T, et al. The area under the concentration-time curve versus trough and peak blood level monitoring in renal transplant recipients on cyclosporine. Transplant Proc. 2005;37(7):3019-21.

98. Landén Ludvigsson M, Peolsson A, Peterson G. http://urn.kb.se/resolve?urn=urn:nbn:se:liu:diva-113865

99. Peolsson A, Landen Ludvigsson M, Overmeer T, Dedering A, Bernfort L, Johansson G, et al. Effects of neck-specific exercise with or without a behavioural approach in addition to prescribed physical activity for individuals with chronic whiplash-associated disorders: a prospective randomised study. BMC Musculoskelet Disord. 2013;14(1):311.

100. Dancey CP, Reidy J. Statistics without maths for psychology. Harlow, England: Pearson; 2014.

101. Eriksson L. Multi- and megavariate data analysis : basic principles and applications. Malmö: MKS Umetrics; 2013.

102. Sterud T, Johannessen HA, Tynes T. Work-related psychosocial and mechanical risk factors for neck/shoulder pain: a 3-year follow-up study of the general working population in Norway. Int Arch Occup Environ Health. 2014;87(5):471-81.

103. Falla D, Jull G, Russell T, Vicenzino B, Hodges P. Effect of neck exercise on sitting posture in patients with chronic neck pain. Phys Ther. 2007;87(4):408-17.

104. Ludvigsson ML, Peterson G, O'Leary S, Dedering A, Peolsson A. The Effect of Neck-specific Exercise with, or without a Behavioral Approach, on Pain, Disability and Self-efficacy in Chronic Whiplash-associated Disorders: A Randomized Clinical Trial. Clin J Pain. 2014.

105. Landen Ludvigsson M, Peterson G, Dedering A, Peolsson A. One- and two-year follow-up of a randomized trial of neck-specific exercise with or without a behavioural approach compared with prescription of physical activity in chronic whiplash disorder. J Rehabil Med. 2015.

106. Peolsson A, Landen Ludvigsson M, Tigerfors AM, Peterson G. Effects of Neck-Specific Exercises Compared to Waiting List for Individuals With Chronic Whiplash-Associated Disorders: A Prospective, Randomized Controlled Study. Arch Phys Med Rehabil. 2016;97(2):189-95.

107. Ludvigsson ML, Peterson G, Dedering A, Falla D, Peolsson A. Factors associated with pain and disability reduction following exercise interventions in chronic whiplash. Eur J Pain. 2016;20(2):307-15.

108. Edmondston S, Bjornsdottir G, Palsson T, Solgard H, Ussing K, Allison G. Endurance and fatigue characteristics of the neck flexor and extensor 
muscles during isometric tests in patients with postural neck pain. Manual therapy. 2011;16(4):332-8.

109. Domenech MA, Sizer PS, Dedrick GS, McGalliard MK, Brismee JM. The deep neck flexor endurance test: normative data scores in healthy adults. Pm R. 2011;3(2):105-10.

110. Dimitriadis Z, Kapreli E, Strimpakos N, Oldham J. Reliability of the chin tuck neck flexion test for assessing endurance of short neck flexors in healthy individuals. Physiother Theory Pract. 2015;31(4):299-302.

111. Grimmer K. Measuring the endurance capacity of the cervical short flexor muscle group. Australian Journal of Physiotherapy. 1994;40(4):251-4.

112. Hogg-Johnson S, van der Velde G, Carroll LJ, Holm LW, Cassidy JD, Guzman J, et al. The burden and determinants of neck pain in the general population: results of the Bone and Joint Decade 2000-2010 Task Force on Neck Pain and Its Associated Disorders. J Manipulative Physiol Ther. 2009;32(2 Suppl):S46-60.

113. Jull GA. Whiplash, headache, and neck pain : research-based directions for physical therapies. Edinburgh ;: Churchill Livingstone; 2008.

114. Louw A, Diener I, Butler DS, Puentedura EJ. The effect of neuroscience education on pain, disability, anxiety, and stress in chronic musculoskeletal pain. Arch Phys Med Rehabil. 2011;92(12):2041-56.

115. Treleaven J, Peterson G, Ludvigsson ML, Kammerlind AS, Peolsson A. Balance, dizziness and proprioception in patients with chronic whiplash associated disorders complaining of dizziness: A prospective randomized study comparing three exercise programs. Man Ther. 2015.

116. Overmeer T, Peterson G, Landen Ludvigsson M, Peolsson A. The effect of neck-specific exercise with or without a behavioral approach on psychological factors in chronic whiplash-associated disorders: A randomized controlled trial with a 2-year follow-up. Medicine. 2016;95(34):e4430.

117. Bandura A. Self-efficacy: toward a unifying theory of behavioral change. Psychol Rev. 1977;84(2):191-215.

118. Hapidou EG, O'Brien MA, Pierrynowski MR, de Las Heras E, Patel M, Patla T. Fear and Avoidance of Movement in People with Chronic Pain: Psychometric Properties of the 11-Item Tampa Scale for Kinesiophobia (TSK-11). Physiother Can. 2012;64(3):235-41.

119. Falla D, Bilenkij G, Jull G. Patients with chronic neck pain demonstrate altered patterns of muscle activation during performance of a functional upper limb task. Spine. 2004;29(13):1436-40.

120. Anderson JS, Hsu AW, Vasavada AN. Morphology, architecture, and biomechanics of human cervical multifidus. Spine. 2005;30(4):E86-91.

121. Madeleine P, Mathiassen SE, Arendt-Nielsen L. Changes in the degree of motor variability associated with experimental and chronic neckshoulder pain during a standardised repetitive arm movement. Exp Brain Res. 2008;185(4):689-98.

122. Moseley GL, Hodges PW. Reduced variability of postural strategy prevents normalization of motor changes induced by back pain: a risk factor for chronic trouble? Behavioral neuroscience. 2006;120(2):474-6.

123. Lindstrom R, Schomacher J, Farina D, Rechter L, Falla D. Association between neck muscle coactivation, pain, and strength in women with neck pain. Man Ther. 2011;16(1):80-6. 
124. Harris KD, Heer DM, Roy TC, Santos DM, Whitman JM, Wainner RS. Reliability of a measurement of neck flexor muscle endurance. Phys Ther. 2005;85(12):1349-55.

125. Juul T, Langberg H, Enoch F, Sogaard K. The intra- and inter-rater reliability of five clinical muscle performance tests in patients with and without neck pain. BMC Musculoskelet Disord. 2013;14:339.

126. Peolsson A, Hamp C, Albinsson AK, Engdahl S, Kvist J. Test position and reliability in measurements of dorsal neck muscle endurance. Adv in Physiotherapy. 2007;9:181-189.

127. Parazza S, Vanti C, O'Reilly C, Villafane JH, Tricas Moreno JM, Estebanez De Miguel E. The relationship between cervical flexor endurance, cervical extensor endurance, VAS, and disability in subjects with neck pain. Chiropr Man Therap. 2014;22(1):10.

128. Oliveira AC, Silva AG. Neck muscle endurance and head posture: A comparison between adolescents with and without neck pain. Man Ther. 2016;22:62-7.

129. Benedetti F, Thoen W, Blanchard C, Vighetti S, Arduino C. Pain as a reward: changing the meaning of pain from negative to positive coactivates opioid and cannabinoid systems. Pain. 2013;154(3):361-7.

130. O'Leary S, Falla D, Jull G, Vicenzino B. Muscle specificity in tests of cervical flexor muscle performance. J Electromyogr Kinesiol. 2007;17(1):35-40.

131. Taljanovic MS, Melville DM, Scalcione LR, Gimber LH, Lorenz EJ, Witte RS. Artifacts in musculoskeletal ultrasonography. Semin Musculoskelet Radiol. 2014;18(1):3-11.

132. Townsend NT, Kendall J, Barnett C, Robinson T. An Effective Curriculum for Focused Assessment Diagnostic Echocardiography: Establishing the Learning Curve in Surgical Residents. J Surg Educ. 2016;73(2):190-6.

133. Barbier P, Mirea O, Cefalu C, Maltagliati A, Savioli G, Guglielmo M. Reliability and feasibility of longitudinal AFI global and segmental strain compared with 2D left ventricular volumes and ejection fraction: intraand inter-operator, test-retest, and inter-cycle reproducibility. Eur Heart J Cardiovasc Imaging. 2015;16(6):642-52.

134. Brown J, Jenkins C, Marwick TH. Use of myocardial strain to assess global left ventricular function: a comparison with cardiac magnetic resonance and 3-dimensional echocardiography. Am Heart J. 2009;157(1):102 e1-5.

135. Woods JJ, Bigland-Ritchie B. Linear and non-linear surface EMG/force relationships in human muscles. An anatomical/functional argument for the existence of both. Am J Phys Med. 1983;62(6):287-99.

136. Uhlig Y, Weber BR, Grob D, Muntener M. Fiber composition and fiber transformations in neck muscles of patients with dysfunction of the cervical spine. J Orthop Res. 1995;13(2):240-9.

137. Cote JN. A critical review on physical factors and functional characteristics that may explain a sex/gender difference in work-related neck/shoulder disorders. Ergonomics. 2012;55(2):173-82. 


\section{Papers}

The articles associated with this thesis have been removed for copyright reasons. For more details about these see:

http://urn.kb.se/resolve?urn=urn:nbn:se:liu:diva-132420 